\title{
Palm Oil and Rubber Price and Trader's Behavior at International towards Local Level
}

\author{
Dissertation \\ to obtain the Ph.D. degree \\ in the International Ph.D. Program for Agricultural Sciences in Goettingen (IPAG) \\ at the Faculty of Agricultural Sciences, \\ Georg-August-University Goettingen, Germany
}

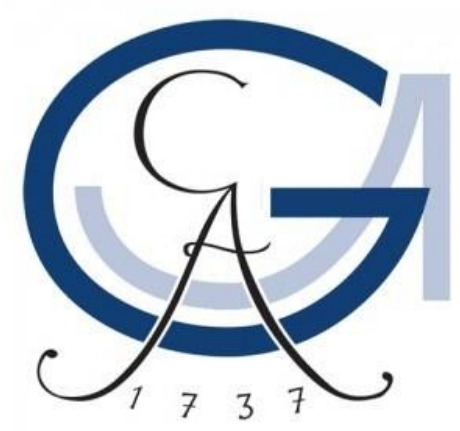

presented by

Rakhma Melati Sujarwo

born in Bontang, Indonesia

Goettingen, May 2020 

D7

Name of supervisor: Prof. Dr. Bernhard Brümmer

Name of co-supervisor: Prof. Dr. Stephan von Cramon-Taubadel

Name of co-supervisor: Prof. Dr. Oliver Mußhoff

Date of Oral Examination: May 20, 2020 



\section{Acknowledgements}

Praise to Allah the Almighty for all His blessings. Having the opportunity to study in Georg-August University Göttingen, Germany gave me one of the most precious experiences in my life. I feel grateful to finally finish my dissertation with all the supports I received from all parties. First and foremost, I would like to express my deepest appreciation to my supervisor Prof. Dr. Bernhard Brümmer. Without his guidance this dissertation would not have been possible. His trust, patience and support are priceless so that I can complete this study with all the shortcomings. Having the opportunity to be part of his team at the Chair of Agricultural Market Analysis has contributed greatly to my career development. Also, I acknowledge the support and help of Prof. Dr. Stephan von Cramon-Taubadel and Prof. Dr. Oliver Mußhoff. in co-supervising this dissertation and being part of the examination committee.

Thanks to my office mate, Yashree, who is an expert in so many things in life. What am I without you? Also, thanks to all other chair members (Tim, Gabriel, Claudia, Tom, Yueming, Yuan, Enrique, Oliver, Bernhard, Jurij, Dela, Nina, and Nina Enke) who give joy and happiness on the $10^{\text {th }}$ floor of the Blue Tower. And to all parties as part of the Collaborative Research Centre 990, Efforts Project. This project, under DFG, has also provided financial support during my study. Special thanks go to all counterparts in IPB University (Dr. Dedi Budiman Hakim and the late Prof. Dr. Rina Oktaviani) and Jambi University (Prof. Dr. Zulkifli Alamsyah and Dr. Mirawati Yanita), as well as my team who helped me during my data collection in Jambi.

Furthermore, my deepest gratitude and super big hug go to my lovely family who always support and encourage me with their dedication during my study: Ayah and Ibu who have always supported the path of life that I have chosen. Also, my lifetime partner, the best dad in the world for our children, who has never left me in supporting my study activities. Salma, the first, who always bears witness to my sadness and happiness in undergoing this process. And Musa, the second, who appeared to bring joy at the critical moments in the completion of this dissertation.

Last, but not least, I am indebted to my many friends and colleagues who supported and gave me invaluable relationships, from PPI Göttingen, Kalam Göttingen, and all my new international friends in Germany. 


\section{Table of Contents}

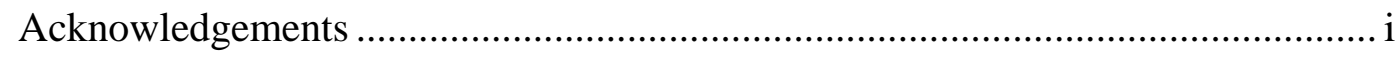

Table of Contents ........................................................................................... ii

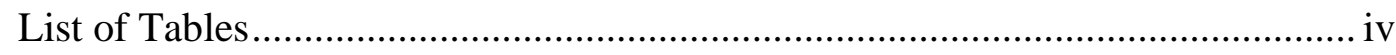

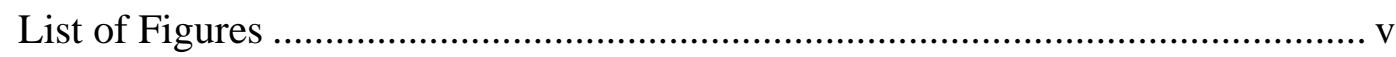

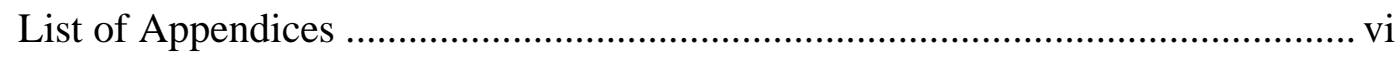

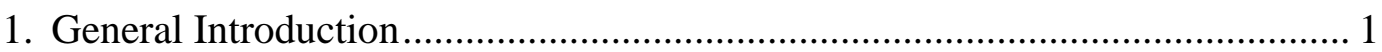

2. Does the Biodiesel EU Antidumping Duty Affect the Indonesian CPO

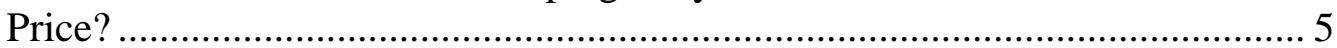

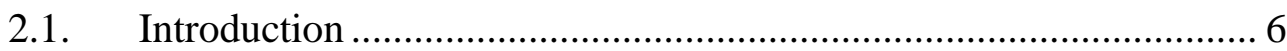

2.2. Background: dumping and retaliation ....................................... 10

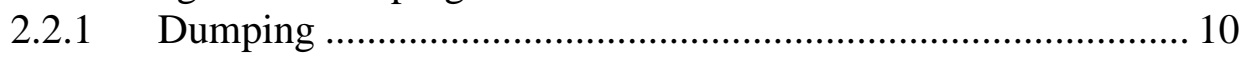

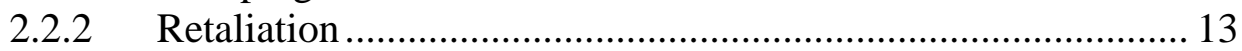

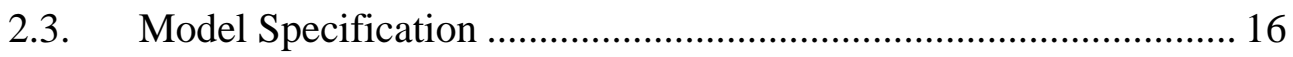

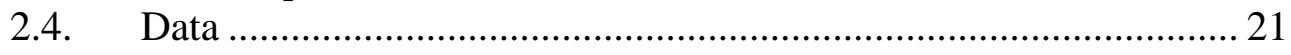

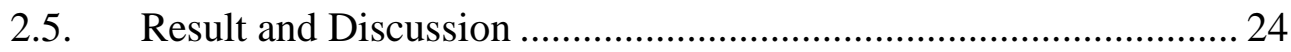

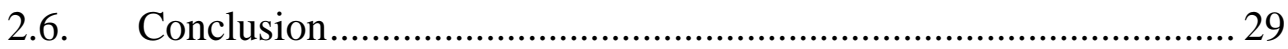

3. Fight or Flight: Factors Affecting Local Traders to Remain in or Exit the

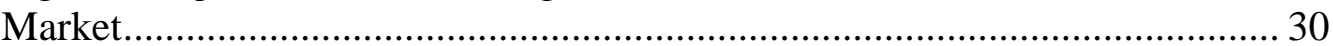

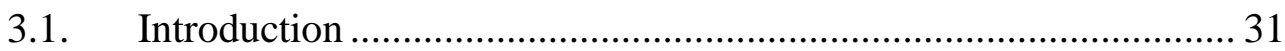

3.2. Role of Local Traders in Jambi ..................................................... 33

3.2.1 The Importance of Traders..................................................... 33

3.2.2 Rubber and Oil Palm Fresh Fruit Bunch (OPFFB) Trading Activities in Jambi .................................................................. 34

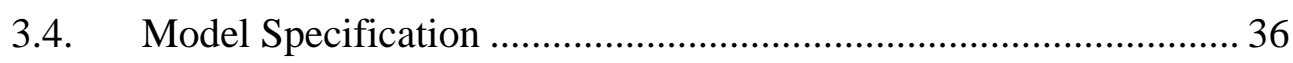

3.4.1 Determinants in Exiting the Market........................................ 36

3.4.2 Binary Logistic Regression and Marginal Effect..................... 38

3.4.3 Goodness of Fit and Logit Postestimation ................................ 39

3.4.4 Statistical Test........................................................................ 40

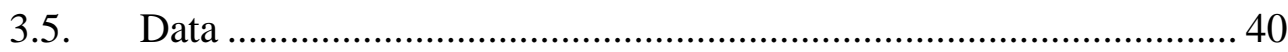

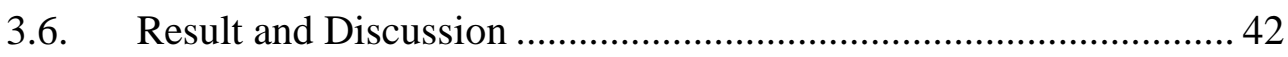

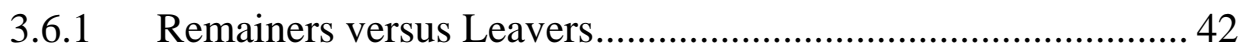

3.6.2 New versus Existing Traders ................................................. 47

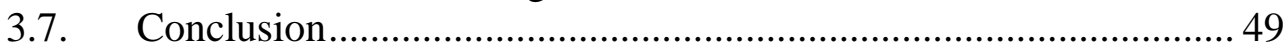

4. The Perils of a Loan: Interdependency between Rubber Quality and Farmer's Debt in Buying Choices by Local Rubber Traders in Jambi

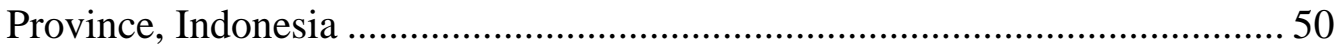

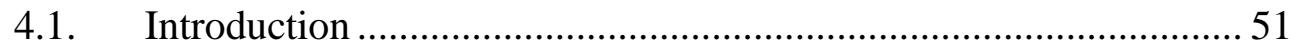

4.2. Overview: Basi versus Price Reduction ....................................... 53

4.3. Background: Random Utility Model (RUM) ............................... 56

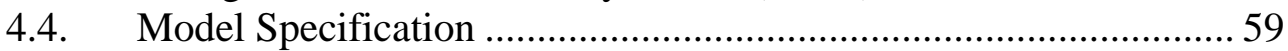

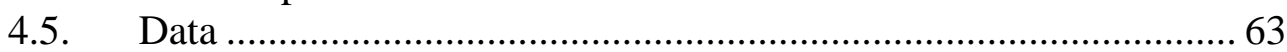

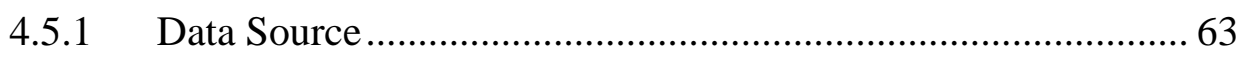

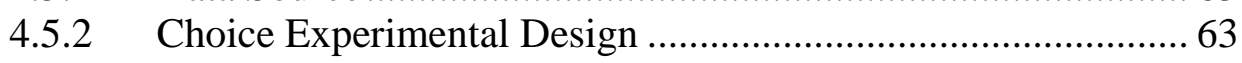


4.5.3 Descriptive Statistics of Socio-Demographic Characteristic

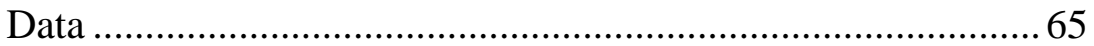

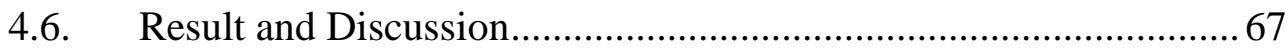

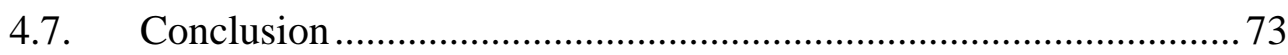

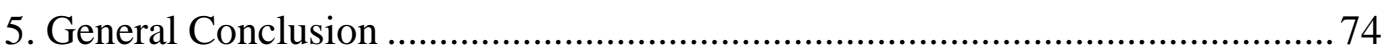

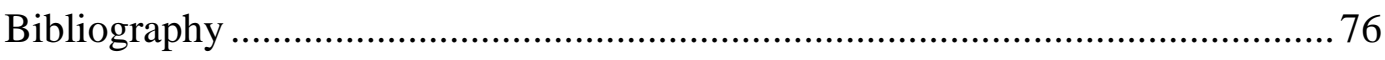

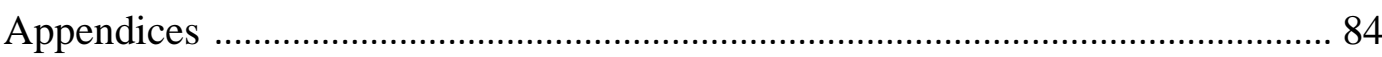

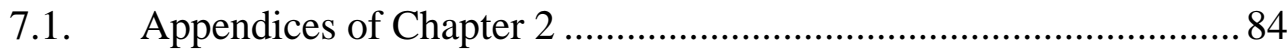

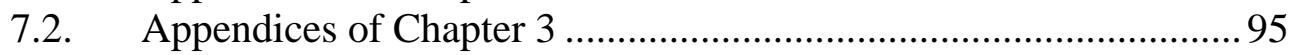

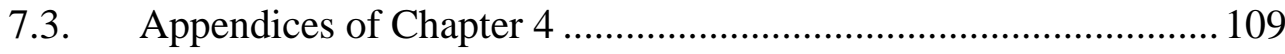

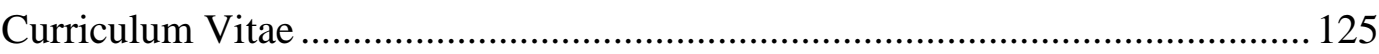

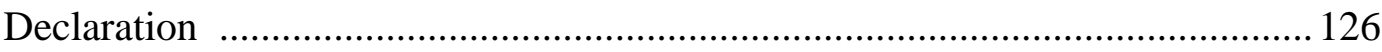




\section{List of Tables}

Table 2. 1 The definitive EU AD rate for Indonesian biodiesel producers........................ 14

Table 2. 2 Summary Statistics of Price Variables (USD/kg) .......................................... 23

Table 2. 3. Log-likelihood Values of Restricted and Unrestricted Models........................ 26

Table 3. 1 Number of All Active Traders in the Survey Area .......................................... 35

Table 3. 2 Transition Matrix of Traders in Period 1 (2012-2015) .................................... 35

Table 3. 3 Transition Matrix of Traders in Period 2 (2015-2018) ...................................... 35

Table 3. 4 Average Income of Traders Existing both in 2012 and 2015 (million IDR) ..... 36

Table 3. 5 Average Income of Traders Existing both in 2015 and 2018 (million IDR) ..... 36

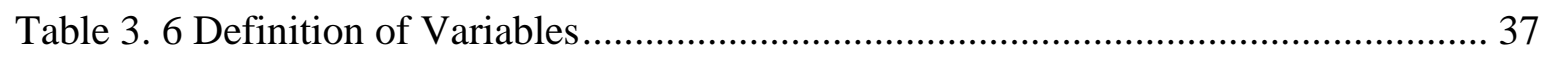

Table 3. 7 Number of All Active Traders in the Survey Area ........................................ 41

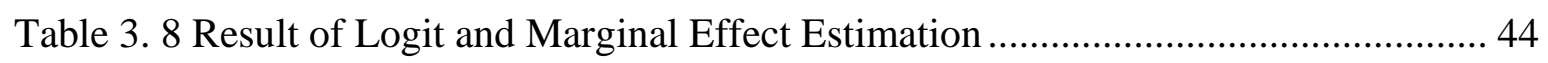

Table 3. 9 New and Existing Traders' Characteristics in 2018 …................................. 48

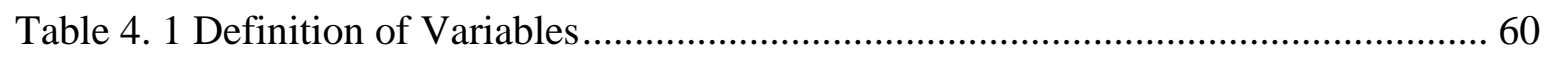

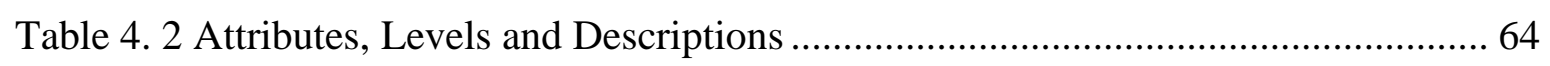

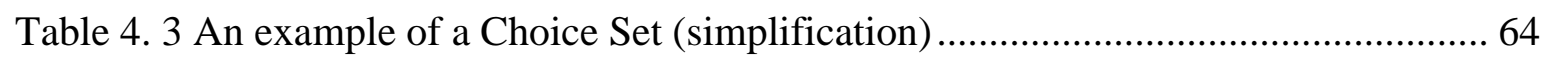

Table 4. 4 Village and Larger Traders' Characteristics .................................................. 65

Table 4. 5 Credit Providers and Traders not Providing Credit Characteristics ................... 66

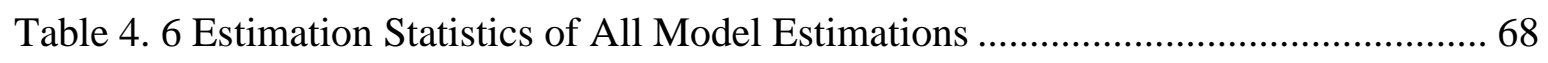

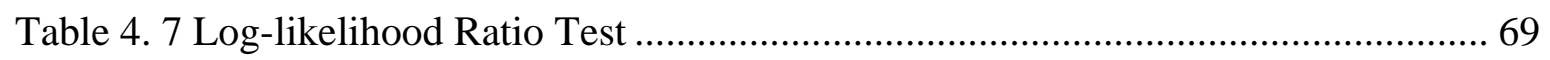

Table 4. 8 Parameter Estimates from the ML_2 Model Estimation................................... 70

Table 4. 9 Rubber Traders' Willingness to Charge Price Reduction for Rubber Attributes71 


\section{List of Figures}

Figure 2. 1 Net CO2 Life Cycle Emissions of Petroleum Diesel and Biodiesel Blends ....... 6

Figure 2. 2 Biodiesel and Renewable Diesel (HVO) in the European Union ...................... 7

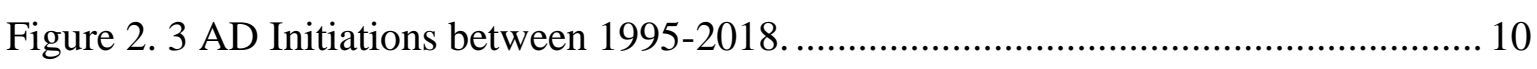

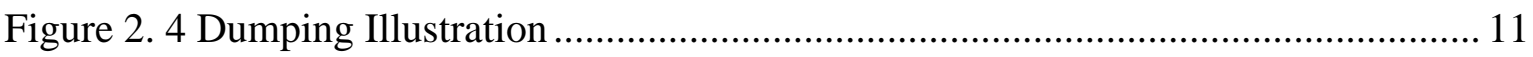

Figure 2. 5 Value of Export Tariff (USD/ton) of Indonesian CPO and Biodiesel .............. 12

Figure 2. 6 Indonesian Biodiesel Dumping Illustration ................................................. 13

Figure 2. 7 Home Equilibrium without Trade, with Trade and with AD in Trade ........... 15

Figure 2. 8 The AD duty Illustration Effect in Indonesia................................................ 16

Figure 2. 9 Share of Indonesian CPO Export Value based on Importing Countries ........... 21

Figure 2. 10 Share of Indonesian CPO Export Value based on Ports' Location................. 22

Figure 2. 11 Area and Production of Oil Palm Plantation in the Jambi Province ............... 22

Figure 2. 12 Time Series Plot of Price Variables ............................................................. 23

Figure 2. 13 Value of Export Tariff and Levy (USD/ton) of Indonesian CPO .................. 24

Figure 2. 14 Time Series Plot with Structural Break........................................................ 25

Figure 2. 15 Export Value of Biodiesel from Indonesia to the EU (USD thousand) .......... 27

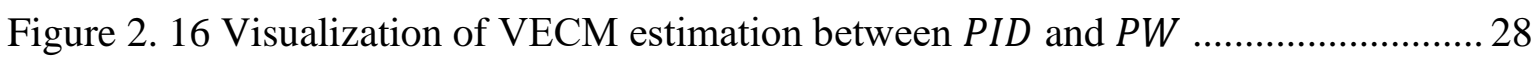

Figure 2. 17 Visualization of VECM estimation between PID and $P W$......................... 29

Figure 3. 1 Price Volatility of Palm Oil and Rubber Price (2008-2019) ............................ 32

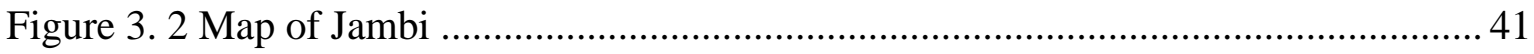

Figure 3. 3 Illustration of the Increase of Probability per Unit Variable............................ 45

Figure 3. 4 Illustration of the Increase of Probability per Unit Interacted Variable............ 47

Figure 3. 5 Frequency of Existing and New Traders by Traded Product........................... 48

Figure 4. 1 Number of Farmers by Ownership................................................................ 51

Figure 4. 2 Probability Design in Unrelated Response Randomized Response Technique 55

Figure 4. 3 Illustration of rubber trader individual preferences ....................................... 57 


\section{List of Appendices}

Appendix 2. 1 Unit Root Tests

Appendix 2. 2 Johansen Cointegration Test between Indonesian and World CPO Prices . 84 Appendix 2. 3 Johansen Cointegration Test between Jambi FFB and Indonesian CPO

Prices . 84

Appendix 2. 4 Gregory-Hansen Cointegration Test between Indonesian and World CPO

Prices 85

Appendix 2. 5 Gregory-Hansen Cointegration Test between Jambi FFB and Indonesian CPO Prices

Appendix 2. 6 Johansen Cointegration Test between Indonesian and World CPO Prices before the Breakpoint

Appendix 2. 7 Johansen Cointegration Test between Indonesian and World CPO Prices

after the Breakpoint. 86

Appendix 2. 8 Johansen Cointegration Test between Jambi FFB and Indonesian CPO

Prices before the Breakpoint 86

Appendix 2. 9 Johansen Cointegration Test between Jambi FFB and Indonesian CPO Prices after the Breakpoint. 86

Appendix 2. 10. VECM Estimation between Indonesian and World CPO Prices 87

Appendix 2. 11 VECM Estimation between Indonesian and World CPO Prices allowing

Structural Break 88

Appendix 2. 12 VECM Estimation between Indonesian and World CPO Prices before the

Breakpoint 89

Appendix 2. 13 VECM Estimation between Indonesian and World CPO Prices after the Breakpoint 90

Appendix 2. 14 VECM Estimation between Jambi FFB and Indonesian CPO prices. 91

Appendix 2. 15 VECM Estimation between Jambi FFB and Indonesian CPO allowing Structural Break

Appendix 2. 16 VECM Estimation between Jambi FFB and Indonesian CPO before the Breakpoint 93

Appendix 2. 17 VECM Estimation between Jambi FFB and Indonesian CPO after the Breakpoint 
Appendix 3. 2 Stata Output of Variable Descriptive Statistics Year 2012 2........................ 96

Appendix 3. 3 Stata Output of Variable Descriptive Statistics Year 2015......................... 96

Appendix 3. 4 Stata Output of Variable Descriptive Statistics Year 2018......................... 97

Appendix 3. 5 Stata Output of Logit Estimation Year 2012 ............................................. 98

Appendix 3. 6 Stata Output of Marginal Effect Estimation Year 2012 ............................. 99

Appendix 3. 7 Stata Output of Logit Estimation Year 2015 …...................................... 100

Appendix 3. 8 Stata Output of Marginal Effect Estimation Year 2015 ........................... 101

Appendix 3.9 Stata Output of Specification Error Year 2012 _....................................... 102

Appendix 3. 10 Stata Output of Specification Error Year 2015 ….................................. 102

Appendix 3. 11 Stata Output of Collinearity Diagnostics Year 2012 .............................. 103

Appendix 3. 12 Stata Output of Collinearity Diagnostics Year 2015 ............................... 104

Appendix 3.13 Stata Output of Wilcoxon Rank-sum (Mann-Whitney Test of Farming

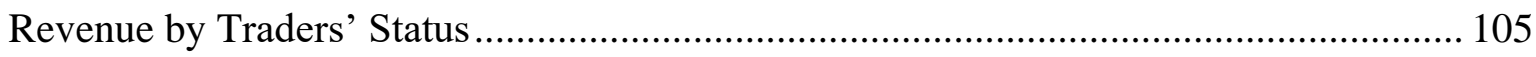

Appendix 3.14 Stata Output of Trading Revenue Summary Statistics by Remain Year 2015 106

Appendix 3. 15 Stata Output of Trading Revenue Summary Statistics Year 2012 and 2015

Appendix 3. 16 Wilcoxon rank-sum (Mann-Whitney) non-parametric test ..................... 107

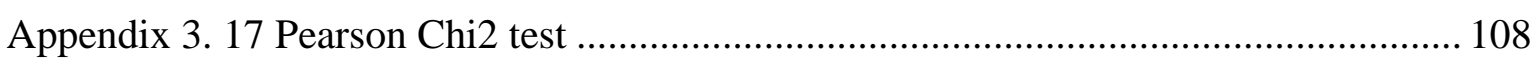

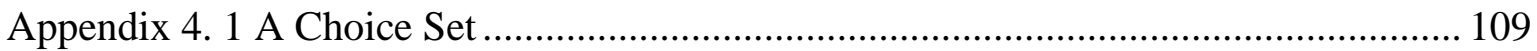

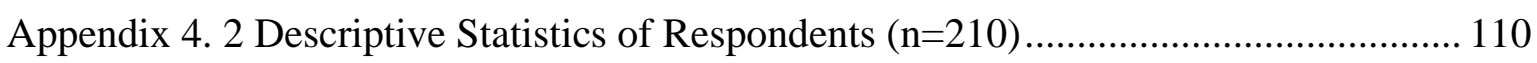

Appendix 4. 3 Stata Output of Shapiro-Wilk Normality Test........................................... 111

Appendix 4. 4 Stata Output of Wilcoxon Rank-sum (Mann-Whitney) Test by Traders'

Status (left) and Credit Provision Status (right) ........................................................... 112

Appendix 4. 5 Stata Output of Spearman's Rank Correlation Coefficients ...................... 113

Appendix 4. 6 Results across Different Model Estimations............................................. 114

Appendix 4. 7 Stata Output of CL_1 Model Estimation .................................................. 115

Appendix 4. 8 Stata Output of CL_2 Model Estimation ................................................. 116

Appendix 4.9 Stata Output of ML_1 Model Estimation ............................................... 117

Appendix 4. 10 Stata Output of ML_2 Model Estimation .............................................. 118

Appendix 4. 11 Stata Output of ML_3 Model Estimation .............................................. 119

Appendix 4. 12 The Cholesky Factorization of the Covariance Matrix............................ 120

Appendix 4. 13 Stata Output of the ML_3 Random Coefficients Covariance Matrix ...... 120 
Appendix 4. 14 Summary of Rubber Traders' WTC Price Reduction for All Attributes

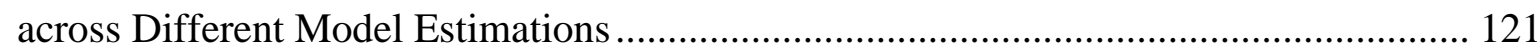

Appendix 4. 15 WTC Stata Output of CL_1 Model Estimation ...................................... 122

Appendix 4. 16 WTC Stata Output of CL_2 Model Estimation ...................................... 122

Appendix 4. 17 WTC Stata Output of ML_1 Model Estimation .................................... 122

Appendix 4. 18 WTC Stata Output of ML_2 Model Estimation ..................................... 123

Appendix 4. 19 WTC Stata Output of ML_3 Model Estimation ..................................... 123

Appendix 4. 20 Stata Output of Wilcoxon Rank-sum (Mann-Whitney) Test of Rubber Quantity Purchased Variable by Transmigrant Status 
Chapter 1

General Introduction 
Trade dynamics are inseparable from the influence of policies, prices, and the role of traders themselves. Trade policies differ between exporting and importing countries (Reed, 2001), with many trade policies supporting domestic markets while simultaneously threatening the foreign markets with whom they are engaged in trade. The impact of the importing countries' policies can be detrimental to the domestic trade sector of the exporting countries and vice versa; one common example is import tariffs created by the importing country to protect its domestic industries which subsequently limit the import quantities produced by exporting countries (Reed, 2001). This impact can usually be observed through changes in domestic price trends due to the emergence of a policy, so research aiming to predict the effects of these policies and subsequent price trends on domestic markets can help governments to be better prepared in facing challenges which will inevitably emerge.

Furthermore, changes in price trends can affect the decisions of traders to remain in or exit a market, and ultimately change the structure of the market itself. Due to increased market competition, higher numbers of traders typically result in more favourable the market conditions, while lower numbers of traders typically mean a higher potential for disproportionate market power (Mas-Colell, Whinston, \& Green, 1995). In the agricultural sector of developing countries, traders are able to bridge the gap between factories and farmers due to farmers' lack of capital, information and knowledge (Kopp, Alamsyah, Fatricia, \& Brümmer, 2014; Zúñiga-Arias, 2007). Understanding traders' behavior is relevant for policy makers in suitably anticipating market structure changes and can help protect farmers by maintaining their market power.

Additionally, as we show in chapter 3, another factor affecting traders' behavior to remain in or exit a market is credit provision. In the agricultural sector, it is a common practice to provide credit for suppliers or farmers, since they still depend on loans, not only for farming activities but also for their daily needs. Carranza and Niles (2019) found that food, agricultural and livestock inputs, and medical expenses are the main loan-dependent expenses among smallholder farmer households. Money lenders certainly carry the risk of losing their money to suppliers who default on their debt, especially when price trends are declining. This may affect traders' decision in determining a price. Observing the effects of individual loan quantities on price determination then becomes very compelling.

To achieve these objectives, we study the case of oil palm and rubber traders in Jambi province, Indonesia. Indonesia represents a largely agricultural country, with an agricultural sector that accounted for nearly 13\% of total Gross Domestic Product in 2018 (Statistics Indonesia, 2019). Among its agricultural outputs, Indonesia's oil palm and rubber trade 
provide a large contribution to the country's foreign exchange (Directorate General of Estate Crops, 2017a, 2017b). Plantation land area in Jambi province, located on Sumatra island, has rapidly expanded, bringing with it many indirect land use change issues (Directorate General of Estate Crops, 2015, 2016a, 2016b, 2017a, 2017b). However, all stakeholders related are benefiting from the sector due to higher income (Bou Dib, Krishna, Alamsyah, \& Qaim, 2018). Moreover, the Indonesian palm oil and rubber industries have resulted in many new domestic employment opportunities. Labor usage within the Palm Oil and Rubber industries increased by about $36 \%$ and $7 \%$, respectively, from 2013 to 2018 (Directorate General of Estate Crops, 2015, 2016a, 2016b, 2017a, 2017b). The contrasting trajectories of these two valuable industries makes studies related to palm oil and rubber of particular interest to policy makers and national governments.

The research objectives of this study are therefore to:

a. Observe the effects of an importing country's trade policy on price in a targeted exporting country

b. Analyse factors affecting local traders' decisions to remain in or exit the market

c. Investigate the influence of farmer's debt on local traders' buying choices and price determination

We pursue these research objectives through three separate papers, summarized below:

Paper 1

The European Union's Biodiesel Antidumping Duty (AD) is one of the most hotly debated international biodiesel trade policies in existence today. In 2013, the EU imposed a biodiesel $\mathrm{AD}$ on exporting countries known to engage in biodiesel dumping, and Indonesia was one of the main countries affected The EU accused Indonesian biodiesel producers of charging artificially lower prices than the world market in the purchasing of raw materials (CPO), which was said to affect the performance of EU biodiesel producers. To the best of our knowledge, this is the first study specifically focusing on the price effects of the EU ADs in countries targeted by the duties. The study aims to observe the effects of the AD on Indonesian exports and local CPO prices by applying a Vector Error Correction Model (VECM) approach to time series data. Result shows that the implementation of the AD has a negative effect on the price of Indonesian CPO and oil palm FFB in Jambi province. 


\section{Paper 2}

Traders play a significant and often underestimated role in agricultural trading activities. Having more traders in the market is favorable for competition, as farmers have more choices as to whom they may sell their products and can choose their most preferred trader. Understanding this role is crucial in understanding the trader's behavior in the market. Some may remain, and some may exit the market, which can then in turn alter the market structure. Therefore, this study focuses on traders' decisions to remain in or exit the market, and the factors influencing this decision. To analyse the probability they remain in the market, we employ a binary logistic regression method to key variables obtained from a 3round data collection process in Jambi. We find clear evidence that human capital (education and experience), trading structure (traded product, credit provision, land area, operational vehicle ownership, and trader status), structural environment (number of competitors), and socioeconomic (trading revenue) factors all affect the decision of traders to remain in or exit the market.

\section{Paper 3}

In the Jambi rubber trade, it is a common practice to reduce the price of rubber to compensate for a contaminated product. However, a farmer's dependence on loans offered by traders may also have an influence on this price reduction. This study aims to observe to what extent, if any, price reduction, rubber quality, and farmers' debt influence rubber traders' preferences in buying rubber, and to estimate how much of a price reduction traders will charge to obtain higher quality rubber or lower farmer's debt. Using data from 210 rubber traders in Jambi Province, Indonesia, we apply a Discrete Choice Experiment and a willingness-to-pay measurement approach to observe this phenomenon. To the best of our knowledge, there is no study implementing this method to capture agricultural traders' or middlemen's behavior in sourcing product and using price reduction as a replacement for willingness to pay; therefore, the methods applied in this study are novel. Result shows that price reduction, rubber quality, and farmer's debt influence traders' preferences in buying rubber, whereas higher price reduction, higher rubber quality, and lower farmer's debt will increase a trader's utility. 
Chapter 2

Does the Biodiesel EU Antidumping Duty Affect the Indonesian CPO Price?

Rakhma Melati Sujarwo, Bernhard Brümmer, Thomas Kopp 


\subsection{Introduction}

In 2003, the European Union (EU) issued a directive advising member states to increase the use of biofuels and other renewable fuels in the transport sector (European Commission, 2003) in an effort to reduce $\mathrm{CO}_{2}$ emission in transportation. Biodiese ${ }^{1}$ is the most widely used type of biofuel in the EU, with a share of $80.7 \%$ of the market in 2017 (Tiseo, 2019). A study performed by (Sheehan, Camobreco, Duffield, Graboski, \& Shapori, 1998) reported that blending higher amounts of biodiesel into petroleum diesel leads to a lower amount of net $\mathrm{CO}_{2}$ life cycle emissions overall ${ }^{2}$ (Figure 2. 1).

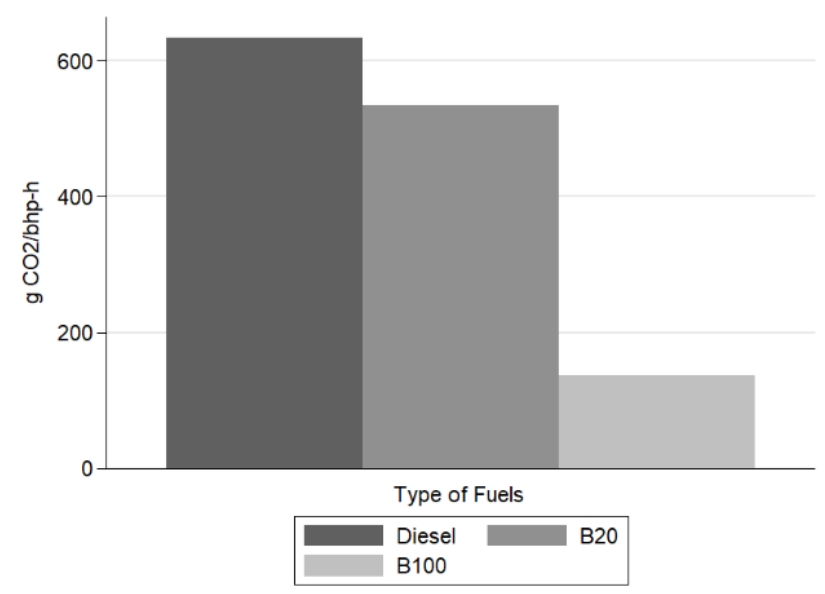

Source: Own production based on data from (Sheehan et al., 1998).

Figure 2. 1 Net CO2 Life Cycle Emissions ${ }^{3}$ of Petroleum Diesel and Biodiesel Blends ${ }^{4}$

The directives aim for new renewable energies to account for at least $32 \%$ of total energy needs in the EU by 2030 (European Commission, 2018). The directives have been further expanded a number of times. One of these changes, issued in 2009, requires that renewable fuel be applied not only to motor vehicles, but also to machinery (Bourguignon, 2015). The directives have caused both an increase in the consumption of biofuels and an expansion of the domestic biodiesel industry; however, this growth in domestic consumption has not entirely translated into production increases, and as of 2011 production quantity was still 21.5\% lower than consumption (Flach, Lieberz, Lappin, \& Bolla, 2018) (Figure 2. 2). The remaining domestic demand was met through imports.

\footnotetext{
${ }^{1}$ Biodiesel is a renewable diesel fuel substitute made from natural oil or fat mixed chemically with alcohol (Sheehan et al., 1998).

${ }^{2} \mathrm{Net} \mathrm{CO}_{2}$ was calculated by setting biomass $\mathrm{CO} 2$ emissions from the tailpipe to zero (Sheehan et al., 1998).

${ }^{3}$ The value is expressed in grams per brake horsepower-hour ( $\mathrm{g} / \mathrm{bhp}-\mathrm{h}$ ) which is the standards for heavy duty engines (Sheehan et al., 1998).

${ }^{4} \mathrm{~B} 20$ and B100 are biodiesel blends that are respectively 20 and 100 percent biodiesel mixed with petroleum diesel.
} 


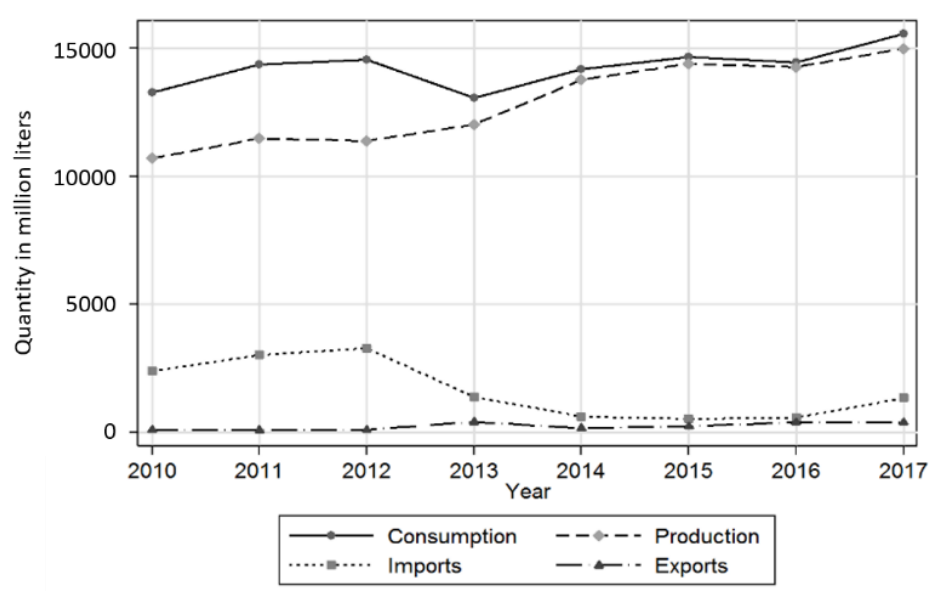

Source: Own production based on Flach et al. (2018) and Flach, Lieberz, Rondon, Williams, \& Wilson (2016).

Figure 2. 2 Biodiesel and Renewable Diesel $\left(\mathrm{HVO}^{5}\right)$ in the European Union

Opening international trade channels for biodiesel commodities put the European producers under competitive pressure from foreign imports. Indonesia is one of the world's leading biodiesel exporters, contributing to around $30 \%$ of total biodiesel imported by the EU in 2012 (Flach et al., 2018; UFOP, 2017). Biodiesel prices charged by Indonesia are very competitive, since it has a competitive advantage in sourcing Crude Palm Oil (CPO), one of the main raw materials used in producing biodiesel

To confront such a challenge, the EU may enforce certain trade barriers to protect domestic producers. According to Reed (2001), there are four reasons a country or region may have such barriers. First, the government may seek to gain more income by charging tariffs to exporters, which are easier to implement and more discrete than raising income taxes outright. Second, the government may attempt to protect certain products, such as staple foods, to achieve self-sufficiency, and price distortions through trade barriers can be a viable option to this end. Third, the government may attempt to politically protect domestic producers from international rivalry in order to obtain higher subsequent bargaining power in the international market. Lastly, very large importing countries may take advantage of their high market power by restricting imports of certain products to reduce the world price; thereby increasing their welfare.

One of the most debated international biodiesel trade policies created by the EU is the Biodiesel EU Antidumping Duty (AD) created in late 2013 (European Commission, 2013a). The EU imposed a biodiesel AD on exporting countries known to engage in biodiesel dumping, with Indonesia being one of the main targets of the policy. The country

\footnotetext{
${ }^{5}$ Hydrogenated Vegetable Oil
} 
was accused of having set export prices below the competitive market price, which negatively affected domestic producers' performance.

This presumption was based on a 2012 study conducted by the EU, which found that Indonesian biodiesel producers were charged far below the world market price in the purchasing of raw materials from Indonesian CPO producers (European Commission, 2012). The price difference was developed by imposing high-value export tariffs on Indonesian $\mathrm{CPO}$ inputs, while maintaining very low export tariffs for the output product of Indonesian biodiesel. The margins generated on dumping were revealed to be between $8.8 \%$ and $23.3 \%$ (European Commission, 2013b).

In response, Indonesia made an appeal against the policy at the World Trade Organization's (WTO) Dispute Settlement Body (DSB) in 2015, as its discussions with the EU had failed to reach a resolution (World Trade Organization, 2018). The court ruled in favor of Indonesia, arguing that the EU failed in their assessment of the situation through inaccurate estimation of production costs, improper formulation of an export price, and insufficient evidence for the existence of a price undercutting scheme. The policy was terminated by the end of 2018, and as of today there are no more ADs imposed by the EU on Indonesian biodiesel (European Union External Action, 2018).

The implementation of trade duties can have important and long-lasting economic effects on stakeholders in target countries. Measuring the effects of the biodiesel AD on the Indonesian CPO industry can provide an important analysis into the economic impacts of trade duties and allow for a quantitative assessment of the effects of ADs on agricultural markets, particularly in developing economies. To the best of our knowledge, there are few studies focusing on the effects of AD's, especially those imposed by the EU, on target countries (Cheong, 2007; Cuyvers \& Dumont, 2005; Jabbour, Tao, Vanino, \& Zhang, 2009). Most studies focus on the effects of AD's in home countries (Asche, 2001; Avşar, 2013; Konings \& Vandenbussche, 2013; Pierce, 2011), with a primary focus on trade destruction and diversion as a result of duty implementation.

The preceding studies (Cheong, 2007; Cuyvers \& Dumont, 2005; Jabbour et al., 2009) applied Ordinary Least Square (OLS) or Propensity Score Matching (PSM) to identify the EU AD's effects on target countries' export growth by measuring export value and volume. Other studies (Brambilla, Porto, \& Tarozzi, 2012; Chandra \& Long, 2013; Lu, Tao, 
\& Zhang, 2013) concentrated on the effects of United States AD's on income and labor productivity in target countries by applying Cross-section and Panel Regression Models.

Even though biodiesel usage may lead to decreased $\mathrm{CO}_{2}$ emissions, the expansion of palm oil production land for the biodiesel industry may have detrimental environmental effects, such as biodiversity loss and indirect land use change (Croezen, Bergsma, Otten, \& van Valkengoed, 2010; Matsuda \& Takeuchi, 2018). Indirect land use change involves the conversion of land from its initial purpose, such as protected forest, grassland, pasture, or agricultural land, into arable land used for biofuel feedstock cultivation, which results in an increase in emissions (Croezen et al., 2010). This indirect increase in emissions is one of the reasons why biodiesel made from palm oil is currently considered unsustainable by the $\mathrm{EU}^{6}$. (European Commission, 2019).

On the positive side, the Indonesian palm oil industry has provided many employment opportunities in the national economy. There was a massive increase in labor usage in the palm oil production sector of about 78\% from 2012-2014 (Directorate General of Estate Crops, 2016a). Furthermore, the industry has boosted the Indonesian national income. The value of Indonesian biodiesel exports reached around 1.1 billion USD in 2014, a 17\% increase from 2012 (UN Comtrade, 2019).

This contrast between potential environmental benefits and ecological harm make any study of the palm oil industry both interesting and complex. This study differs from previous literatures in its aim to observe the effects of the EU AD on Indonesian exports and local CPO prices by employing time series data to a Vector Error Correction Model (VECM). By comparing Johansen and Gregory-Hansen tests in our model specification, we can prove whether there is a structural break representing the AD duty implementation which captures the effect of the policy implementation on both Indonesian CPO prices and local prices

The study is structured as follows: the subsequent section provides an overview of the alleged dumping occurring in Indonesia and subsequent EU response to the situation. The model specification section describes the methodology implemented and is followed by a description of the data used in the study. We discuss the results before summarizing our study in the conclusion section.

\footnotetext{
${ }^{6}$ The EU stated that $45 \%$ of the oil palm area expansion caused forest devastation; in contrast, that the case for only $8 \%$ and less for other biodiesel sources (European Commission, 2019).
} 
2.2. Background: dumping and retaliation

\subsubsection{Dumping}

The implementation agreement of Article VI of the 1994 General Agreement on Tariffs and Trade expressed an opposition to the practice of dumping (World Trade Organization, 1994). However, many countries still engage in the practice with various products (Figure 2.3). From an international trade perspective, dumping is associated with a form of price discrimination wherein exporting countries charge a lower price on the world market than they do domestically, or evaluate a product at a value lower than the product's average cost (Feenstra \& Taylor, 2014).

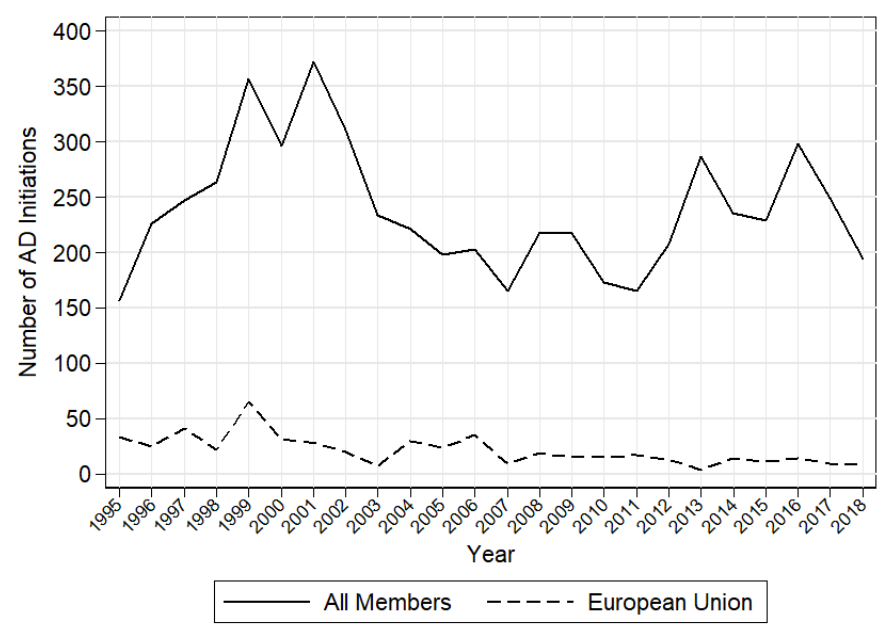

Source: Own production based on data from World Trade Organization (2019).

Figure 2. 3 AD Initiations between 1995-2018.

However, Lindsey and Ikenson (2003) argue that a country can be accused of dumping even when charging equal prices on both the world market and the domestic market; or even a higher world price than domestic price. According to the authors, reasons for this include the effect of fluctuation, the asymmetric treatment of indirect selling expenses, and the exclusion of below-cost sales which are able to influence the value of dumping margins.

To illustrate the general dumping situation, we assume a condition called Foreign Discriminating Monopoly (Feenstra \& Taylor, 2014) as shown in Figure 2. 4. The firm is assumed to be in perfect competition on the world market and exercises monopolistic market power on the domestic market. It sets Marginal Cost (MC) equal to Marginal Revenue (MR) to maximize profits. Also, it discriminates between prices set on the local market and those of export markets. To maximize profit, it produces $\mathrm{Q}_{\mathrm{E}}$, where its local MC meets export 
market $M R_{E}$ at point $O$. However, it sells only at $Q_{D}$ to its local market, where $M R_{D}$ meets $\mathrm{MR}_{\mathrm{E}}$ at point $\mathrm{N}$. The difference between $\mathrm{Q}_{\mathrm{E}}$ and $\mathrm{Q}_{\mathrm{D}}$ is the quantity to be exported.

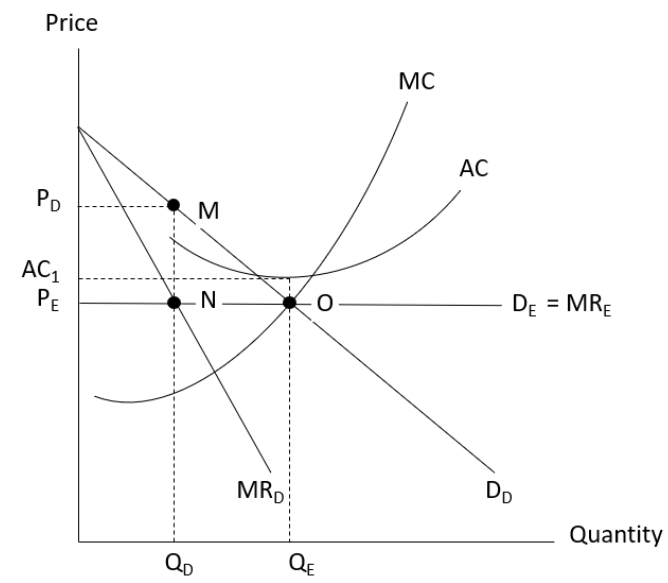

Source: Own production based on data from Feenstra and Taylor (2014).

Figure 2. 4 Dumping Illustration

Additionally, it charges a price $\mathrm{P}_{\mathrm{D}}$ on the domestic market, while $\mathrm{P}_{\mathrm{E}}$ is charged on the export market. In this case, $\mathrm{P}_{\mathrm{E}}$ is lower than $\mathrm{P}_{\mathrm{D}}$, even lower than the local Average Cost (AC). This price discrimination is called dumping. In such a condition, nevertheless, the firm still profits. Feenstra and Taylor (2014) mentioned that, even though the export price value is lower than that of average cost (AC), the firm, or the foreign monopoly producer, still benefits from this condition if the export price value is higher than the $\mathrm{MC}^{7}$.

However, the alleged dumping scheme exercised by Indonesia is a more complex case. The EU claimed that CPO, the raw material for Indonesian biodiesel, is sold at artificially cheaper prices domestically than internationally (European Commission, 2013b). This reduces Indonesian biodiesel manufacturers costs below the costs of outside CPO manufacturers, which rely on CPO from Indonesia as an input. The EU further claims that this was caused by a large difference between the value of export tariffs between CPO and biodiesel, where dumping margin arises (European Commission, 2013b). This situation, where there is a difference in the value of export tariffs between input and output products is known as an export tariff escalation (Nogués, 2011).

The objective of imposing an export tariff escalation is to protect the processing industries in the exporting countries (Nogués, 2011). Consequently, the tariff escalation is visible when the raw material export tariff is higher than that of processed product (Corzine,

\footnotetext{
${ }^{7}$ Every unit exported raises profit by the discrepancy between price and MC
} 
2008; Nogués, 2011). Thus, it will encourage the domestic processing industries to grow and increase their competitiveness.

$$
T W=T-t
$$

TW $=$ Normal tariff wedge

$\mathrm{T}=$ Tariff in ad valorem equivalent of the output commodity

$\mathrm{t}=$ Tariff in ad valorem equivalent of the input commodity

There is a measurement of tariff escalation, called tariff wedge (TW) ${ }^{8}$ (Elamin \& Khaira, 2003), which is defined as the discrepancy between output and input commodity tariff values (eq. 1). It is more often applied to calculate import than export tariff wedge. Thus, the interpretation of TW should be reversed, where export tariff escalation appears when $\mathrm{TW}<0$. Meanwhile, export tariff de-escalation occurs when tariff wedge is higher than zero. Another condition called export tariff parity happens when TW=0.

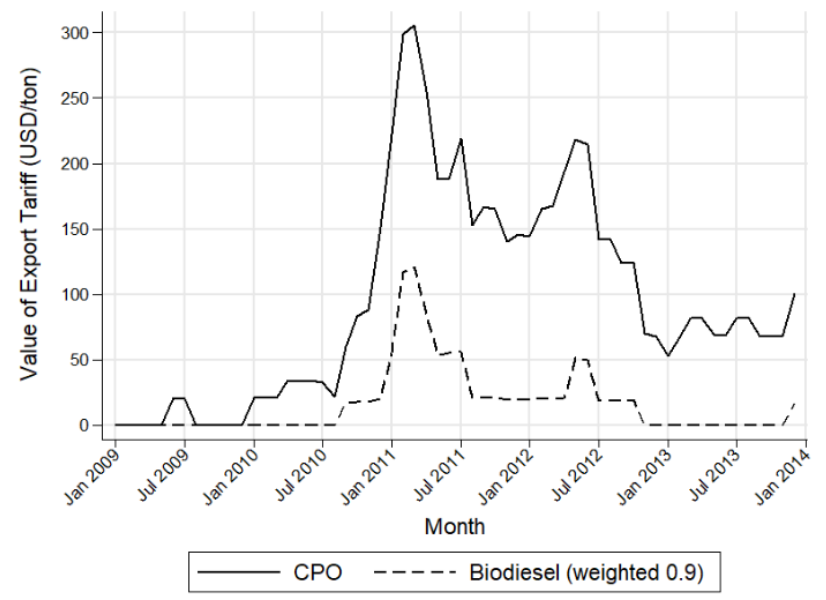

Source: Own calculation based on data from Minister of Trade of the Republic of Indonesia (2019) and Ministry of Finance of the Republic of Indonesia (2019).

Figure 2. 5 Value of Export Tariff (USD/ton) of Indonesian CPO and Biodiesel ${ }^{9}$

Figure 2. 5 depicts the deviation of export tariff values ${ }^{10}$ of Indonesian CPO and biodiesel. Since the export tariff value of Indonesian CPO is mostly higher than that of

\footnotetext{
${ }^{8}$ Another measurement, called Effective Rate of Protection, is applied to avoid issue caused by the presence of multiple input and/or output. However, in this case TW is sufficient since CPO is the main raw material in biodiesel production, while other additional materials are negligible.

${ }^{9}$ By processing 1 ton of CPO, 0.9 ton of biodiesel is produced (Andarani, Nugraha, \& Wieddya, 2017)

${ }^{10}$ The CPO export tariff value was calculated by multiplying its export tariff with its Export Standard Price (ESP), where similar process was conducted for biodiesel. The ESP for both CPO and biodiesel were defined based on the CPO Free on Board (FOB) average price. Both CPO and biodiesel export tariffs refer to the CPO reference price which were based on Cost, Insurance, and Freight (CIF) Rotterdam CPO average price and Malaysian and/or Jakarta exchange CPO average price. The export tariff classification regulations were determined by the Ministry of Finance of the Republic of Indonesia. Each is valid until the Ministry decides
} 
Indonesian biodiesel, it can be concluded that the tariff wedge is mostly lower than 0 in the period of 2009-2013. This condition indicates that the export tariff escalation exists. In addition to that, the figure only presents the condition before the EU AD duty imposition, which was started at the end of 2013.

The export tariff imposition will create higher MC for the CPO producers overseas. Since the domestic CPO price is below the world CPO price due to the export tariff, the MC in exporting biodiesel by Indonesia $\left(\mathrm{MC}_{\mathrm{EX}}\right)$ becomes lower than that incurred by the $\mathrm{EU}$ $\left(\mathrm{MC}_{\mathrm{EU}}\right)$ (Figure 2. 6), which is also due to biodiesel low export tariff ${ }^{11}$. This difference moves the equilibrium along the demand curve $\left(\mathrm{D}_{\mathrm{EU}}\right)$; from point $\mathrm{O}$ to $\mathrm{B}$. In response to this new price $\left(\mathrm{P}_{\mathrm{EX}}\right)$, the quantity produced by the $\mathrm{EU}$ is reduced from $\mathrm{Q}_{\mathrm{EU} 1}$ to $\mathrm{Q}_{\mathrm{EU}}$, where the $\mathrm{EU}$ also starts to import $\mathrm{Q}_{\mathrm{EX}}-\mathrm{Q}_{\mathrm{EU} 2}$. This artificially low $\mathrm{MC}_{\mathrm{EX}}$ means this situation was previously counted as dumping, which was also supported by the dumping margin calculation by the EU. It is consistent with the previous statement by Lindsey and Ikenson, (2003) that even though the world price is higher than the domestic price, a country can still be accused of dumping.

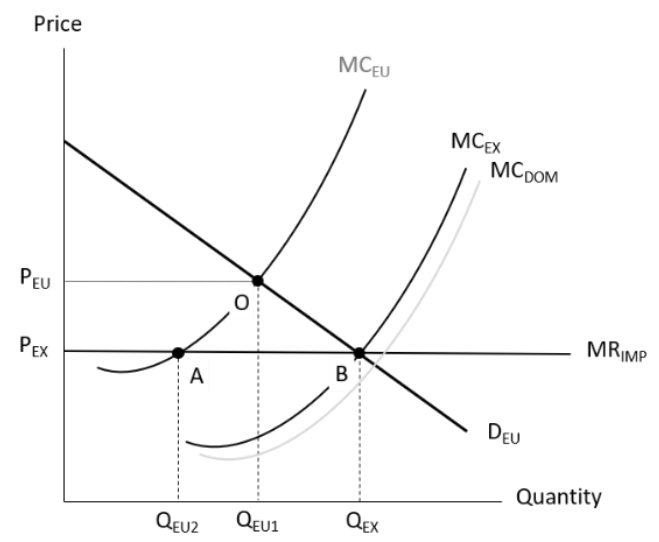

Source: Own illustration.

Figure 2. 6 Indonesian Biodiesel Dumping Illustration

\subsubsection{Retaliation}

To tackle dumping, the EU imposed an AD. The case was initiated in August 2012. It was a follow up from the complaint the European Biodiesel Board's (EBB) filed one month before. The EU biodiesel producer who filed the case represents more than $60 \%$ of the total EU biodiesel production (European Commission, 2013a). The evidence provided

\footnotetext{
that the new regulation is required to be authorized. On the other hand, the CPO reference price and ESP were determined by the Ministry of Trade of the Republic of Indonesia on a monthly basis (Minister of Trade of the Republic of Indonesia, 2019; Ministry of Finance of the Republic of Indonesia, 2019).

${ }^{11}$ The low biodiesel export tariff creates the gap between export market $\mathrm{MC}_{\mathrm{Ex}}$ and local $\mathrm{MC} \mathrm{C}_{\mathrm{DOM}}$.
} 
was deemed by the EU to be sufficient to initiate a proper investigation into a potential a dumping scenario. Then, the EU began an investigation into Indonesian exporting producers as well as EU producers, and both parties were required to provide data to be processed as part of the investigation.

Further, dumping and injury margins were examined, and both were compared to determine the $\mathrm{AD}$ rates (Table 2. 1), which were imposed at the end of 2013 (European Commission, 2013a). These rates were adjusted to the level of the purity of the biodiesel imported. Additionally, according to Feenstra and Taylor (2014) there are three ways to determine the $\mathrm{AD}$ rate: by (1) comparing the import price to the exporter's local price, (2) comparing this to that of a similar product in another country, and (3) comparing that to the exporter's AC.

Table 2. 1 The definitive EU AD rate for Indonesian biodiesel producers.

\begin{tabular}{llll}
\hline Company & $\begin{array}{l}\text { Dumping } \\
\text { Margin }\end{array}$ & $\begin{array}{l}\text { Injury } \\
\text { Margin }\end{array}$ & AD rate \\
\hline PT Ciliandra Perkasa, Jakarta & $8.8 \%$ & $19.7 \%$ & $\begin{array}{l}8.8 \% \\
\text { (EUR 76.94) }\end{array}$ \\
PT Musim Mas, Medan & $18.3 \%$ & $16.9 \%$ & $\begin{array}{l}16.9 \% \\
\text { (EUR 151.32) }\end{array}$ \\
PT Pelita Agung Agrindustri, Medan & $16.8 \%$ & $20.5 \%$ & $\begin{array}{l}16.8 \% \\
\text { (EUR 145.14) }\end{array}$ \\
$\begin{array}{l}\text { PT Wilmar Bioenergi Indonesia, Medan; PT } \\
\text { Wilmar Nabati Indonesia, Medan }\end{array}$ & $23.3 \%$ & $20.0 \%$ & $\begin{array}{l}20.0 \% \\
\text { (EUR 174.91) }\end{array}$ \\
Other cooperating commpanies & $20.1 \%$ & $18.9 \%$ & $\begin{array}{l}18.9 \% \\
\text { (EUR 166.95) }\end{array}$ \\
All other companies & & & $\begin{array}{l}20.5 \% \\
\text { (EUR 178.85) }\end{array}$ \\
\hline
\end{tabular}

Source: (European Commission, 2013a).

In the same period, the EU imposed the biodiesel AD not only on Indonesia but also on Argentina, where the value of dumping and injury margins, as well as AD rates, are higher for Argentina than they are for Indonesia. The AD rates for Argentina were between 22.025.7\% (European Commission, 2013a). Additionally, the United States (US) has also imposed the AD on both Argentina and Indonesia since April 2018, when the International Trade Commission (ITC), an independent US federal trade regulations agency, affirmed that the industry in the US was negatively affected as a result of dumping (Smith, 2018). The 
estimated weighted-average dumping margins are much higher than those implemented by the EU.

In the $\mathrm{EU}$, the $\mathrm{AD}$ causes an increase in import prices as illustrated in Figure 2. 7, where the price increases from $\mathrm{P}_{\mathrm{w}}$ to $\mathrm{P}_{\mathrm{w}}+$ duty. When trade is introduced, the Home Consumer Surplus (CS) expands excessively, while Home producers are worse off. However, there is an increase in the Home total surplus, where area AOB (No Trade) shifts into area $\mathrm{ABCD}$ (Free Trade). Under this condition, the import quantity becomes $\mathrm{Q}_{3}-\mathrm{Q}_{2}$, while home producers produce only Q2. If producers charge a price higher than $\mathrm{Pw}$, the consumers will import the product.

In a case where the government imposes an $\mathrm{AD}$ (Free Trade with $\mathrm{AD}$ ), the price will increase to $\mathrm{Pw}+$ duty. Consequently, the import quantity will fall to $\mathrm{Q}_{5}-\mathrm{Q}_{4}$. The Home CS decreases, while there is surplus transfer from consumer to producer. Apart from that, the government will gain revenue from the duty not exceeding the area of $\mathrm{EE}_{1} \mathrm{FF}_{1}$. In this case, area CEE1+DFF1 is Dead Weight Loss, and is no longer part of the total surplus. Even though the total surplus decreases by issuing an $\mathrm{AD}$, the government still considers that imposing this policy is beneficial for the reasons mentioned in the previous chapter (Reed, 2001). In this situation, the EU seeks to protect its domestic biodiesel producers from dumping.

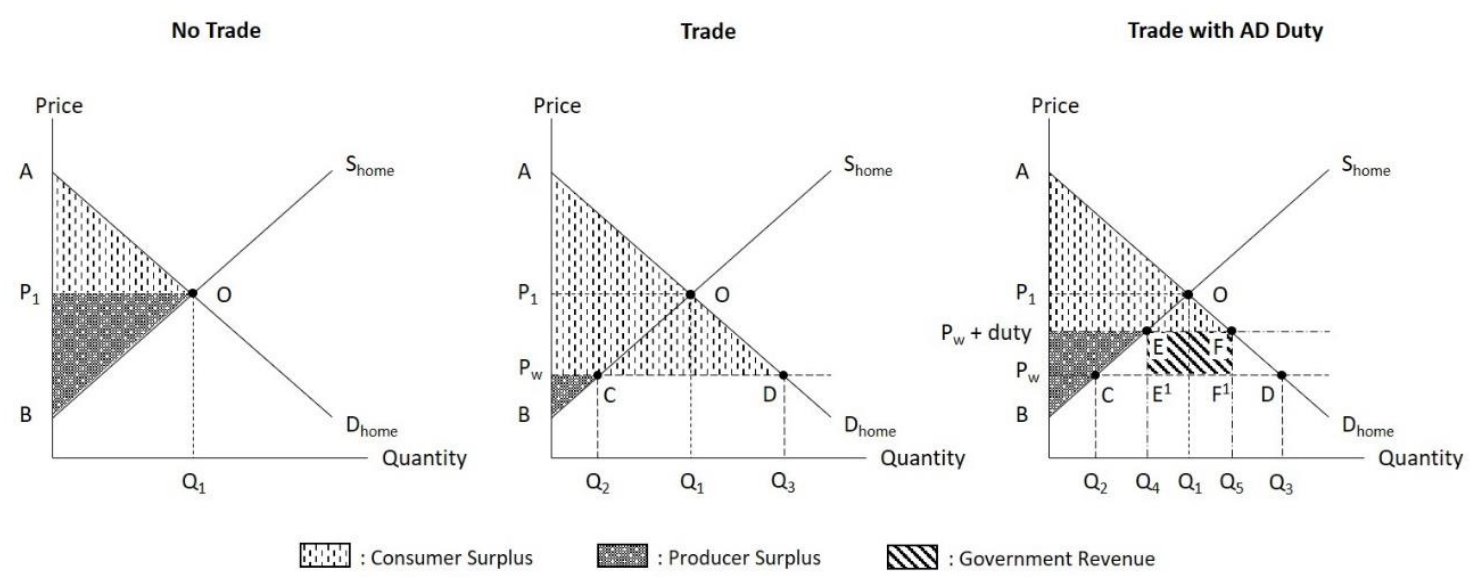

Source: Own production based on Reed (2001) and Feenstra and Taylor (2014).

Figure 2. 7 Home Equilibrium without Trade, with Trade and with AD in Trade

On the other hand, the possible effect that occurs in Indonesia is illustrated in Figure 2. 8, which is derived from the Foreign Discriminating Monopoly curve. When the export price increases to $\mathrm{P}_{\mathrm{E}}+$ duty, the domestic price increases. Moreover, the quantity produced will be limited to $\mathrm{Q}_{\mathrm{E} 2}$ where $\mathrm{Q}_{\mathrm{D} 2}$ is sold domestically and $\mathrm{Q}_{\mathrm{E} 2}-\mathrm{Q}_{\mathrm{D} 2}$ is exported. Both the 
quantity sold domestically and exported may be less than before, and are shown by QD and $\mathrm{Q}_{\mathrm{E}}-\mathrm{Q}_{\mathrm{D}}$, respectively. However, the effect of the biodiesel $\mathrm{AD}$ duty on the Indonesian CPO industry will be discussed further in the results section.

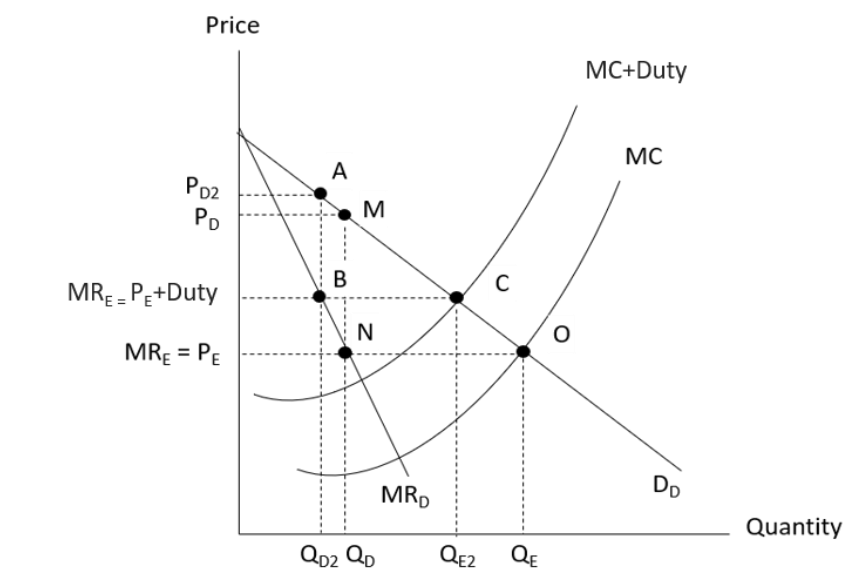

Source: Own illustration.

Figure 2. 8 The AD duty Illustration Effect in Indonesia

\subsection{Model Specification}

We aim to observe the effects of the EU biodiesel $\mathrm{AD}$ on Indonesian export prices and local prices by applying a VECM to time series data. To do so, we test for the existence of a structural break (SB) in the long-run relationship between two price time series. We analyze two relationships - the relationship between world CPO price and Indonesian CPO price, as well as the relationship between Indonesian CPO price and the local price of Fresh Fruit Bunches (FFB) of oil palm in Jambi Province. The existence of a structural break (SB) would indicate changes in long- or short-run relationship between prices caused by the duty imposition if a significant SB occurs around the duty imposition date.

The first step is to ensure that all price variables are stationary on the first difference (I(1)) to avoid the problem of a spurious regression. Thus, we employed Augmented Dicky Fuller (ADF), Phillips-Perron (PP), and Zivot-Andrews (ZA) unit root tests to examine the stationarity. ADF and PP test model are shown by equation 2 and 3 (Asteriou \& Hall, 2016). Dickey-Fuller extended their test procedure by suggesting an augmented version of the test which includes lagged terms of the dependent variable to eliminate autocorrelation (Waheed, Alam, \& Ghauri, 2007). the unit root presents itself, i.e. the variable is non-stationary, when the null hypothesis cannot be rejected. Therefore, to obtain the I(1) variable, we expect to reject it on the first difference. Another stationarity test is ZA test (eq. 4) (Zivot \& Andrews, 
1992), which allows for the univariate existence of a SB. The purpose of the ZA test is to ensure the stationarity robustness and test the initial SB indication in each variable.

$$
\begin{gathered}
\Delta y_{t}=a_{o}+\beta y_{t-1}+\gamma t+\sum_{i=1}^{p} \beta_{i} \Delta y_{t-i}+e_{t} \\
\Delta y_{t}=a_{o}+\beta y_{t-1}+e_{t} \\
\Delta y_{t}=a_{o}+\beta y_{t-1}+\gamma t+\zeta D U_{t}+\sum_{i=1}^{p} \beta_{i} \Delta y_{t-i}+e_{t}
\end{gathered}
$$

$D U=1$ if $t>$ break date and 0 if otherwise

Next, we must test the cointegration of the two-pair time series to confirm that they hold a long-run relationship. They are cointegrated if both are integrated in the same order, in this case on $\mathrm{I}(1)$, and if there is a linear combination of both series on the level $\mathrm{I}(0)$ where in this case the $e_{t}$ in equation 5 or 6 is stationary. Initially, we conducted Johansen cointegration test to observe the cointegration. In a later step, we performed a GregoryHansen $(\mathrm{GH})$ cointegration test to analyze the cointegration allowing for a SB. These results will be compared to identify whether the SB genuinely exists or not, in the form of VECM.

Before we proceed to the cointegration tests, we need to determine the optimum lag order necessary to reduce bias by using model selection criterions in the form of Akaike information criterion (AIC), Bayesian information criterion (BIC), and Hannan-Quinn information criterion (HQIC) (Mills \& Prasad, 1992). We consider all criterions for robustness motivation. The difference between these criteria lie in how the number of estimated parameters and observations are penalized (Mills \& Prasad, 1992).

The Johansen cointegration test determines the rank of a time series relationship or the number of cointegrating vectors in a bivariate relationship study with only one possible cointegrating vector (eq. 5). The Johansen test is a maximum likelihood method based on specific correlations (Johansen, 1988). Trace and maximum eigenvalue statistics are also approaches to be observed (Asteriou \& Hall, 2016; Johansen, 1988).

$$
y_{1 t}=a_{1}+\beta y_{2 t}+e_{t}
$$

Meanwhile, the GH cointegration test is based on ADF and Phillips $\left(Z_{\alpha}\right.$ and $\left.Z_{t}\right)$ test statistic to examine the presence of cointegration allowing SB (Gregory \& Hansen, 1996). There are three different possibilities of SB in the cointegration vector (equation 6); these are (1) a level shift (eq. 6a), (2) a level shift and trend (eq. 6b), and (3) a regime shift (eq. 
6c). We determine the best of these a la Gregory and Hansen (1996). The best model is determined by model selection criteria and test statistics and is presented in the results section. However, in this study, we do not consider cointegration with SB in level and trend (eq. 6b) since there is no indication of trend present in the series and there is a common price volatility. Also, the breakpoint is suggested during this test. Nevertheless, we currently have 2 possibilities left of equation 6 (eq. $6 \mathrm{a}$ and $6 \mathrm{~b}$ ), since equation $6 \mathrm{~b}$ is neglected.

$$
\begin{gathered}
y_{1 t}=a_{1}+a_{2} D U_{t}+\beta y_{2 t}+e_{t} \\
y_{1 t}=a_{1}+a_{2} D U_{t}+a_{3} T+\beta y_{2 t}+e_{t} \\
y_{1 t}=a_{1}+a_{2} D U_{t}+a_{3}\left(D U_{t} \cdot y_{2 t}\right)+\beta y_{2 t}+e_{t}
\end{gathered}
$$

$D U=1$ if $t>$ breakpoint and 0 if otherwise

When the relationships are properly cointegrated, we proceed to estimate and interpret the long-run relationship by using VECM with log-likelihood function. Equations above (eq. 5, 6a, and 6c) capture the two long-run relationships between the two-pair time series which are distinctly presented below (eq. 7, 8a, 8b and 9, 10a, 10b). All price variables, namely world CPO price $\left(P_{W}\right)$, Indonesian CPO price $\left(P_{I D}\right)$, and Jambi FFB price $\left(P_{J B}\right)$, are in the natural logarithm form. However, we consider extra variables, namely export tariff values in USD/ton (ET) and tax levy $(T L)$ in dummy form, in the relationship between $P_{I D}$ and $P_{J B}$, since those extra variables are part of $P_{I D}$. The coefficient $\alpha_{1}, \alpha_{2}, \alpha_{3}, \beta, \xi$, and $\rho$ are the parameters to be estimated.

$$
\begin{gathered}
\ln P_{I D}=\alpha_{1_{1}}+\beta_{1} \cdot \ln P_{W}+e c t \\
\ln P_{I D}=\alpha_{1_{2}}+\alpha_{2_{1}} S B+\beta_{2} \cdot \ln P_{W}+e c t \\
\ln P_{I D}=\alpha_{1_{3}}+\alpha_{2_{2}} S B+\alpha_{3_{1}} S B \cdot \ln P_{W}+\beta_{3} \cdot \ln P_{W}+e c t \\
\text { and } \\
\ln P_{J B}=\alpha_{1_{4}}+\beta_{4} \cdot \ln P_{I D}+\xi_{1} \cdot E T+\rho_{1} \cdot T L+e c t \\
\ln P_{J B}=\alpha_{1_{5}}+\alpha_{2_{3}} S B+\beta_{5} \cdot \ln P_{I D}+\xi_{2} \cdot E T+\rho_{2} \cdot T L+e c t \\
\ln P_{J B}=\alpha_{1_{6}}+\alpha_{2_{4}} S B+\alpha_{3_{2}} S B \cdot \ln P_{I D}+\beta_{6} \cdot \ln P_{I D}+\xi_{3} \cdot E T+\rho_{3} \cdot T L+e c t
\end{gathered}
$$

In addition to that, VECM can segregate the long-run equilibrium, represented by the error correction term (ect), from the short-run dynamics. Thus, any shock that occurs in a certain period lets both prices adjust to return to the equilibrium (Patterson, 2000). The shortrun equations are presented below. Equation 11a and $11 \mathrm{~b}$ represent the short-run equilibrium of the relationship between $P_{I D}$ and $P_{W}$, while equation $12 \mathrm{a}$ and $12 \mathrm{~b}$ represent the relationship 
between $P_{J B}$ and $P_{I D}$. Subscript $t$ represents time; $n$ describes the number of lags $(0, \ldots, k)$; and $\gamma, \delta$, and $\theta$ are parameters to be estimated.

$$
\begin{aligned}
& \Delta \ln P_{I D t}=\sum_{n=1}^{k} \gamma_{1_{n}} \Delta \ln P_{I D_{t-n}}+\delta_{1} \Delta \ln P_{W_{t-n}}+\theta_{1} e c t_{t-1} \\
& \Delta \ln P_{W t}=\sum_{n=1}^{k} \gamma_{2_{n}} \Delta \ln P_{I D_{t-n}}+\delta_{2} \Delta \ln P_{W_{t-n}}+\theta_{2} e c t_{t-1} \\
& \text { and } \\
& \Delta \ln P_{J B t}=\sum_{n=1}^{k} \gamma_{3_{n}} \Delta \ln P_{J B_{t-n}}+\delta_{3} \Delta \ln P_{I D_{t-n}}+\theta_{3} e c t_{t-1} \\
& \Delta \ln P_{I D t}=\sum_{n=1}^{k} \gamma_{4_{n}} \Delta \ln P_{J B_{t-n}}+\delta_{4} \Delta \ln P_{I D t-n}+\theta_{4} e c t_{t-1}
\end{aligned}
$$

Additionally, the VECM can be briefly presented in matrix notation, as presented below. Equations 19a and 19b represent the two-pair time series relationships without a SB, where the long-run equation is inserted as ect within the short-run equation. Matrices $\mathrm{A}$ and B denote the effects of prices in the previous periods. Matrix $\varepsilon$ denotes normally distributed errors. Equations 20a and 20b define the two-pair time series relationships with SB, where there is a level shift in the model, while equations $21 \mathrm{a}$ and $21 \mathrm{~b}$ define where there is a regime shift in the model. Those equations are differed into parts with a dummy 0 (before SB or $\mathrm{t} \leq$ breakpoint) and dummy 1 (after SB or $\mathrm{t}>$ breakpoint).

First, one cointegration vector model allowing for a SB is chosen between two; thus, there is only one model left representing the SB (eq. 20a and 20b or 21a and 21b). Then, that model is compared to the model without the SB (eq. 19a and 19b) to confirm that the effect of SB is legitimate. Again, to do so, we compare the model-selection criteria value for both models: the lower the value, the better the model. Also, the higher the log-likelihood value, the better the model. Another criterion is that when all the GH cointegration test possibilities provide significant results, it is most likely that the model with the SB fits best. 


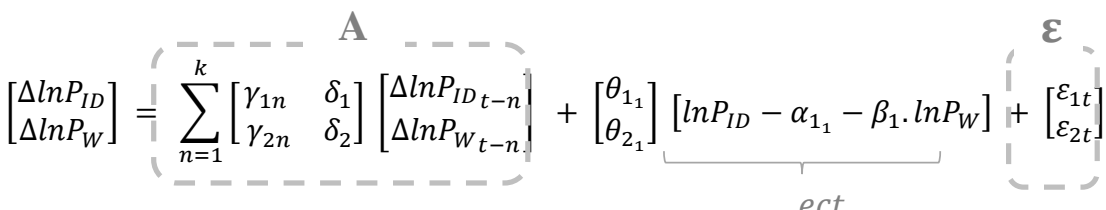

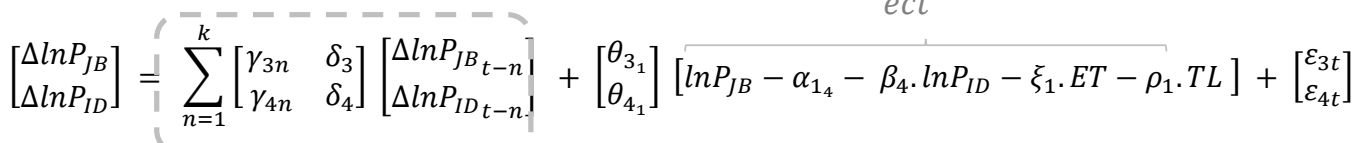

$$
\begin{aligned}
& \text { B }
\end{aligned}
$$

$\left[\begin{array}{l}\Delta \ln P_{J B} \\ \Delta \ln P_{I D}\end{array}\right]=\left\{\begin{array}{lll}\mathrm{B}+\left[\begin{array}{l}\theta_{3_{3 a}} \\ \theta_{4_{3 a}}\end{array}\right] & {\left[\ln P_{J B}-\alpha_{1_{6 a}}-\alpha_{2_{4 a}} S B-\alpha_{3_{2 a}} S B \cdot \ln P_{I D}-\beta_{6 a} \cdot \ln P_{I D}-\xi_{3 a} \cdot E T-\rho_{3 a} \cdot T L\right]+\varepsilon, \quad \mathrm{SB}=0} \\ \mathrm{~B}+\left[\begin{array}{l}\theta_{3_{3 b}} \\ \theta_{4_{3 b}}\end{array}\right] & {\left[\ln P_{J B}-\alpha_{1_{6 b}}-\alpha_{2_{4 a}} S B-\alpha_{3_{2 b}} S B \cdot \ln P_{I D}-\beta_{6 b} \cdot \ln P_{I D}-\xi_{3 b} \cdot E T-\rho_{3 b} \cdot T L\right]+\varepsilon, \quad \mathrm{SB}=1}\end{array}\right.$

At last, if the SB effect is legitimate, we compare the full model (also called the restricted model) which allows for the presence of the SB (eq. 20 or eq. 21) to the unrestricted model (also called as separated model). The unrestricted model represents the separation of equation 19 into before and after the breakpoint, thus we will have two long-run relationships (two-unrestricted model). To do so, a Likelihood Ratio (LR) test is required, since the VECM model determination employs the log-likelihood function. The log-likelihood discrepancy between a full model and the two-unrestricted model determines the LR value (eq. 22), which is then compared with a chi-square $\left(\chi^{2}\right)$ distribution (Wooldridge, 2013). The twounrestricted model is better than the full model if we can reject the null hypothesis.

$$
L R=2\left(L_{u r}-L_{r}\right)
$$




\subsection{Data}

We use data on world CPO price $\left(P_{W}\right)$, Indonesian CPO price $\left(P_{I D}\right)$, and Jambi FFB price $\left(P_{J B}\right)$ at a weekly frequency. $P_{W}$ and $P_{I D}$ are obtained from DataStream Navigator by Thomson Reuters (2019a, 2019b), while $P_{J B}$ data are gathered from the Estate Crop Office of the Jambi Province (2019). The series starts in October 2011, when the data is most recently available, and ends in November 2018, when the EU biodiesel AD imposition ended. It is expected that within that time period, the effect of the duty imposition can be analyzed.

We utilized CPO Cost, using Insurance and Freight (CIF) Rotterdam Price as a proxy for the $P_{W}$. Rotterdam is considered the main export entrance for the EU countries. Its price frequently influences the domestic price of exporting countries. Based on Figure 2. 9, the $\mathrm{EU}$ is the second largest Indonesian CPO importer, and EU countries absorbed around $25 \%$ of total Indonesian CPO export quantity in between 2012-2017. Meanwhile, India remains the largest importing country, consuming more than $60 \%$ of the total Indonesian CPO export quantity in 2017.

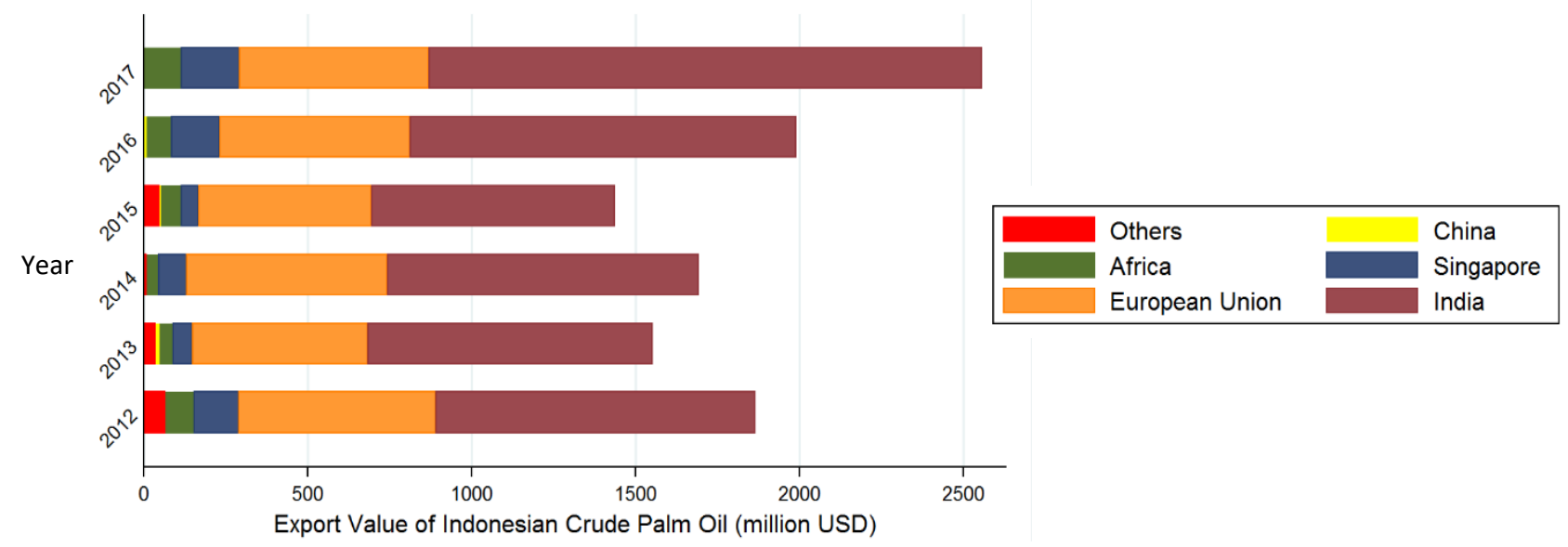

Source: Own production based on (Statistics Indonesia, 2018)

Figure 2. 9 Share of Indonesian CPO Export Value based on Importing Countries

We used CPO Free on Board (FOB) price in the Indonesian ports of Dumai and Belawan as a proxy for $P_{I D}$, as these are the main ports for CPO export activities. They accommodate more than 50\% of total Indonesian CPO export quantity in 2017 (Figure 2. 10). Those ports are located in Sumatra island, where the majority of Indonesian CPO production originates. They are also easily accessible from the Jambi province. 


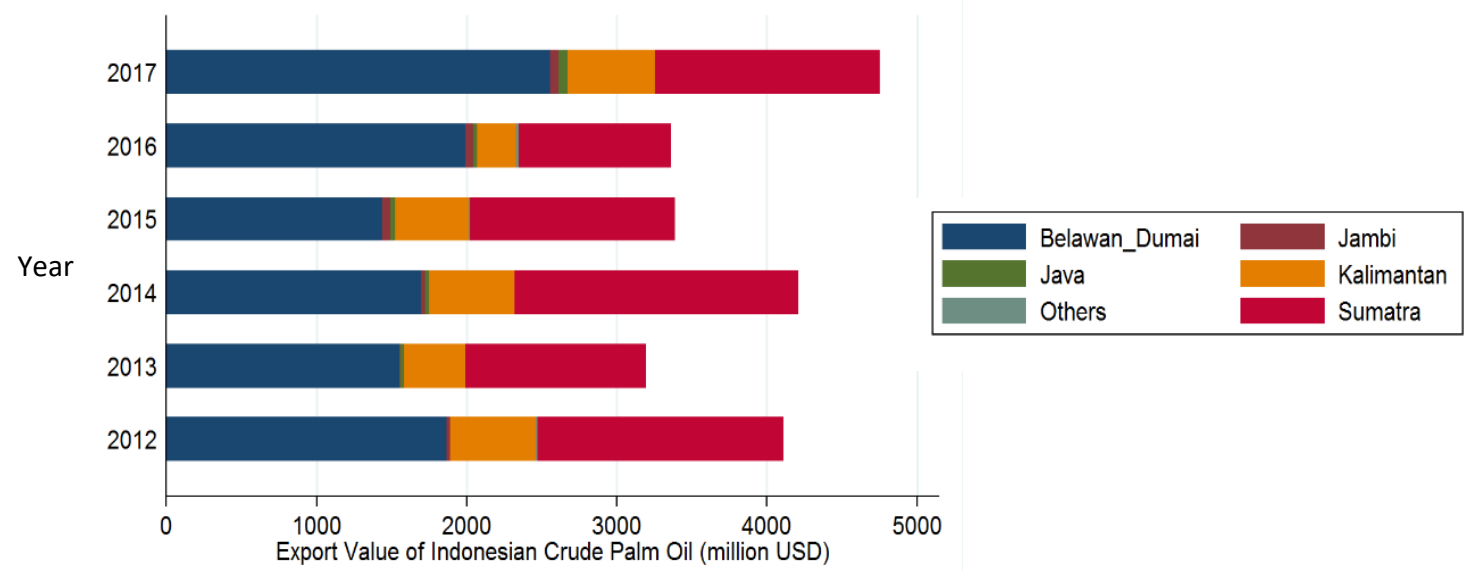

Source: Own production based on (Statistics Indonesia, 2018)

Figure 2. 10 Share of Indonesian CPO Export Value based on Ports' Location

We use Jambi province to represent local Indonesian areas. The province widely expanded the development of both oil palm land area and production from 2011-2017 (Figure 2. 11), and the number of oil palm farmers in the province increased $20 \%$ during this period(Directorate General of Estate Crops, 2015, 2016a). Oil palm accounted for nearly 12\% of Indonesian CPO export value in 2017 (Statistics Indonesia, 2018). The local price, $P_{J B}$, is the price of oil palm FFBs, which are freshly harvested and delivered on the same day to prevent any deterioration in quality received by farmers at the factory level (Estate Crops Office, 2019)..

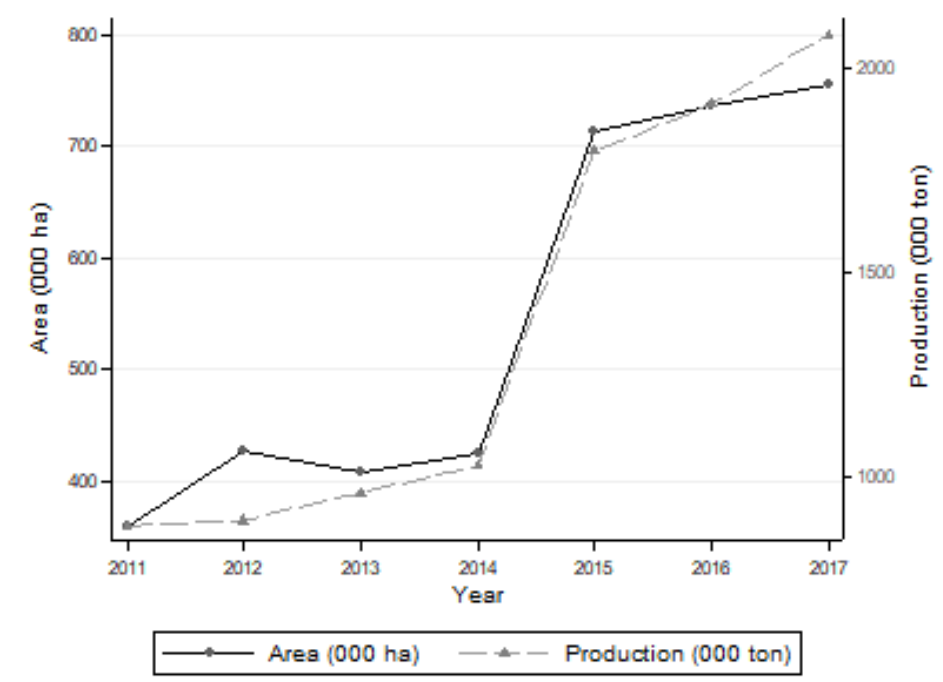

Source: (Directorate General of Estate Crops, 2015, 2016a)

Figure 2. 11 Area and Production of Oil Palm Plantation in the Jambi Province

Summary statistics of these price variables in USD/kg are presented in Table 2. 2. We employ weekly price data, and thus have 373 observations. The $P_{J B}$ restricts any higher 
of a data frequency ${ }^{12}$, which would have been preferable, since it is determined once per week $^{13}$ by the Jambi Governmental Office of Plantations ${ }^{14}$.

Table 2. 2 Summary Statistics of Price Variables (USD/kg)

\begin{tabular}{llllll}
\hline Variables & Obs & Mean & Std. Dev. & Min & Max \\
\hline FFB - Jambi price $\left(P_{J B}\right)$ & 373 & 0.14 & 0.03 & 0.08 & 0.21 \\
CPO FOB - Indonesia price $\left(P_{I D}\right)$ & 373 & 0.72 & 0.15 & 0.43 & 1.15 \\
CPO CIF - World price $\left(P_{W}\right)$ & 373 & 0.77 & 0.15 & 0.44 & 1.19
\end{tabular}

Source: Own production based on (Estate Crops Office, 2019; Thomson Reuters, 2019a, 2019b).

As expected, the mean price $P_{W}$ is higher than that of other prices. The large gap between Indonesian and World CPO prices and $P_{J B}$ is due to CPO processing costs and the input-output ratio ${ }^{15}$. Similarly, the standard deviation of both $P_{I D}$ and $P_{W}$ is higher than that of $P_{J B}$, implying that both prices fluctuate more than $P_{J B}$ does. The time series plot of variables can be seen in Figure 2. 12.

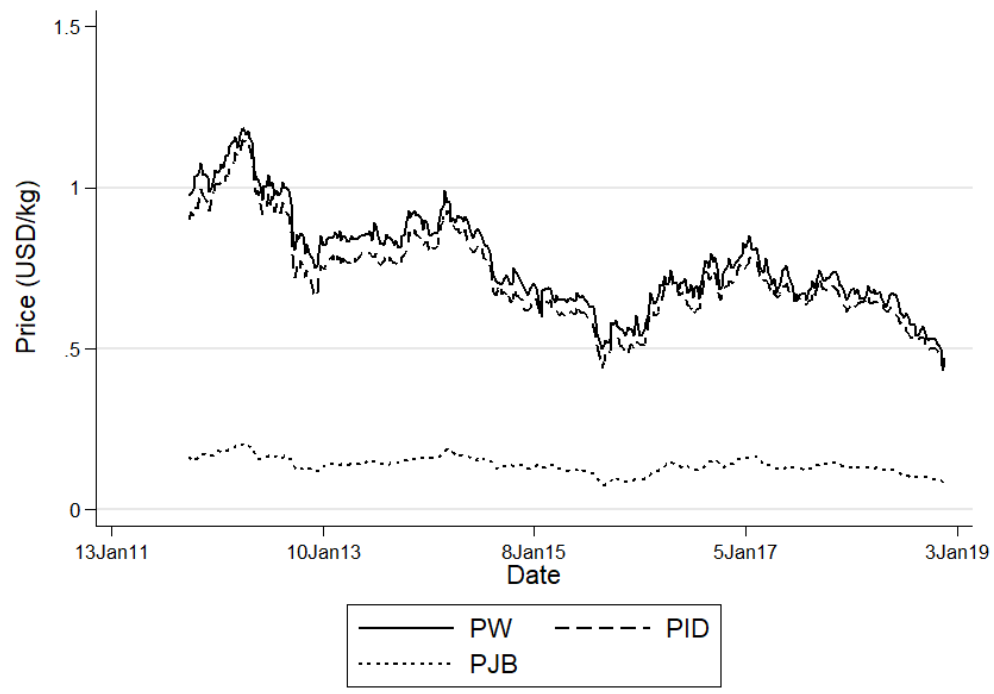

Source: Own production based on (Estate Crops Office, 2019; Thomson Reuters, 2019a, 2019b).

Figure 2. 12 Time Series Plot of Price Variables

Other additional data gathered are the value of export tariffs and levies imposed during the period of interest (Figure 2. 13). The regulation concerning the stipulation of CPO export tariffs was replaced on July 14, 2015 (Minister of Finance of the Republic of

\footnotetext{
12 Other prices were adjusted to the frequency level of $P_{J B}$

${ }^{13}$ We attended the weekly meeting where all palm oil stakeholders can come.

${ }^{14} P_{J B}$ determination is based on CPO local, CPO export, and Kernel local price.

${ }^{15} \mathrm{An}$ interview to the one of $\mathrm{CPO}$ factories mentioned that the processing cost can reach more than $50 \%$ of the CPO price.
} 
Indonesia, 2011, 2015a). Another regulation imposing a CPO export levy of \$50 USD/ton was instituted on July 16, 2015 (Minister of Finance of the Republic of Indonesia, 2015b). The government claims that the goal of the export levy was to provide funds for the development of sustainable plantation businesses, encourage the development of downstream plantation industries, increase the optimization of the use of plantation products, and improve the welfare and sustainability of smallholder plantations (Directorate General of Customs and Excise, 2015). Another reason for the tariff was that the CPO price was below the threshold to be recognized by the export tariff for some time, causing losses in government revenue.

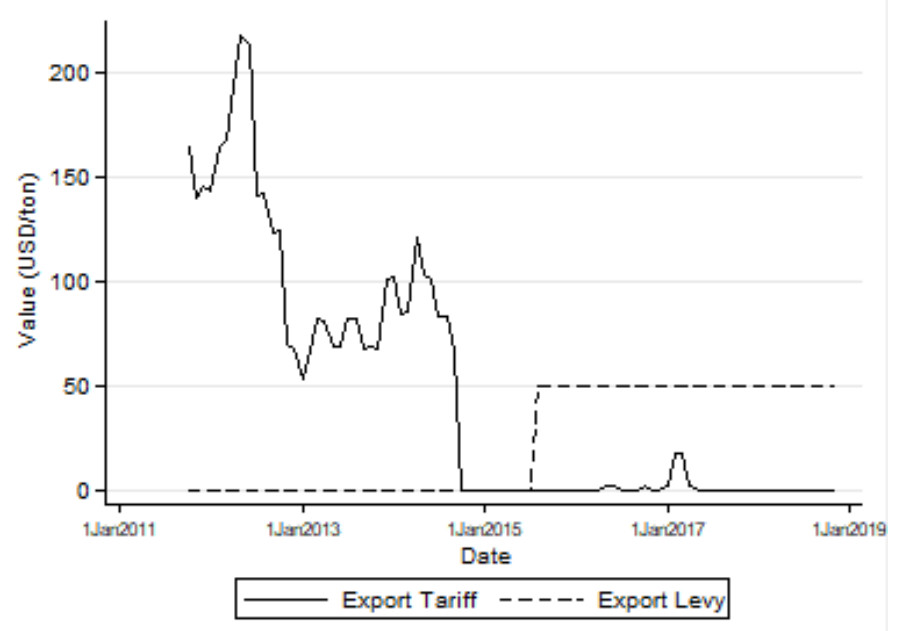

Source: Own production based on data from Minister of Trade of the Republic of Indonesia (2019) and Ministry of Finance of the Republic of Indonesia (2019).

Figure 2. 13 Value of Export Tariff and Levy (USD/ton) of Indonesian CPO

\subsection{Result and Discussion}

We employ a series of unit root tests (Appendix 2. 1). All test-statistic values are higher than their critical values and the null hypothesis cannot be rejected, indicating that variables have unit root and are not stationary. Meanwhile, we can reject the null hypothesis at first difference indicating these have no unit root and are stationary on I (1). Additionally, the ZA test results support ADF and PP test results due to robustness motivation. Results show that SB exist in each variable, which may indicate that a SB also exist in the long-run relationships.

We also perform a Johansen cointegration test. As the trace statistic values are less than the critical values, we cannot reject the null hypothesis that there is a one or fewer cointegration equation (Appendix 2. 2 and 2.3). We also compare the maximum statistics 
test result and determine that values are less than their critical values here as well. This supports the result that we cannot reject the null hypothesis. Also, some model selection criteria suggest that there is a lag of price which may influence both two-pair long-run relationships.

We then employ a GH cointegration test to consider the presence of a SB in the cointegration vector. Several suggestions appear on the result (Appendix 2. 4 and 2. 5). We evaluate two model possibilities to find the best estimated model. Models allowing for a change in regime suggest December 19, 2013 to be the breakpoint for both two-pair relationships (Figure 2.14) and provide the lowest value of test statistics. Even though the model with a change in level in the relationship between $P_{J B}$ and $P_{I D}$ suggests a similar breakpoint date, the same model used to analyze the relationship between $P_{I D}$ and $P_{W}$ does not suggest the same, making this model option less robust. Model selection criteria are also considered. All tests indicate lag 1 to be the optimal lag used in further estimations.

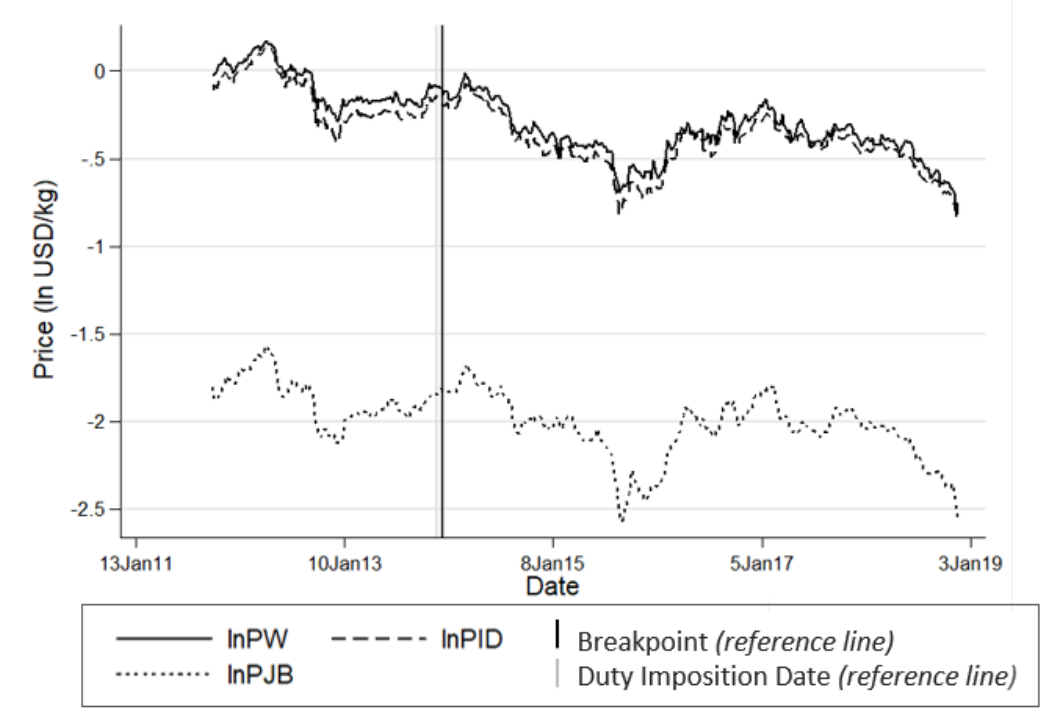

Source: Own production based on (Estate Crops Office, 2019; Thomson Reuters, 2019a, 2019b).

Figure 2. 14 Time Series Plot with Structural Break

We currently have two two-pair models to be compared, i.e. models without a SB (Appendix 2. 10 and 2. 14) and models allowing for a SB (Appendix 2. 11 and 2. 15). As stated before, lower model selection criteria values (AIC, BIC, and HQIC) and higher loglikelihood values indicate a better model. Thus, models allowing for the SB provide the best fit. Since SB models seem to be the best fit, we compare full/restricted models (Appendix 2. 11 and 2. 15) with unrestricted models, separating by breakpoint (Appendix 2. 12-2. 13 and 2. 16-2. 17). To do so, we employ the LR test (eq. 22). 
Table 2. 3. Log-likelihood Values of Restricted and Unrestricted Models

\begin{tabular}{lllll}
\hline \multirow{2}{*}{ Model } & \multicolumn{2}{c}{$P_{I D}$ and $P_{W}$} & \multicolumn{2}{c}{$P_{J B}$ and $P_{I D}$} \\
\cline { 2 - 5 } & Log-likelihood Value & $\mathrm{df}$ & Log-likelihood Value & $\mathrm{df}$ \\
\hline \multirow{2}{*}{ Restricted } & 1811.8278 & $371-4=367$ & 1761.7651 & $371-6=365$ \\
\multirow{2}{*}{ Unrestricted } & $583.80093+1415.2962$ & $(114-2)+(255-2)$ & $535.81993+1220.6718$ & $(114-3)+(255-4)$ \\
\hline & $=1999.09713$ & $=365$ & $=1756.49173$ & $=362$ \\
\hline
\end{tabular}

Source $=$ Own production based on Appendix 2. 11-2. 17

We calculate the computed and critical LR test ${ }^{16}$ according to the data in Table 2. 3. Since the computed $\mathrm{LR}_{1}$ test $>$ the critical $\mathrm{LR}_{1}$ test, the null hypothesis can be rejected; thus, the unrestricted model fits best for long-run relationship between $P_{I D}$ and $P_{W}$. In contrast, since the computed $\mathrm{LR}_{2}$ test < the critical $\mathrm{LR}_{2}$ test, the null hypothesis cannot be rejected; thus, the restricted model fits best for a long-run relationship between $P_{J B}$ and $P_{I D}$. The final estimations to be interpreted for both two-pair relationships are:

a. VECM estimation between $P_{I D}$ and $P_{W}$ before the breakpoint

$$
\begin{gathered}
\ln P_{I D}=-0.06+1.17 \ln P_{W}+e c t \\
\Delta \ln P_{I D t}=-0.11 \Delta \ln P_{I D_{t-n}}+0.16 \Delta \ln P_{W_{t-n}}+0.08 e c t_{t-1} \\
\Delta \ln P_{W t}=0.07 \Delta \ln P_{I D_{t-n}}-0.05 \Delta \ln P_{W_{t-n}}+0.40^{* *} e c t_{t-1}
\end{gathered}
$$

b. VECM estimation between $P_{I D}$ and $P_{W}$ after the breakpoint

$$
\begin{gathered}
\ln P_{I D}=-0.04+1.00 \ln P_{W}+e c t \\
\Delta \ln P_{I D t}=0.06 \Delta \ln P_{I D t-n}+0.10 \Delta \ln P_{W_{t-n}}-0.02 e c t_{t-1} \\
\Delta \ln P_{W t}=0.16 \Delta \ln P_{I D_{t-n}}-0.02 \Delta \ln P_{W_{t-n}}+0.37^{* * *} e c t_{t-1}
\end{gathered}
$$

c. VECM estimation between $P_{J B}$ and $P_{I D}$ with SB

$$
\begin{gathered}
\ln P_{J B}=-1.44+0.06 S B-0.10 S B \cdot \ln P_{I D}+1.44 \ln P_{I D}-1.48 E T-0.04 T L+e c t \\
\Delta \ln P_{J B t}=0.19^{* * *} \Delta \ln P_{J B_{t-n}}+0.38^{* * *} \Delta \ln P_{I D t-n}-0.22^{* * *} e c t_{t-1} \\
\Delta \ln P_{I D t}=0.11^{* *} \Delta \ln P_{J B_{t-n}}+0.21^{* * *} \Delta \ln P_{I D t-n}+0.13^{* * *} e c t_{t-1}
\end{gathered}
$$

The breakpoint identified in the econometric analysis occurs three weeks after the biodiesel EU AD imposition date on November 27, 2013 (European Commission, 2013a). Export trade agreements are generally made in advance; thus, the effect of the duty cannot be expected to be observed in the same week, but rather with a time lag. The period during which we find empirical effects provides a very plausible explanation for a causal interpretation. As previously mentioned, even though the policy was intended to impose a

$16 \quad L R_{1 \text { computed }}=2(1999.09713-1811.8278)=374,53866 \quad ; \quad L R_{1}$ critical $=\chi 2(0.95,(367-365))=$ $\chi 2(0.95,2)=5.991465 \quad ; \quad L R_{2}$ computed $=2(1756.49173-1761,7651)=-10,54674 \quad ; \quad L R_{2}$ critical $=$ $\chi 2(0.95,(365-362))=\chi 2(0.95,3)=7.814728$ 
higher duty on biodiesel imported from Indonesia, Indonesian CPO prices may be affected, since CPO is the main raw material for biodiesel production in Indonesia. However, the effects on EU biodiesel import demand from Indonesia can be seen in Figure 2. 15; we see a clear decline in export value as Indonesia faces a challenge in replacing the EU as their most valuable biodiesel importer.

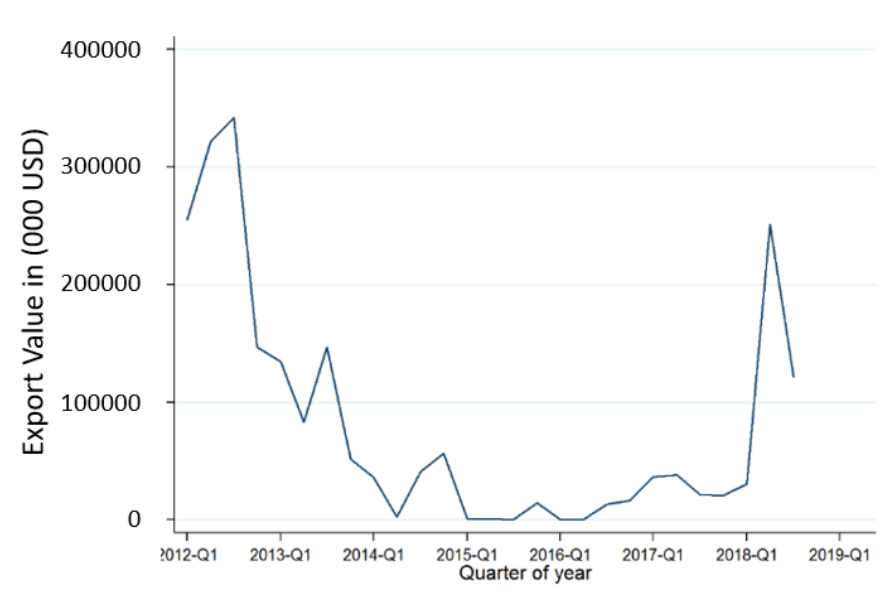

Source: Own production based on Trade Map (2019)

Figure 2. 15 Export Value of Biodiesel from Indonesia to the EU (USD thousand)

Our theoretical considerations yield ambiguous results as to whether decreasing demand for Indonesian biodiesel results in beneficial or detrimental effects on Indonesian domestic CPO demand. It benefits Indonesia when the EU domestic biodiesel companies require more raw materials in the production of biodiesel; therefore $P_{I D}$ may increase. In contrast, it harms the Indonesian CPO demand when Indonesian biodiesel companies' demand decreases, as illustrated in Figure 2. 8, which causes $P_{I D}$ to decrease.

Empirical results show that the duty results in a lower price of CPO received by Indonesia (eq. 23a and 24a). In previous periods, an increase in $P_{W}$ by $1 \%$ was followed by an increase in $P_{I D}$ of approximately $1.17 \%$, whereas after the breakpoint an increase in $P_{W}$ by $1 \%$ results in an increase in $P_{I D}$ of approximately $1 \%$. Decreasing Indonesian CPO demand leads to a demand shift, resulting in a price reduction. This indicates that the detrimental effect has a stronger effect to the model. Thus, the duty imposition negatively affects the Indonesian CPO price.

Furthermore, both VECM short-run estimations between $P_{I D}$ and $P_{W}$ (eq. 23b-c and 24b-c) show interesting and significant results as to how $P_{W}$ adjust to any disequilibriumcausing, while the $P_{I D}$ does not. Visualization of this phenomenon can be seen in Figure 2. 2. 16 , where $\theta_{2}>0$ and $\theta_{1}=0$ when there is a shock in $\mathrm{t}_{0}$. A high contribution of Indonesian 
biodiesel to the world market causes $P_{W}$ to react more in periods following a shock. Indeed, $P_{W}$ has a slower reaction to disequilibrium after the breakpoint, which indicates that $P_{W}$ gains more power due to the imposition of duties. It reduces from a $40 \%$ to a $37 \%$ correction of any deviation from long-run equilibrium per period, in this case in another week. A lower biodiesel quantity imported by the EU makes it less dependent on Indonesia.

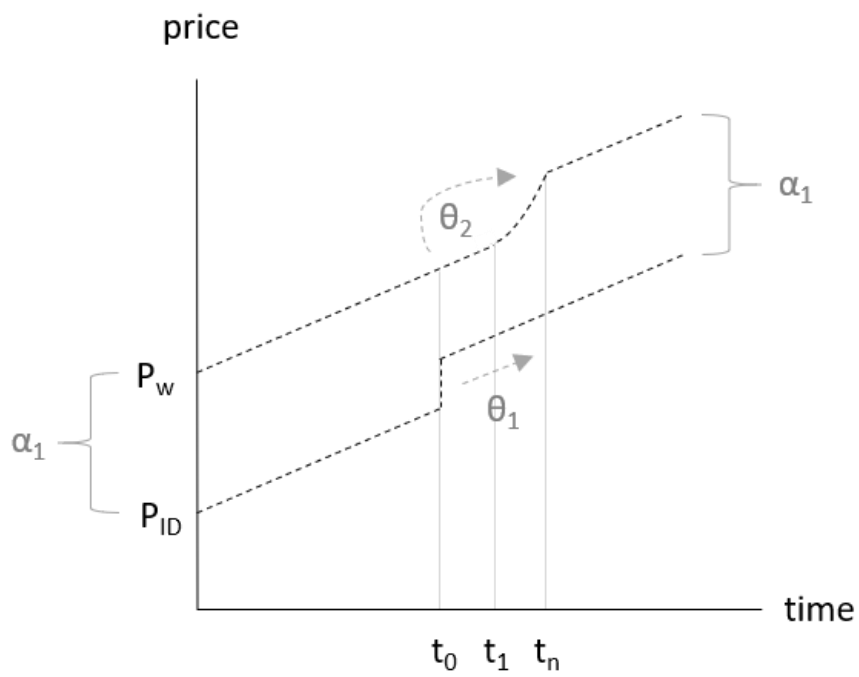

Source: Own illustration

Figure 2. 16 Visualization of VECM estimation between $P_{I D}$ and $P_{W}$

The VECM estimation result of the relationship between $P_{J B}$ and $P_{I D}$ allows for a interpretation. We could separate the long-run VECM estimation into periods before and after the breakpoint. To do so, we include $\mathrm{SB}=0$ when $\mathrm{t} \leq$ breakpoint and $\mathrm{SB}=1$ when $\mathrm{t}>$ breakpoint to Estimation 25a, which can be seen below:

$$
\begin{aligned}
& \ln P_{J B}=-1.44+1.44 \ln P_{I D}-1.48 E T-0.04 T L+e c t, \quad S B=0 \\
& \ln P_{J B}=-1.38+1.34 \ln P_{I D}-1.48 E T-0.04 T L+e c t, \quad S B=1
\end{aligned}
$$

Similarly, results show that the duty creates a lower FFB price received by oil palm farmers in Indonesia (eq. 25a0 and 1). Decreases in demand for Indonesian CPO lead to a decrease in demand for Jambi FFB among Indonesian CPO producers. Previously, an increase in $P_{I D}$ by $1 \%$ was followed by an increase in $P_{J B}$ of approximately $1.44 \%$, whereas after the breakpoint, an increase in $P_{I D}$ by $1 \%$ is followed by an increase in $P_{J B}$ of approximately $1,34 \%$. This demand shift causes a price reduction. Thus, the duty imposition also negatively affects the Jambi FFB price.

However, in the short run, there is only one pair of estimations (eq. $25 \mathrm{~b}$ and c) to interpret, where there is an adjustment from both $P_{J B}$ and $P_{I D}$ if any disequilibrium exists. Visualization of this phenomenon can be seen in Figure 2. 17, where $\theta_{2}>0$ and $\theta_{1}<0$ when 
there is a shock in $\mathrm{t}_{0}$. Both adjustments are clearly visible and significant, where $P_{J B}$ corrects $22 \%$ per period from the long-run deviation to return to the equilibrium when any shocks appear, while $P_{I D}$ corrects $13 \%$ per period. Since $P_{I D}$ corrects slower than $P_{J B}$ does, we assume that $P_{I D}$ acts more as a leader, while $P_{J B}$ acts more as a follower. In total, there will be around $35 \%$ correction when a shock occurs in the short-run.

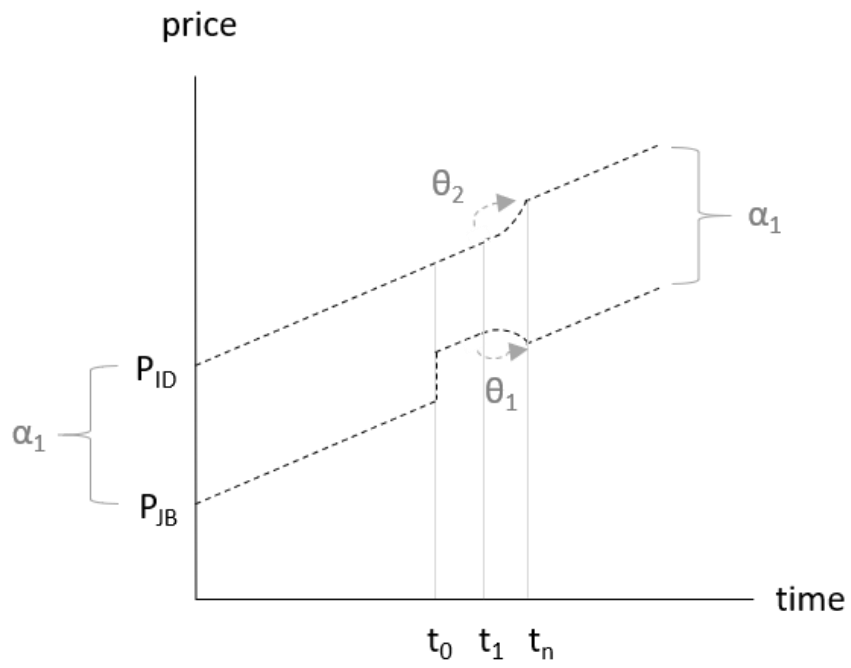

Source: Own illustration

Figure 2. 17 Visualization of VECM estimation between $P_{I D}$ and $P_{W}$

\subsection{Conclusion}

The imposition of the EU biodiesel AD generated a SB in the cointegration estimation between Indonesian and world CPO prices, and between Jambi FFB and Indonesian CPO prices. This could indicate that the duty had an effect on the price after the breakpoint. Results show that the duty negatively affected the Indonesian CPO and local Jambi FFB price, whereas the world CPO market gained more power after the duty implementation. Decreases in Indonesian CPO demand due to decreased demand for imported biodiesel by the EU lead to a price reduction caused by a shifting of demand. 


\section{Chapter 3}

\section{Fight or Flight: Factors Affecting Local Traders' Decisions to Remain in or Exit the Market}




\subsection{Introduction}

Traders play a significant and often underestimated role in agricultural trading activities and can be decisive actors in agricultural marketing channels. In the agricultural sector, traders are often able to bridge the gap between factory and farmer by mediating issues with geographical distance and logistics, gaps in capital, and supply chain continuity, which can be difficult for farmers to remedy. Furthermore, Coughlan, Anderson, Stern, \& El-Ansary (2006) explains that the right intermediaries must be considered in order for a product to be marketed and sold through the optimal channel.

Having more traders in the market is favourable for competition, as farmers have better options for selling their products to the preferred trader of their choice. If there are only few traders available in the area, traders could gain more market power as a result (MasColell, Whinston and Green, 1995). However, existing market power structures within agricultural markets are not easily overcome. In Indonesian rubber value chains, there exist a significant amount of trader market power (Kopp \& Brümmer, 2017), particularly in remote areas and in smaller markets. Nevertheless, the traders' role remains considered.

Additionally, agricultural products have specific handling requirements, in terms of shipping and distribution, which set them apart from other products, mainly due to their inherent perishability and bulkiness. Fluctuating prices, differences in capital requirements, and differences in post-harvest handling all may become significant obstacles for traders, and addressing these obstacles is necessary in understanding the trader's behaviour in the market. In the presence of some influential economic divergence, for example a falling price in the traded product, traders' behaviours will likely diverge as a result. Some may remain in the market and some may exit, which can in turn alter the market's overarching structure. Understanding this situation is relevant for policy makers in predicting fluctuations in agricultural market structures.

To study these issues further, we focus on the case of oil palm and rubber traders in the Jambi province, Indonesia. Indonesia has a strong agricultural sector which accounted for nearly 13\% of total national Gross Domestic Product in 2018 (Statistics Indonesia, 2019), and the Indonesian oil palm and rubber trade provide a significant contribution to the country's foreign exchange (Directorate General of Estate Crops, 2017a, 2017b).

The Jambi province is located in Sumatra island in western Indonesia. Recently, oil palm and rubber plantations in the province have rapidly expanded, resulting in a number of indirect land use change issues (Directorate General of Estate Crops, 2015, 2016a, 2016b, 2017a, 2017b), and most relevant stakeholders are benefiting from higher incomes due to 
the expansion of the sector (Bou Dib et al., 2018). The Indonesian palm oil and rubber industries have also created many new employment opportunities for the country, and there was an increase in labor usage in the Palm Oil and Rubber industries of about $36 \%$ and 7 \%, respectively, from 2013 to 2018 (Directorate General of Estate Crops, 2015, 2016a, 2016b, 2017a, 2017b). This unique contrast makes studying the palm oil and rubber industries particularly appealing for researchers and national governments alike.

Oil palm and rubber traders in Jambi face different obstacles to survive. Palm oil and rubber prices have both fluctuated rather unexpectedly over the past few years (Figure 3. 1); however, palm oil has seen more pronounced fluctuations than rubber, on average. Rubber prices have been constantly declining since 2012, whereas palm oil prices have more promising situation where there are times that prices go up momentarily.
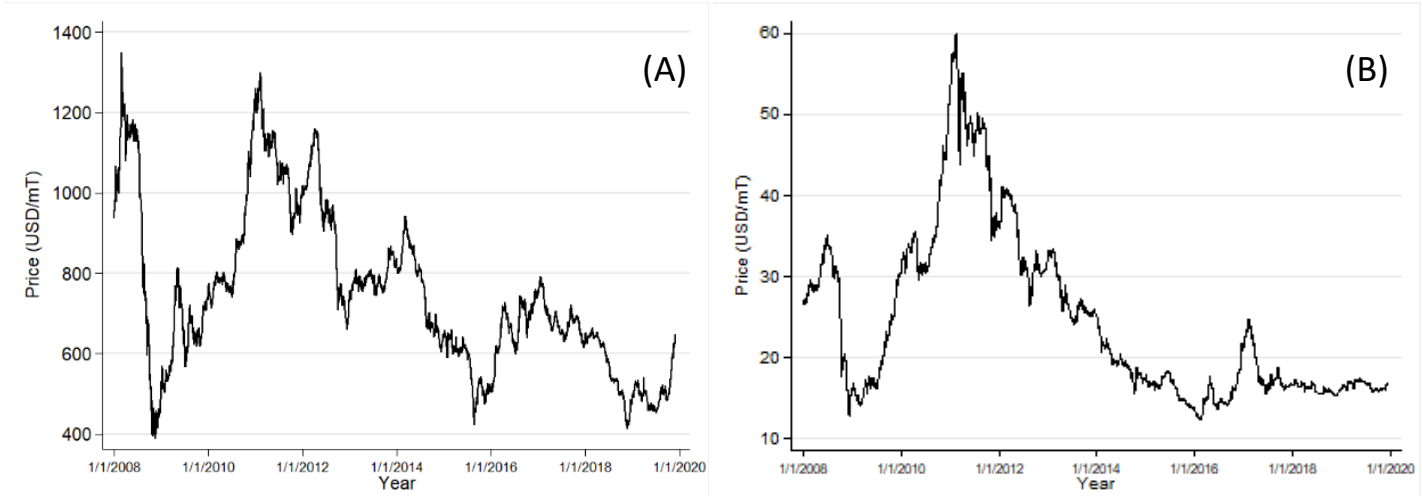

Source: Own Production based on Thomson Reuters (2019b, 2019a)

Figure 3. 1 Price Volatility of Palm Oil and Rubber Price (2008-2019)

Another issue to consider is the perishability of the products being traded. Oil palm fresh fruit bunches are more perishable than rubber, therefore prompt delivery is essential in preventing quality deterioration. Meanwhile, the lower the water content in rubber, the higher the rubber quality, so storing rubber will not be a problem. Differences in bulkiness between goods can also lead to different handling requirements when shipping products to the factory, and conveyances such as trucks, pickup trucks, or even motorbikes can all play a role in alleviating these issues. These challenges all have an impact on traders' ability to survive in the market.

Bearing in mind these considerations, this study focuses on trader's decisions to remain in or exit the market, and the various factors influencing this decision. To analyse the probability of remaining in the market, we employ a binary logistic regression method to variables obtained from 3-rounds of primary data collection in Jambi. 
Studies of traders' adaptations to economic divergence have been limited in the literature. Some studies have focused on how financial market traders survive in the presence of market competition (Benos, 1998; Kogan, Ross, \& Westerfield, 2006), but none have focused on agricultural product traders, thus the required approaches may be quite different. Those studies have pointed out that risk-taker traders are expected to have higher profits than risk-averse traders, and thus are more likely to remain in the market. However, numerous studies of similar behaviour among farmers have analysed which factors affect farmers' decisions to remain in or exit the market (Bragg \& Dalton, 2004; Ferjani, Zimmermann, \& Roesch, 2015; Kimhi \& Bollman, 1999; Nag et al., 2018; Stiglbauer \& Weiss, 2000)

These are the most relevant studies in the literature, since, to the best of our knowledge, trader- level studies of agricultural products have not been undertaken. Therefore, this study is intended to fill this gap and to further diversify the existing research on the topic.

The study is structured as follows: the next few sections provide an overview of the role of local traders in Jambi. The model specification section describes the methodology implemented and is followed by a description of the data used in the study. We then discuss the results before summarizing our study in the conclusion section.

\subsection{Role of Local Traders in Jambi}

\subsubsection{The Importance of Traders}

It is important to understand the crucial role traders play in several different marketing functions in agricultural markets. Traders serve as intermediaries, performing many transactional and exchange-related activities, such as "buying, selling, and risk taking" (Kerin, Hartley, \& Rudelius, 2013). In terms of physical/logistical functions, intermediaries may also undertake tasks such as "assorting, storing, sorting, and transporting" of agricultural products (Kerin et al., 2013). Additionally, intermediaries may partake in important "facilitating" functions, like "financing, grading, and marketing information and research" (Kerin et al., 2013).

From a demand perspective, there are 2 important advantages to the existence of intermediaries: their ability to facilitate demand connections between producers and endusers, and their ability to fulfill the demand requirement of end-buyers by sorting products (Coughlan et al., 2006). Moreover, Kerin, Hartley and Rudelius (2013) outlined 4 consumer benefits gained from the existence of intermediaries, namely time, place, form and possession utilities. On the supply-side, there are also two advantages provided by 
intermediaries: reducing producers' distribution costs by arranging frequent transactions, and reducing transaction or contact costs incurred by producers (Coughlan et al., 2006). Indeed, intermediaries increase profits on both the demand-side and the supply-side.

Zúñiga-Arias (2007) noted that traders have substantial knowledge of important marketing information not available to farmers (Kopp et al., 2014) like price, quality, quantity, and various purchasing requirements of end-buyers. Therefore, traders could help to bridge the information gap between farmers and end-buyers.

Moreover, traders have superior access to transportation (Zúñiga-Arias, 2007). This is an important factor, especially in developing countries, where smallholder farmers are often located in remote areas like Jambi Province, where location and capital constraints can affect farmers' choices of an appropriate channel destination for their products (Kopp et al., 2014). Less capital-constrained, traders may have more ready access to vehicles, which can aid farmers in distributing products to end-buyers.

Furthermore, if producers have difficulties in meeting market requirements, traders can help them find alternative channels (Zúñiga-Arias, 2007). Another important role played by the trader is in value-added generation through grading, packing, and in certain cases treating products. Also, with their relatively higher working capital, traders are better able to increase the value-added of agricultural products. In Jambi, traders may also act as informal financiers for producers or other intermediary traders. Indeed, traders may arguably be the best facilitators in bridging the gap between the production and marketing sides of the marketing chain (Zúñiga-Arias, 2007), and this is likely true in the case of Jambi province.

\subsubsection{Rubber and Oil Palm Fresh Fruit Bunch (OPFFB) Trading Activities in Jambi}

There was a decline in the number of rubber and oil palm fresh fruit bunch traders between 2012 and 2015 due to rubber and palm oil falling price. This decrease in rubber prices was due to an over-supply of rubber and a decline in crude oil price (Aidenvironment, 2016), which led to lower prices of synthetic rubber, a common substitute for natural rubber. The same situation occurred in the oil palm market as well (Abd, Nambiappan, Palm, \& Board, 2013).

When we returned to Jambi to collect data for second round, we faced many rejections and a cynical attitude from locals, who initially thought we were debt collectors. Many would first hide from us and have another family member say that they were out of town, and only after we explained that we were from an educational institution would their views change, and they be willing to be interviewed. This fearful response illustrates the 
challenging situation that many faced due to weak prices during that time period, in which trader populations declined by $19.7 \%$ in the survey area. These declines continued until round 3, where we observed losses of around $5 \%$ of the total trader population compared to round 2 (Table 3.1 ).

Table 3. 1 Number of All Active Traders in the Survey Area

\begin{tabular}{lccc}
\hline & & Year & \\
& 2012 & 2015 & 2018 \\
\hline Rubber & 309 & 197 & 185 \\
Rubber + OPFFB & 15 & 19 & 26 \\
OPFFB & 127 & 109 & 119 \\
Total & 451 & 362 & 342 \\
\hline
\end{tabular}

Source: Own production

In detail, we can see that the number of both rubber and palm oil traders decreased from 2012 to 2015. Meanwhile, there was an increase in the number of oil palm traders between 2015-2018, while the number of rubber traders decreased during that same period. A plausible explanation for this situation is that the palm oil sector may be more profitable and promising than the rubber industry.

Table 3. 2 Transition Matrix of Traders in Period 1 (2012-2015)

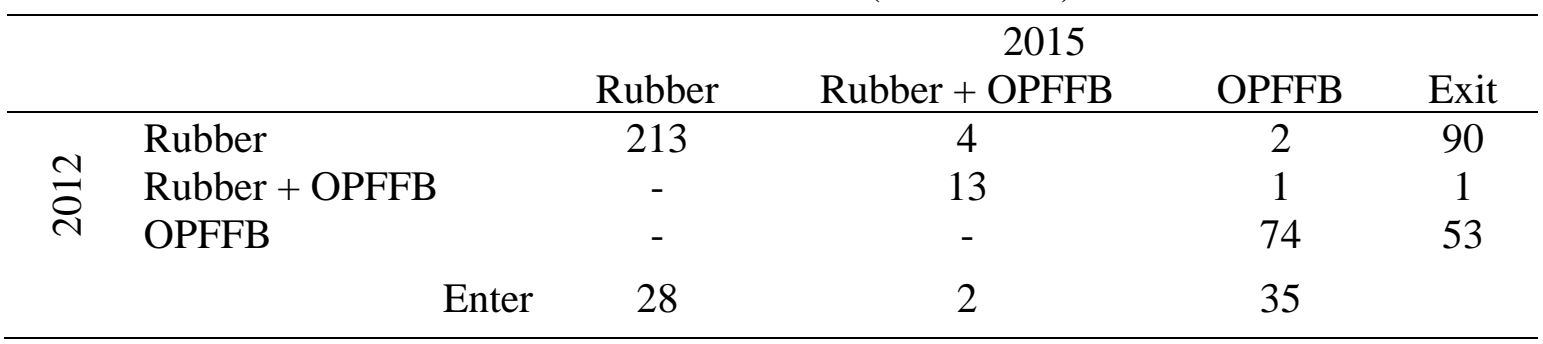

Source: Own production

Table 3. 2 and 3. 3 present the transition matrix of products traded between a certain period, divided into two periods. The first took place in between 2012-2015, where traders were interviewed first in 2012 and then recalled back in 2015 to observe whether they remained in or exited the market. The same procedure was performed for the second period, from 2015-2018. Both tables illustrate whether traders who remained in the market traded the same product or not, where in most cases, traders remained to trade the same product.

Table 3. 3 Transition Matrix of Traders in Period 2 (2015-2018)

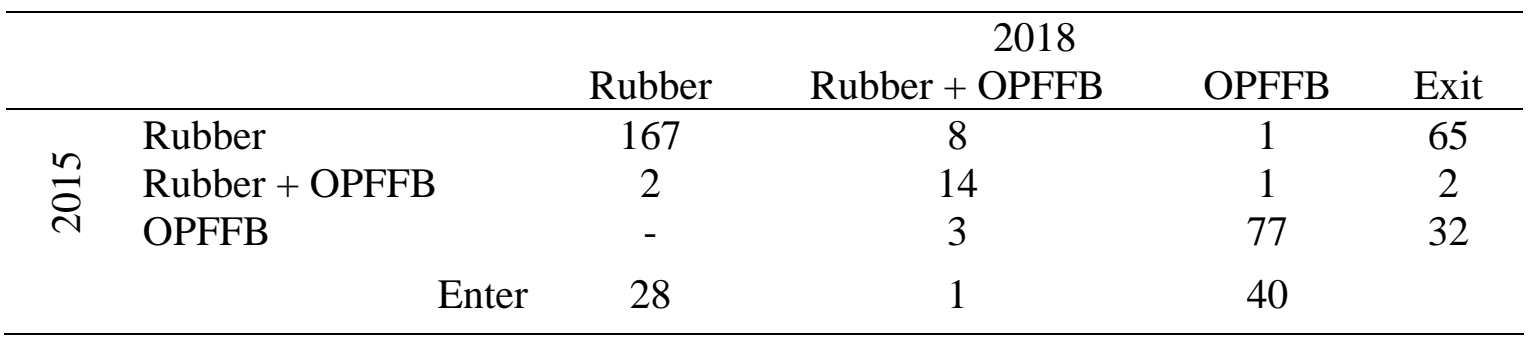

Source: Own production 
Table 3. 4 Average Income of Traders Existing both in 2012 and 2015 (million IDR)

\begin{tabular}{lrrrr}
\hline 2012 & & \multicolumn{2}{c}{2015} & \\
& Oil Palm & Rubber & \multicolumn{1}{c}{ Both } & \multicolumn{1}{c}{ Unobserved } \\
\hline Oil Palm & $10.9 \rightarrow 8.5$ & $21.4 \rightarrow 6.0$ & $1.0 \rightarrow 3.0$ & $20.5 \rightarrow 0.0$ \\
Rubber & $4.8 \rightarrow 5.3$ & $25.7 \rightarrow 6.8$ & $9.5 \rightarrow 22.3$ & $18.3 \rightarrow 0.0$ \\
Both & 0 & 0 & $26.0 \rightarrow 8.0$ & $12.5 \rightarrow 0.0$ \\
\hline
\end{tabular}

Source: Own production

The dynamics of trader's incomes are presented in aggregate in Table 4 and 5 . The figures illustrate that traders generally earned less in 2015 compared to 2012 and earned more still in 2018 compared to 2015. These income increases may be due to more stable market conditions overall, or due to traders generally being more adaptable to the market situation than they were before.

Table 3. 5 Average Income of Traders Existing both in 2015 and 2018 (million IDR)

\begin{tabular}{|c|c|c|c|c|}
\hline \multirow{2}{*}{2015} & \multicolumn{4}{|c|}{2018} \\
\hline & Oil Palm & Rubber & Both & Unobserved \\
\hline Oil Palm & $9.9 \rightarrow 24.6$ & 0 & $2.7 \rightarrow 40.9$ & $9.4 \rightarrow 0.0$ \\
\hline Rubber & $1.5 \rightarrow 3.0$ & $6.3 \rightarrow 11.5$ & $3.9 \rightarrow 21.1$ & $7.1 \rightarrow 0.0$ \\
\hline Both & $4.5 \rightarrow 5.7$ & $7.5 \rightarrow 26.6$ & $15.6 \rightarrow 16.2$ & $12.0 \rightarrow 0.0$ \\
\hline
\end{tabular}

Source: Own production

\subsection{Model Specification}

\subsubsection{Determinants in Exiting the Market}

As mentioned in section 3.1, several studies have sought to determine which factors affect financial market traders' decisions on whether to remain in or exit the market (Benos, 1998; Kogan et al., 2006). One of the key findings was that risk-taker traders are more willing to remain in the market while anticipating higher future profits than their risk-averse counterparts. Even though this was observed only in the financial market, it can be adopted into our study. Another study was performed to investigate trader behavior in the off-farm labor market using panel data from Austrian farm households. A probability model was utilized, and it was found that an increase in wages increases the probability that a worker will change their status from full-timer to part-time worker (Weiss, 1997).

Comparable studies (Bragg \& Dalton, 2004; Ferjani et al., 2015; Kimhi \& Bollman, 1999; Nag et al., 2018; Stiglbauer \& Weiss, 2000) have also been performed to observe which factors affect farmers' decisions in remaining in or exit the agricultural sector. A study found that large farms tend to stay in the sector, since they have more assets. Also, younger 
farmers in Canada and Israel were found to exit the market more than their older counterparts (Kimhi \& Bollman, 1999).. This could also represent the determinants in exiting the market by traders. For this reason, a probit model is used.

Table 3. 6 Definition of Variables

\begin{tabular}{|c|c|c|}
\hline Variables & Definition & $\begin{array}{c}\text { Expected } \\
\text { Sign }\end{array}$ \\
\hline \multicolumn{3}{|c|}{ Dependent Variable } \\
\hline remain & Dummy variable: remain in (1) in or exit (0) from the market & \\
\hline \multicolumn{3}{|c|}{ Independent Variables } \\
\hline \multicolumn{3}{|c|}{ Factor 1: Human Capital } \\
\hline$e d u$ & $\begin{array}{l}\text { Dummy variable of trader's education: having at least primary school } \\
\text { education (1) or not (0) }\end{array}$ & - \\
\hline $\exp$ & Traders' experience in trading (in number of year) & + \\
\hline func & $\begin{array}{l}\text { Dummy variable of trader's function in the village: having at least one } \\
\text { village's function (such as a village head) (1) or not (0) }\end{array}$ & + \\
\hline info & $\begin{array}{l}\text { Dummy variable of knowledge in price information: having the access } \\
\text { to get the price information (1) or not }(0)\end{array}$ & + \\
\hline \multicolumn{3}{|c|}{ Factor 2: Trading Structure } \\
\hline$t p$ & $\begin{array}{l}\text { Dummy variable of traded product: only rubber or both rubber \& } \\
\text { OPFFB (1) or only OPFFB (0) }\end{array}$ & - \\
\hline stat & $\begin{array}{l}\text { Dummy variable of trader's status: a larger trader (1) or a village-level } \\
\text { trader }(0)\end{array}$ & + \\
\hline vehic & $\begin{array}{l}\text { Dummy variable of operational vehicle ownership: having operational } \\
\text { vehicle (1) or not (0) }\end{array}$ & + \\
\hline num & Number of workers & + \\
\hline comp & Dummy variable of computer ownership: having computer (1) or not (0) & + \\
\hline smph & $\begin{array}{l}\text { Dummy variable of smartphone ownership: having smartphone (1) or } \\
\text { not (0) }\end{array}$ & + \\
\hline cred & $\begin{array}{l}\text { Dummy variable of credit provision by traders: credit provider (1) or not } \\
\text { (0) }\end{array}$ & - \\
\hline land & Land area owned by traders (in ha) & - \\
\hline \multicolumn{3}{|c|}{ Factor 3: Structural Environment } \\
\hline supp & Number of suppliers & + \\
\hline $\mathrm{com}$ & Number of competitors & - \\
\hline \multicolumn{3}{|c|}{ Factor 4: Socioeconomic } \\
\hline trans & $\begin{array}{l}\text { Dummy variable of transmigration's status: part of the transmigration } \\
\text { scheme (1) or not (0) }\end{array}$ & + \\
\hline trrev & Trading revenue (in million IDR) & + \\
\hline & $\begin{array}{l}\text { Distance measured by how long it takes to travel by vehicle from trader's } \\
\text { location to the closest factory (in minutes) }\end{array}$ & - \\
\hline
\end{tabular}

Source: Own production

Bragg and Dalton (2004) sought to determine which factors affect farmers' decisions to exit dairy farming markets, employing a binary logistic regression model. They found that older producers, higher off-farm income, lower variable cost, and greater diversification of farm income led to an increase in the probability of farmers exiting the market. Nag et al. 
(2018) also employed a binary logit regression to observe the factors affecting Indian rural farm youths' decision to remain in or exit the agricultural sector.

Another study examines the determinants of farmer exit from farming markets in Western Europe (Breustedt \& Glauben, 2007). They determined that farm characteristics and policy environment both affect the decisions of farmers to exit or remain in the industry. Ferjani, Zimmermann, and Roesch (2015), who analyzed determinants of farmer exit in agriculture markets in Switzerland, provide a better structure to be adjusted and utilized in our study. They employed a logit estimation and considered four factors influencing the farm exit decision, which we adapt to our study: human capital, trading structure, structural environment, and socioeconomic factors (Table 3.6). Grouping and expected signs are based on the abovementioned studies and relevant assumptions according to the condition in the survey area.

\subsubsection{Binary Logistic Regression and Marginal Effect}

In order to analyse determinants affecting traders' decisions to remain in or exit the market, a Binary Logistic Regression (logit) model is employed. The model is applied by determining and implementing relevant dummy dependent variables (Cameron \& Trivedi, 2005); in this case a binary variable equal to 1 for traders' remaining in the market, and 0 for traders' exiting the market. Within this model we observe the probability, $y_{i}$, of those traders' preferences. The following equation explains the probability, characterized by

$$
y_{i}=\operatorname{Pr}\left(Y_{i}=1 \mid x_{i}\right)=\frac{\exp \left(\beta_{0}+\beta_{i} x_{i}\right)}{1+\exp \left(\beta_{0}+\beta_{i} x_{i}\right)}=F\left(x_{i} \beta_{i}\right)
$$

where $x_{i}$ is constructed by all explanatory variables considered in the model and $\beta_{i}$ represents all parameters estimated.

It is worth noting that marginal effects are used to obtain a straightforward interpretation in logistic models (Cameron \& Trivedi, 2005). In the case of a linear regression model, marginal effect can be directly implied from the coefficient $(\beta)$, where the marginal effect of

$$
\mathrm{E}[\mathrm{y} \mid \mathrm{x}]=x^{\prime} \beta
$$

is

$$
\frac{\partial \mathrm{E}[\mathrm{y} \mid \mathrm{x}]}{\partial \mathrm{x}}=\beta
$$


meanwhile, in the case of a logistic regression model, it can be illustrated that, $\mathrm{E}[\mathrm{y} \mid \mathrm{x}]$ is in the form of $\operatorname{Pr}\left(Y_{i}=1 \mid x_{i}\right)$. Therefore, the marginal effect will be:

$$
\frac{d y_{i}}{d x_{i}}=\frac{\exp \left(\beta_{0}+\beta_{i} x_{i}\right)}{1+\exp \left(\beta_{0}+\beta_{i} x_{i}\right)^{2}} \beta_{i}
$$

Furthermore, a marginal effect estimation must be performed in logistic regression models in order to obtain $\beta_{i}$. To do so, we employ the Average Marginal Effect (AME) estimation directly after performing a logit model estimation.

Using the statistical model illustrated above, the new form of statistical model is developed (Eq. 5) based on Equation 1. Aligned with this study, the linear predictors are customized by all explanatory variables (Table 3. 6). The new model formed is:

$$
\begin{gathered}
y_{i}=\operatorname{Pr}\left(Y_{i}=1 \mid x_{i}\right)=\beta_{0}+\beta_{1} \text { edu }+\beta_{2} \text { exp }+\beta_{3} \text { func }+\beta_{4} \text { info }+\beta_{5} \text { tp } \\
+\beta_{6} \text { stat }+\beta_{7} \text { vehic }+\beta_{8} \text { num }+\beta_{9} \text { comp }+\beta_{10} \text { smph }+\beta_{11} \text { cred } \\
+\beta_{12} \text { land }+\beta_{13} \text { supp }+\beta_{14} \text { com }+\beta_{15} \text { trans }+\beta_{16} \text { trrev }+\beta_{17} \text { loc }+\varepsilon
\end{gathered}
$$

\subsubsection{Goodness of Fit and Logit Postestimation}

The logit estimation examines whether all variables combination effect differ from zero, proved by its significant value (Prob>chi2) using log likelihood chi-square test (Cameron \& Trivedi, 2005; UCLA, 2020a). Unlike the OLS regression estimation, the logit model employs a Pseudo $\mathrm{R}^{2}$ measurement of McFadden (Cameron \& Trivedi, 2005) to observe the goodness of fit of the model, which is

$$
\text { Pseudo } R^{2}=1-\left(\frac{l l_{\text {model }}}{l l_{\text {null }}}\right)
$$

where $l l_{\text {model }}$ represents the log-likelihood of the model and $l l_{\text {null }}$ represents the loglikelihood of the intercept-only model. The log-likelihood based Pseudo- $\mathrm{R}^{2}$ value provides the interpretation that higher values of Pseudo- $\mathrm{R}^{2}$ mean better improvements in the new model compared to the null model (Hemmert, Schons, Wieseke, \& Schimmelpfennig, 2018; McFadden, 1973).

As part of the logit postestimation, we are required to verify the absence of multicollinearity among independent variables in the model. VIF and tolerance value of all variables are examined, where anything close to 1 indicates that the variable is uncorrelated to each other (UCLA, 2020a).

We employ another test observe the existence of specification error in the model. Specification error occurs either when the logit is not the proper function for the model, or when all relevant variables are not considered in the model. To test for this, the linktest 
command in Stata is employed after the logit command. This command constructs the predicted value and predicted value squared from the model, where the predicted value must be significant, while the predicted value squared must not. If the significances turn to be the other way around, this is an indication of model specification error (UCLA, 2020a).

\subsubsection{Statistical Test}

We perform a statistical test to examine the difference between groups of existing traders and new traders using the round 3 (2018) dataset. Initially we observe the type of variables considered (Table), then we divide the variables into metric and nominal variables. We test the metric variables for normality using a Shapiro-Wilk Normality Test (Royston, 1992) to decide which test can be performed. Since none of the variables are normally distributed, we pursue the Wilcoxon-Mann-Whitney test as non-parametric test for equality between groups based on their median values (Mann \& Whitney, 1947; Wilcoxon, 1947). We then employ a Pearson's Chi-square test to deal with nominal (dummy) variables by group (UCLA, 2020b). The tabulate command in Stata is used to examine the test statistics and p-values.

\subsection{Data}

Data collection was performed in 3 rounds, taking place at the end of 2012, 2015, and 2018. The data collection was part of the Collaborative Research Centre (CRC) project in Ecological and Socioeconomic Functions of Tropical Lowland Rainforest Transformation Systems in the Jambi province, Indonesia, a joint project between the University of Goettingen and 3 Indonesian Universities (IPB University, Jambi University, and Tadulako University).

Five regencies - Sarolangun, Batanghari, Muaro Jambi, Tebo, and Bungo - were selected purposefully ${ }^{17}$ to determine the survey location (Figure 3. 2). Later, stratified random sampling was applied in selecting districts and villages. An advantage to using stratified random sampling is that it minimizes survey costs without compromising accuracy (Cameron \& Trivedi, 2005). Initially, 22 districts and 40 villages were chosen in 2012 (Appendix 3. 1). However, due to time constraints and traders' unwillingness to be interviewed, the number of villages was reduced to 38 in the following rounds.

\footnotetext{
${ }^{17}$ Performed by Krishna and Euler, members of CRC's team, and also stated on the EFForTS Discussion Paper by Faust et al. (2013).
} 


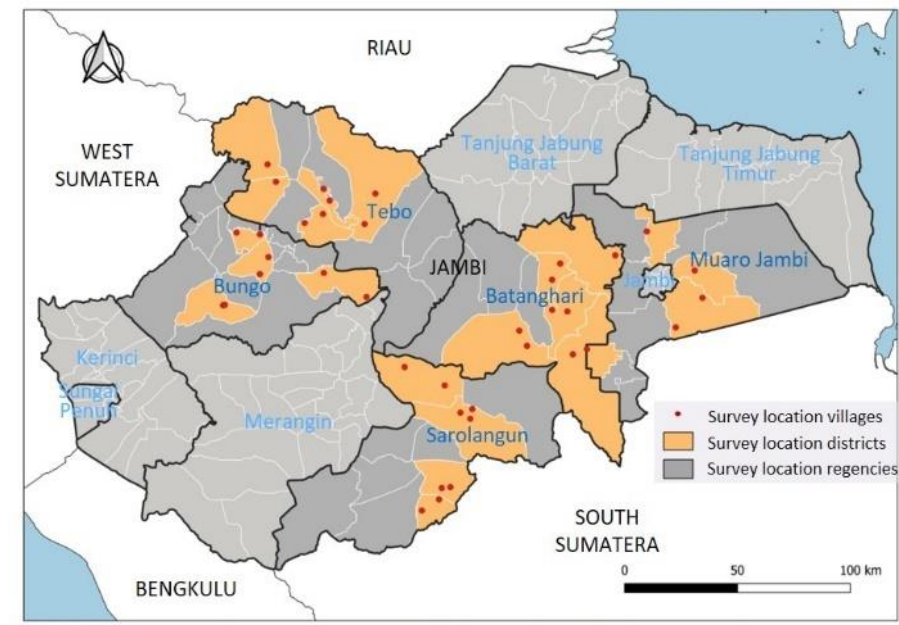

Source: Village map-geoprocessed ${ }^{18}$ from BPS-Statistics of Jambi Province (2018)

Figure 3. 2 Map of Jambi

Data was obtained directly from respondents, using interview questionnaires ${ }^{19}$ to administered to active small traders of oil palm fresh fruit bunches and rubber within the survey area. All active traders were attempted to be contacted for interviews. Table 3. 7 illustrates the final number of individuals reached in each survey round: a final sample of 295, 292, and 325 observations were obtained for further analysis from round 1, 2, and 3, respectively. We were unable to obtain $100 \%$ of the population for our sample due to time constraints and traders' unwillingness to participate, as well as some irreplaceable missing values and outliers. Nevertheless, the number of observations is still suitable for a representative analysis.

Table 3. 7 Number of All Active Traders in the Survey Area

\begin{tabular}{lrrrrrr}
\hline & \multicolumn{2}{c}{2012} & \multicolumn{2}{c}{2015} & \multicolumn{2}{c}{2018} \\
\cline { 2 - 7 } & Population & Sample & Population & Sample & Population & Sample \\
\hline Rubber & 309 & 207 & 234 & 196 & 197 & 185 \\
Rubber + OPFFB & 15 & 5 & 19 & 13 & 26 & 24 \\
OPFFB & 127 & 83 & 109 & 83 & 119 & 116 \\
Total & 451 & 295 & 362 & 292 & 342 & 325 \\
$\%$ of population & & $65 \%$ & & $81 \%$ & & $95 \%$ \\
\hline
\end{tabular}

Source: Own production

We also employed data from 2018 to compare individual characteristics of existing traders and new traders. All available variables were examined to observe which factors specifically characterize new traders. In table 3. 3, we can see that $58 \%$ of new traders choose

\footnotetext{
${ }^{18}$ Supported by Purnama Dept. Forest Inventory and Remote Sensing - Univ. Goettingen

${ }^{19}$ Similar questionnaire with the one used by (Kopp and Brümmer (2017)
} 
to trade OPFFB, indicating that this product may be currently more attractive and promising to traders.

\subsection{Result and Discussion}

\subsubsection{Remainers versus Leavers}

A logit estimation is initially employed to determine which variables affect traders' decisions to remain in or exit the market, with marginal effect estimations subsequently applied. Results are divided into two periods based on data observation round (Table 3. 8). The period 1 logit estimation converges to the log-likelihood of -173.537 , while the period 2 logit estimation converges to the log-likelihood of -157.614 . The iteration process begins from iteration 0 , represented by the intercept-only model. The iteration log performed by both estimations exhibits convergence in 4 iterations (Appendix 3.5 and 3. 7); such a prompt convergence may indicate that both estimation models are less prone to multicollinearity issues (Cameron \& Trivedi, 2010).

The estimation examines whether the combined effect of all variables considered in the model differs from zero or not. This is supported by the significance values (Prob>chi2) of both estimations, which supports the expectation that the model has relevant explanatory power. As mentioned earlier, higher values of Pseudo-R2 indicate improvements in the new model compared to the null model (Hemmert et al., 2018; McFadden, 1973); thus, both estimations provide improvements over the intercept-only model of $15.1 \%$ and $11.8 \%$ for period 1 and 2, respectively.

In order to verify the absence of multicollinearity among independent variables in the model, we examine the VIF and tolerance value of all variables subsequent to logit estimation (Appendix 3. 11 and 3. 12). Both the VIF and the tolerance values of each variable are close to 1 , indicating that all variables are uncorrelated with each other. Another test, called a link test, is applied to examine the possible existence of specification error (Table 3. 8). Both logit estimations provide variable_hat, representing the predicted value from the model, which is required to be statistically significant. Thus, it can be assumed that the considered predictors are meaningful. Additionally, the insignificant variable _hatsq represents the predicted value squared. This variable is not required to be significant or to have a high predictive power (UCLA, 2020a), as expected, hence we can assume that there is no indication of model specification error. 
As mentioned previously, we employed AME estimation after logit estimation to obtain a more informative output. The coefficient value resulting from logit estimation cannot be interpreted directly. In the logit estimation, the marginal effect of the function was weighted by both the estimator and the regressors (Cameron \& Trivedi, 2005). However, the variables' coefficient signs resulting from logit estimation remain consistent with those gained from the marginal effect estimation (Table 3. 8). Meanwhile, some variables are found to have different response in term of significance.

Unexpectedly, even though rubber price drops worse than OPFFB price, we found that rubber traders tend to remain in the market more often than OPFFB traders. This interesting behavior occurs both in period 1 and in period 2, where we see $16.7 \%$ and $13.5 \%$ increases in the probability of remaining in the market among rubber traders in both periods, respectively. A plausible reason for this is that, technically, rubber traders are able to store their $b_{o k a r}{ }^{20}$ as long as desired, much longer than OPFFB traders; some rubber traders reported having stored bokar for more than 6 months while anticipating a rubber price increase. Meanwhile, storage is not an option for OPFFB traders, as traders risk quality losses from storage which can affect the prices they receive or result in rejection from buyers. Thus, the effects of falling prices of rubber and palm oil are more visible in the OPFFB market than in rubber trading activities.

Another variable which has a significant effect on the decision of traders to remain in or exit the market in both periods is education. We observe $21.5 \%$ and $12.8 \%$ decreases in the probability of remaining in the market, in periods 1 and 2, respectively, if traders have not completed their primary school education. Having no education leaves traders no other option in finding another job. Interestingly, the number of agricultural worker in Jambi province decreased by $16.9 \%$ between August 2017 and August 2018, while the number of non-agricultural worker increased by $19.5 \%$ during the same period (Statistics Jambi Province, 2019).

More experienced traders tend to remain in the market, as shown in the period 2 estimation, and we observe a $0.8 \%$ increase in the probability of remaining in the market for every one-year increase in trader experience. This probability increase is illustrated in Figure 3. 3. It's possible that traders' experiences in period 1 make them more capable of facing difficult situations related to persistently weak prices in period $2.62 .3 \%$ of traders remaining

\footnotetext{
${ }^{20}$ bokar is a common thicker form of rubber slab produced by local farmers
} 
in the market have 3 or more years of trading experience, which means that they have previously experienced price reduction in period 1.

Table 3. 8 Result of Logit and Marginal Effect Estimation

\begin{tabular}{|c|c|c|c|c|c|c|c|c|c|c|}
\hline \multirow{3}{*}{ Remain } & \multicolumn{4}{|c|}{ Period 1 (2012-2015) } & \multicolumn{6}{|c|}{ Period 2 (2015-2018) } \\
\hline & \multicolumn{2}{|c|}{ Logit est. } & \multicolumn{2}{|c|}{ Marginal Effect est. } & \multicolumn{3}{|c|}{ Logit est. } & \multicolumn{3}{|c|}{ Marginal Effect est. } \\
\hline & Coef. & \multirow[t]{2}{*}{ SE } & $\mathrm{dy} / \mathrm{dx}$ & \multirow[t]{2}{*}{ SE } & \multicolumn{2}{|l|}{ Coef. } & \multirow[t]{2}{*}{ SE } & \multirow[t]{2}{*}{$\mathrm{dy} / \mathrm{dx}$} & \multirow{2}{*}{\multicolumn{2}{|c|}{ SE }} \\
\hline Variables & & & & & & & & & & \\
\hline tp & $0.813 * *$ & 0.314 & $0.167 * * *$ & 0.063 & 0.721 & $* *$ & 0.337 & 0.135 & $* *$ & 0.064 \\
\hline edu & $-1.110 *$ & 0.643 & $-0.215 *$ & 0.112 & -0.783 & $*$ & 0.452 & -0.128 & $* *$ & 0.065 \\
\hline $\exp$ & -0.008 & 0.018 & -0.002 & 0.004 & 0.043 & $*$ & 0.024 & 0.008 & $*$ & 0.004 \\
\hline func & -0.410 & 0.337 & -0.083 & 0.068 & 0.540 & & 0.434 & 0.092 & & 0.068 \\
\hline info & -0.107 & 0.280 & -0.022 & 0.057 & 0.092 & & 0.307 & 0.017 & & 0.055 \\
\hline stat & $0.603 *$ & 0.338 & $0.121 *$ & 0.066 & 0.439 & & 0.363 & 0.077 & & 0.061 \\
\hline num & 0.012 & 0.027 & 0.002 & 0.005 & 0.007 & & 0.042 & 0.001 & & 0.008 \\
\hline cred & $-1.726 * * *$ & 0.328 & $-0.356 * * *$ & 0.057 & 0.752 & $* *$ & 0.334 & 0.147 & $* *$ & 0.068 \\
\hline land & 0.005 & 0.011 & 0.001 & 0.002 & -0.040 & $* * *$ & 0.013 & -0.007 & $* * *$ & 0.002 \\
\hline vehic & 0.071 & 0.366 & 0.014 & 0.074 & 0.797 & $* *$ & 0.381 & 0.157 & $* *$ & 0.079 \\
\hline comp & -0.367 & 0.301 & -0.074 & 0.061 & -0.633 & & 0.489 & -0.123 & & 0.099 \\
\hline smph & 0.033 & 0.348 & 0.007 & 0.070 & -0.150 & & 0.394 & -0.028 & & 0.073 \\
\hline supp & 0.002 & 0.004 & 0.000 & 0.001 & 0.000 & & 0.006 & 0.000 & & 0.001 \\
\hline com & -0.000 & 0.026 & -0.000 & 0.005 & -0.048 & $*$ & 0.028 & -0.009 & $*$ & 0.005 \\
\hline trans & $0.834 * *$ & 0.357 & $0.168 * *$ & 0.069 & 0.044 & & 0.340 & 0.008 & & 0.065 \\
\hline trrev & -0.012 & 0.005 & -0.002 & 0.002 & 0.053 & $*$ & 0.027 & 0.010 & $* *$ & 0.005 \\
\hline loc & -0.000 & 0.005 & -0.000 & 0.001 & 0.002 & & 0.005 & 0.000 & & 0.001 \\
\hline _cons & 1.394 & 0.909 & & & -0.271 & & 0.808 & & & \\
\hline \multicolumn{11}{|c|}{ Goodness of Fit Measures } \\
\hline Obs. & 295 & & & & 292 & & & & & \\
\hline LL & -173.537 & & & & -157.614 & & & & & \\
\hline $\begin{array}{l}\text { LR } \\
\text { chi2(17) }\end{array}$ & 61.720 & & & & 42.190 & & & & & \\
\hline Prob $>$ chi 2 & 0.000 & & & & 0.001 & & & & & \\
\hline Pseudo $\mathrm{R}^{2}$ & 0.151 & & & & 0.118 & & & & & \\
\hline \multicolumn{11}{|c|}{ Specification Error } \\
\hline _hat & $0.985 * * *$ & 0.146 & & & 1.246 & $* * *$ & 0.266 & & & \\
\hline _hatsq & 0.187 & 0.123 & & & -0.149 & & 0.107 & & & \\
\hline _cons & -0.149 & 0.163 & & & -0.004 & & 0.192 & & & \\
\hline
\end{tabular}

Source: Own production (Appendix 3. 5-3.10)

Note: ${ }^{\text {a) }} * * * \mathrm{p}<0.01, * * \mathrm{p}<0.05, * \mathrm{p}<0.1$

Smaller, village-level traders tend to exit the market more often, as shown in our period 1 estimation, and we observe a $12.1 \%$ higher probability of remaining in the market among larger traders. A plausible reason for this is that larger traders are often more effective in managing their trading costs to obtain higher profits. Also, they often have more assets (such as bigger storage, in the case of rubber traders), more savings, and other sources of 
income; we found that larger traders gain significantly higher farming revenues than smaller, village-level traders (Appendix 3.13). Most traders, $88.81 \%$ of the sample, are also farmers.

One of our most compelling results is the influence a trader's credit provision has on their decision in remaining in or exit the market. This effect is found to be significant in both periods; however, the signs are different. Traders who provide credit to suppliers tend to exit the market more often in period 1, and we observe a $35.6 \%$ decrease in the probability of remaining in the market among credit-providers during this period. Meanwhile, these traders tend to remain in the market more often in period 2, and we observe a $14.7 \%$ increase in the probability of remaining in the market among this group. Traders in 2012 experienced higher rubber prices and OPFFB prices, and thus many of them do not hesitate to provide credit for suppliers, and in fact $71.53 \%$ of the sample were found to provide credit. However, a drastic decrease in prices after 2012 caused many traders and farmers to experience sudden losses, resulting in many bad loans. Thus, providing credit may ultimately lead to traders deciding to exit the market. During the 2015 survey round, in which traders from the first round were recalled, many initially refused to be interviewed because they thought we were debt collectors. Additionally, the traders in period 2 became more careful in providing credit, and we observed traders using their ability to provide credit as a way of maintaining a continuous supply from farmers. We employed a further study related to this matter in the next chapter and found that rubber traders providing credit offer higher price for bokar than those providing no credit (Table 4.9). However, they tend to offer less amount of credit due to reduction in risk of loss.
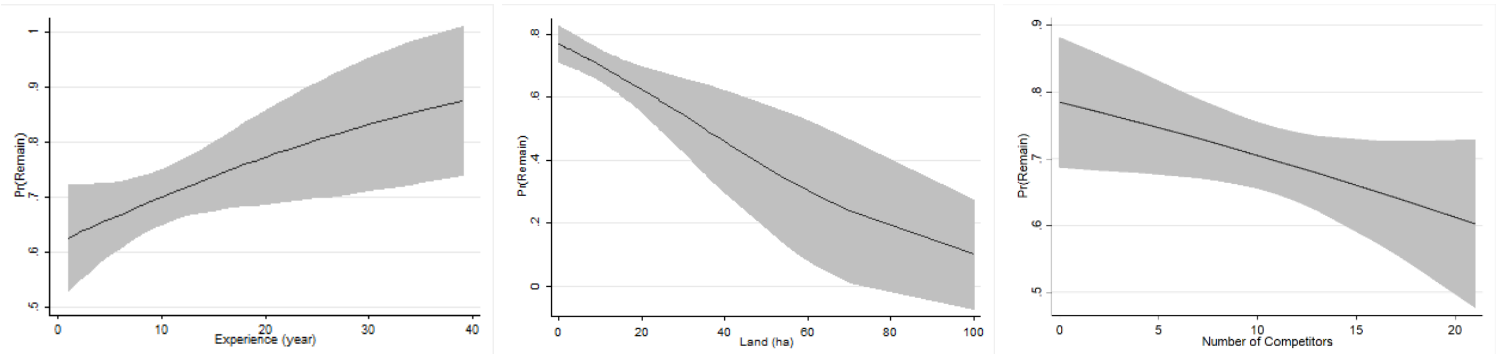

Source: Own production

Figure 3. 3 Illustration of the Increase of Probability per Unit Variable

Other variables significantly influencing the traders' decision to remain in or exit the market during period 2 are land area and status and type of operational vehicle ownership among traders. The more land area owned by traders, the less likely traders are to remain in the market, and we observed a $0.7 \%$ decrease in the probability of traders remaining in the market for every hectare increase in land area. This increase in probability is illustrated in 
Figure 3. 3. Traders have an option to focus on farming activities when they own more land, since trading activities are no longer profitable for them. They also have the option of renting the land as a profitable investment, while working in a different sector. On the other hand, traders who own an operational vehicle are $15.7 \%$ more likely to remain in the market. Owning an operational vehicle can allow traders to pick up of products from suppliers and/or deliver products to buyers, reducing traders' transaction cost and making it is easier for them to adapt to falling prices.

Having fewer competitors makes traders more likely to remain in the market, as shown in period 2 estimation; we see a $0.9 \%$ decrease in the probability of remaining in the market for every one-unit increase in traders' competitors (see Figure 3.3). Having fewer competitors is associated with an increase in market power among traders, who are able to maximize their profit without fear of losing their potential suppliers. Suppliers, likewise, have an already limited choice of potential buyers (traders).

The last significant effect observed in period 1 is that transmigrant traders have a $16.8 \%$ higher likelihood of remaining in the market compared to their non-transmigrant peers. Since transmigrant traders are typically sponsored by their government (Leinbach \& Smith, 1994), they tend to be more settled in their farming and trading activities. Agricultural extension programs and other supporting activities are routinely provided by the government and help them to overcome this challenging situation; therefore, they tend to remain in the market.

Traders with higher trading revenues tend to remain in the market, as observed in period 2. There is a $1.0 \%$ increase in the probability of remaining in the market for everyone million IDR increase in trader revenue. Higher trading revenues are generally related to higher profits; therefore, it is understandable that traders with higher revenues would be more adaptable to difficult conditions than others. The mean trading revenue of traders who remain in the market are higher than those of traders who leave the market and were observed to be 6.83 million IDR and 4.61 million IDR, respectively (Appendix 3. 14)).

We construct an interaction between trading revenues and the type of product traded and observe the resulting change in the probability of remaining in the market. Initially, we found that the interaction between trading revenue and rubber traded product increases the probability of remaining in the market. However, we identified that at a certain level of trading revenue, the type of product traded has no further influence, and the probability is only affected by trading revenue (Figure 3.4). 


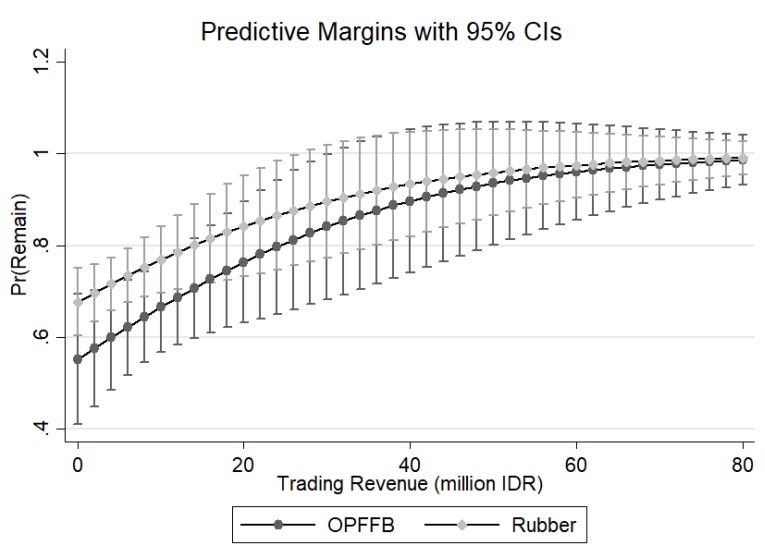

Source: Own production

Figure 3. 4 Illustration of the Increase of Probability per Unit Interacted Variable

It is intriguing that some variables are only significant in particular periods but not in others. This is due to overall market situations and resulting trading behavior fluctuating over time. One example of this is in period 1, where the trading revenue variable turns insignificant. The mean trading revenue in 2015 was calculated to be much less than that in 2012 (Appendix 3. 14), even adjusting for inflation. Therefore, it is most likely that the trader revenues from period 2 respondents are closer to the threshold of traders' decision to remain in or exit the market. On the other hand, the price situation in period 1 is very profitable for traders. They may collectively have higher trading revenues; thus, variance in trading revenues does not affect their decision to remain in or exit the market.

\subsubsection{New versus Existing Traders}

In this section, characteristics between new and existing traders (Figure 3. 5) are compared. The results illustrate the differences in characteristics between both groups. As mentioned in the model specification section, we initially performed a Shapiro-Wilk normality test for our metric variables to decide on the appropriate test of differences between groups. However, we found that not all metric variables are normally distributed; therefore, a Wilcoxon rank-sum (Mann-Whitney) non-parametric test is performed to test for equality between groups based on their median values (Table 3. 9) (Mann \& Whitney, 1947; Wilcoxon, 1947).

Results imply that the number of workers, land area owned (ha) and trading revenues (million IDR) of the existing traders are significantly higher than those of new traders. This is very plausible, as new traders face challenges in adapting to their new trading competition. They usually start small, with limited resources; thus, they employ fewer workers and gain just enough revenue for living. 
Table 3. 9 New and Existing Traders' Characteristics in 2018

\begin{tabular}{|c|c|c|c|c|c|}
\hline \multirow{2}{*}{$\begin{array}{l}\text { Variables } \\
\text { workers }\end{array}$} & \multicolumn{2}{|c|}{$\begin{array}{l}\text { Existing Trader } \\
\text { actual rank sums }\end{array}$} & \multicolumn{2}{|c|}{$\begin{array}{c}\text { New Trader } \\
\text { actual rank sums }\end{array}$} & \multirow{2}{*}{$\begin{array}{l}\text { Sign } \\
* * *\end{array}$} \\
\hline & 44231.0 & $>$ & 8744.0 & $<$ & \\
\hline Land Area & 44718.5 & $>$ & 8256.5 & $<$ & $* * *$ \\
\hline Number of suppliers & 42455.0 & $>$ & 10520.0 & $<$ & \\
\hline Number of competitors & 41840.0 & $<$ & 11135.0 & $>$ & \\
\hline Trading revenue & 43588.0 & $>$ & 9387.0 & $<$ & $* *$ \\
\hline Location & 42112.0 & $>$ & 10863.0 & $<$ & \\
\hline $\begin{array}{c}\text { expected rank sums } \\
\text { number of obs. }\end{array}$ & & 42 & & 109 & \\
\hline
\end{tabular}

Source: Own production (Appendix 3.16)

Note: $* * * \mathrm{p}<0.01, * * \mathrm{p}<0.05, * \mathrm{p}<0.1$

To test for independence between two nominal (dummy) variables, we employ a Pearson's chi-square test (Appendix 3. 17), which will determine whether each categorical value of variables within a two-way table are independent of one another. We found the combination of type of product traded and type of trader to be statistically significantly independent of each other. Interestingly, $58.2 \%$ of the new traders chose OPFFB as the traded product. Even though one of the determinants of remaining in the market is having rubber as the traded product, newcomers seem to choose OPFFB as their traded product of choice. A plausible explanation for this is that a higher stability of prices and the need for quick delivery of OPFFB may lead to a faster profit turnover among traders.

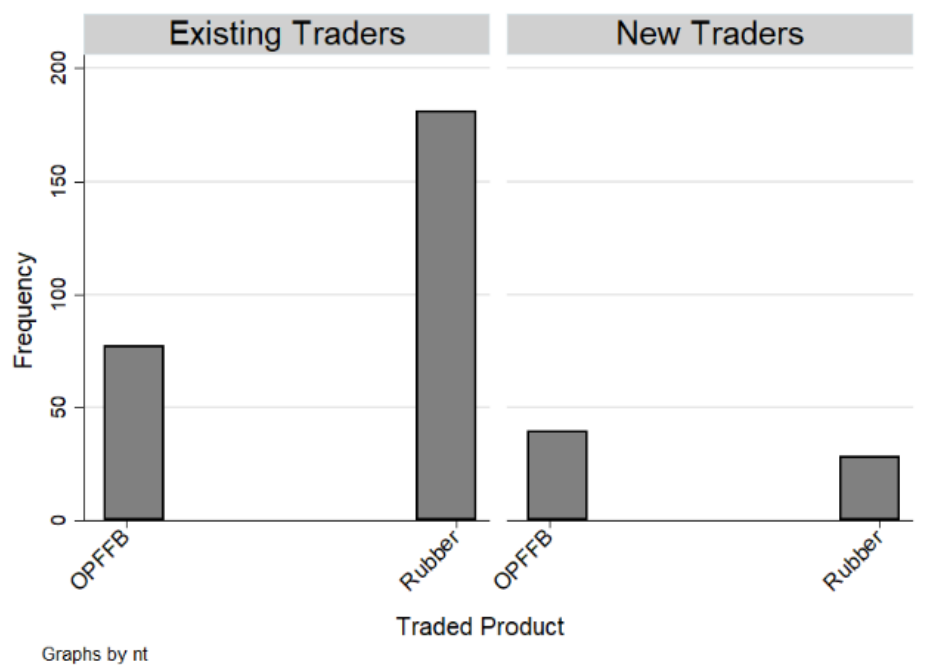

Source: Own production

Figure 3. 5 Frequency of Existing and New Traders by Traded Product 


\subsection{Conclusion}

Many traders changed their activities due to falling oil palm and rubber prices during the period of study. These price fluctuations seem to raise uncertainty among traders, affecting their decisions to remain in or exit the market. In light of this evidence, it is clear that human capital (education and experience), trading structure (traded product, credit provision, land area, operational vehicle ownership, and trader status), structural environment (number of competitors), and socioeconomic (trading revenue) factors affect the decisions of traders to remain in or exit the market. It is also interesting that some variables are only significant in particular periods but not in others, due to different situations and different trader behavior over time. 


\section{Chapter 4}

The Perils of a Loan: Interdependency between Rubber Quality and Farmer's Debt in Buying Choices among Local Rubber Traders in Jambi Province, Indonesia

Rakhma Melati Sujarwo, Bernhard Brümmer 


\subsection{Introduction}

Many smallholder farmers depend on loans, not only for farming activities but also for their daily needs. Carranza and Niles (2019) found that food, agricultural and livestock inputs, and medical expenses are the main loan-dependent expenses among smallholder farmer households. Loans can be obtained from both formal and informal financial institutions; however the latter may be more desirable for smallholder farmers because of lower transaction costs and risk (Guirkinger, 2008). The source of the loan may be related to how the loan is spent. Informal loans are mostly spent on food, while formal loans are generally utilized for agricultural inputs (Carranza \& Niles, 2019). Additionally, the level of a farmers education, income, and age are factors which may affect a farmer's decision to ask for a loan or not (Oni, Oladele, \& Oyewole, 2005).

These conditions are all very relevant to rubber farmers in Indonesia, the second largest rubber producer ${ }^{21}$ in the world (Jegede, 2019). The majority of rubber farmers in Indonesia are smallholder farmers (Figure 4. 1). With the largest rubber plantation area in Indonesia, Sumatera island accounts for $68 \%$ of the total number of Indonesian smallholder farmers (Directorate General of Estate Crops, 2018). Jambi province in Sumatra is currently experiencing a rapid development in its rubber production industry, which increased $20.41 \%$ from 2014 to 2018 . The number of rubber farmers in the area increased by $7.10 \%$ during the same period (Directorate General of Estate Crops, 2018), and the majority of these new farmers are smallholder farmers.

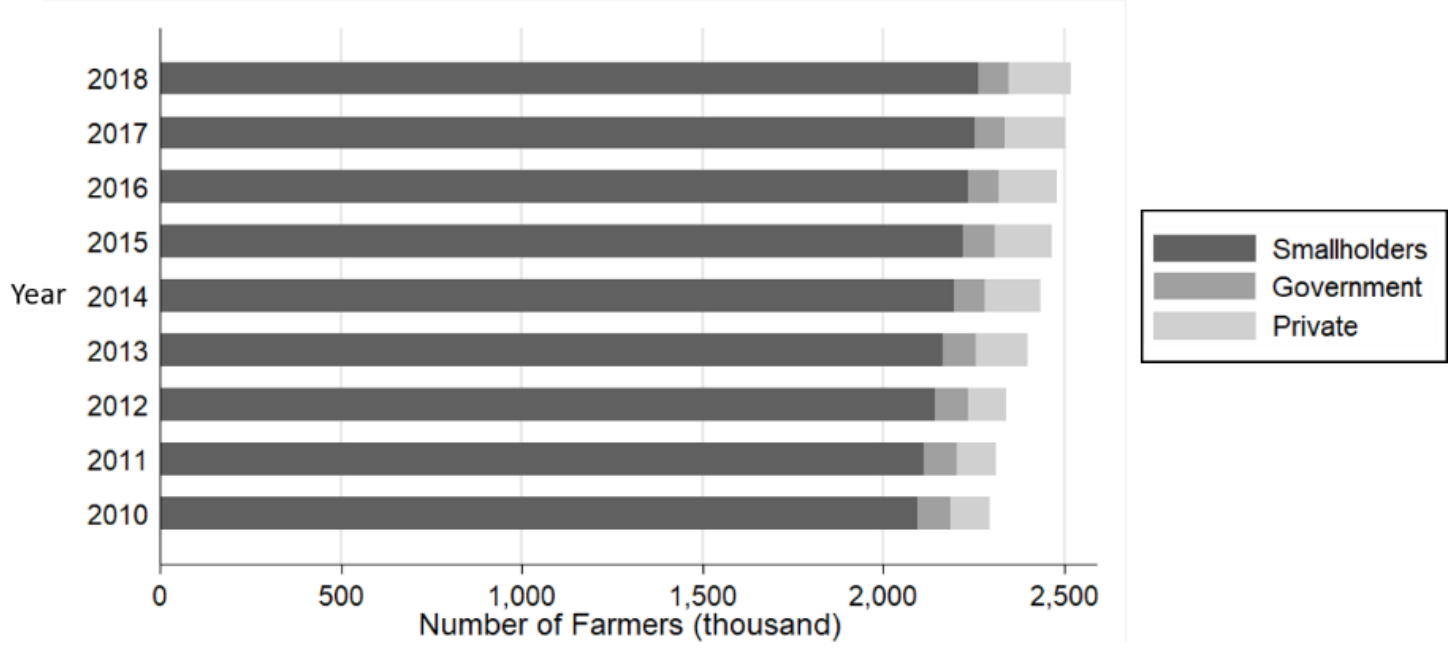

Source: Own production based on Directorate General of Estate Crops (2018)

Figure 4. 1 Number of Farmers by Ownership

\footnotetext{
${ }^{21}$ Indonesia contributes to $27.3 \%$ of the total rubber production in the world (Jegede, 2019)
} 
49.64\% of Jambi rubber smallholder farmers require either formal or informal loans, and $32.95 \%$ of those requiring loans take a loan from rubber traders, considered to be informal financial institutions ${ }^{22}$. Obtaining an informal loan from a trader is quite different from obtaining a formal loan and can induce a reciprocal seller-buyer relationship; when a farmer is indebted to a trader, the farmer feels obligated to sell their rubber to the trader. Based on our initial survey in 2018, $82.38 \%$ of all rubber trader respondents provide credit for their suppliers, and $79.77 \%$ require their suppliers to sell their rubber to them. This is also proved by the study in the previous chapter that showed that credit is one of the main factors influencing the decision of rubber traders to remain in the market. This shows that credit can secure the constant supply of rubber for traders, giving traders leverage in their relationships with farmers.

In Jambi rubber trading, there is a common local term called basi. This is defined as the percentage of impurities of a bokar - a common thicker form of rubber slab produced by local farmers - which will then be transferred as a percentage of price reduction from the current asking price. The basi value is determined solely by the trader, and thus many factors may affect its value other than simple impurities. A supporting study showed that $11.8 \%$ of respondents overestimated the basi value for indebted suppliers (Kopp \& Brümmer, 2017). We also performed a serial study applying the unrelated question randomized response model to capture possible hidden responses due to a particularly sensitive question, where we assume that manipulating basi estimation is an improper action. As expected, it captures a higher proportion of respondents, showing that they give lower basi to debt-free farmers than to indebted farmers. It reaches $86.62 \%$ of the proportion. The high number of respondents demonstrates that there is another factor besides quality affecting basi, namely debt. Both studies will be explained in more detail in the next section. Additionally, the approaches cannot capture how much basi traders are willing to charge when a farmer has a certain amount of debt.

Thus, due to the fact that the basi is influenced not only by rubber quality but also by farmer's debt, further studies to understand how much they influence price reduction are particularly appealing. To investigate this further, we test whether price reduction, rubber quality, and farmers' debt influence traders' preferences in buying rubber, and estimate how much of a price reduction, traders are willing to charge to obtain higher quality or lower

\footnotetext{
${ }^{22}$ Based on survey collected by C07, as part of the CRC project in Jambi, Indonesia, in 2015.
} 
debt. We also measure the impact of the respondents' socio-demographic characteristics and the interaction variables between those characteristics and the main attributes.

We implement a method called a Discrete Choice Experiment (DCE), which is broadly used to asses consumer preference and willingness to pay for certain products with different attributes (Asante-Addo \& Weible, 2019; Gao \& Schroeder, 2009; Hasselbach \& Roosen, 2015). This method can disguise questions that are slightly sensitive and illicit a more candid response. DCE was initially performed in the literature on marketing and transport economics (Louviere \& Hensher, 1982; Louviere \& Woodworth, 1983). A random utility model (Manski, 1977), influenced by Lancaster's characteristics theory of value (Lancaster, 1966), is the theoretical background for this method (Bennett \& Birol, 2010).

First, by comparing the conditional and mixed logit method as part of the estimation strategy, we will test for the existence of heterogeneity in the model, thus forming a model with the best fit (Asante-Addo \& Weible, 2019; Cameron \& Trivedi, 2010; Elshiewy, Guhl, \& Boztug, 2017; Hensher, Rose, \& Greene, 2005). In this step we capture how price reduction, rubber quality, and farmers' debt affect the traders' preference in rubber buying choice. Then, to observe how much price reduction traders are willing to charge (WTC) when a farmer offers a certain quality and has a certain amount of debt, we employ a willingness to pay (WTP) measurement approach (Elshiewy et al., 2017; Hensher et al., 2005), which is derived from the result of the conditional and mixed logit model. To the best of our knowledge, there are no studies implementing DCE to capture agricultural traders' or middlemen's behavior in buying decisions and, no studies using price reduction (WTC) as a replacement for WTP; therefore, the methods applied in this study are a novel approach in the literature.

The subsequent sections provide an overview of basi manipulation captured by Kopp and Brümmer (2017) and our supporting study, as well as the difference between basi and price reduction. The next section provides the theoretical background of the DCE and is followed by the estimation strategy and data sections. Results and a discussion will be provided in detail, before we summarize our findings in the conclusion section.

\subsection{Overview: Basi versus Price Reduction}

Rubber farmers tap rubber directly from rubber trees. The sap is collected and coagulated, and dries into a material called bokar, which is a common, thicker form of rubber 
slab produced by local farmers. Bokar may contain contamination in three forms. First, it may contain impurities known known as tatal caused by a contamination of dirt from dust, tree bark, or tree branches during the process of making the bokar. A second possible form of contamination is an introduction of water content into the bakar; the higher the water content, the worse the bokar quality. The third possible form of contamination is the types of coagulant that are not in accordance with the standard ${ }^{23}$.

However, even though it has been clearly suggested by the downstream rubber buyers that farmers should reduce the bokar contamination to obtain higher price, the farmers still do not want to follow these requirements. In fact, they further worsen the contamination. The price obtained by farmers is based on the bokar weight; they believe that by increasing contamination, they will increase the bokar weight to get more profit than they could receive by following the requirements. This becomes a loophole farmer can use to cheat to receive a higher price.

In Jambi, this phenomenon led to the emergence of a term called basi, which is the percentage of contamination in bokar ${ }^{24}$. Basi is determined unilaterally by rubber traders, and is then transmitted to a price reduction, as a substitute for the risk of traders who will lose profits due to the selling of contaminated rubber to large traders or factories.

To determine a basi value, the traders choose the bokar, suspected to have the greatest level of contamination, and rip it apart for inspection. The basi value determined does not have any standard reference; it will simply serve to generalize the overall quality of rubber held by farmers at that time. Additionally, the level of contamination is often simply an estimate made without any inspection, so the basi and price reduction evaluation tends to be unstable and can be influenced by other factors. However, in the end, a trader's utility will increase with the higher price reduction, meaning that a higher basi is anyway typically preferred. Also, it should be emphasized that the basi system is more familiar to rubber farmers than price reductions.

Apart from that, as previously mentioned, Kopp and Brümmer (2017) performed a rubber trader market power study in 2012 in which $11.8 \%$ of respondents were shown to have manipulated the basi estimation for indebted suppliers. Results indicate that the

\footnotetext{
${ }^{23}$ Coagulants that are in accordance with factory demand standard contains acetic acid (trademark: Cuko 61 or Gentong), so that the rubber can clot perfectly. However, farmers prefer cheaper coagulants (such as plant fertilizer and floor cleaner) to the suggested one, where its use can cause the rubber does not clot perfectly and damage the rubber quality. However, the difference cannot be seen in plain view.

${ }^{24}$ For example, $10 \%$ basi from $100 \mathrm{~kg}$ bokar means there is $10 \mathrm{~kg}$ contamination in bokar
} 
determination of a basi can indeed be influenced by a farmer's debt. However, data on the influence of debt on the basi was gathered by directly asking the question: "Is there an additional price reduction if farmers are in debt?", which may cause the respondent to feel intimidated, or to otherwise feel that they have done something inappropriate. With that in mind, these results may not capture the true effect. Additionally, the survey mentioned that $94.1 \%$ of all respondents provide credits to suppliers.

To further explore how many respondents, perform basi manipulation, and to reduce the bias of respondents who do not want to answer sensitive questions, we conducted a serial study applying Randomized Response Technique (RRT) model in 2018. RRT aims to capture hidden response due to sensitive question (Blair, Imai, \& Zhou, 2015; Warner, 1965), where we assume that, for respondents, admitting to manipulating the basi estimation is admitting to an improper action. In the RRT model, the respondent is prompted to provide a" yes" or "no" answer to a question which appears based on random probability from two or more questions. The question selected is not revealed to the interviewer, and thus respondents feel secure and act more honestly in answering sensitive questions. There are several basic designs of RRT which develop with time, namely mirrored question, forced response, disguised response, and unrelated question design (Blair et al., 2015). The main difference among these is the probability design parameters.

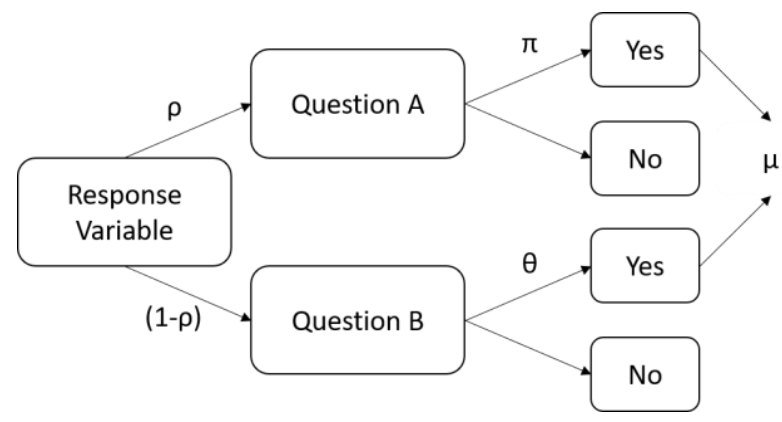

Source: Own illustration based on Greenberg et al. (1969)

Figure 4. 2 Probability Design in Unrelated Response Randomized Response Technique

We selected the unrelated question design, which was developed by Greenberg et al. (1969). Respondents were required to role a dice; if they rolled an odd number, they were required to answer the more sensitive question: "Do you provide lower price reduction to debt-free farmers?", whereas if they rolled an even number, they were required to answer a less sensitive alternative question: "Did you consume fruits or vegetables last week?" Thus, the probability of respondent answering each question was $50 \%(\rho)$. Information about which alternative questions the respondents answered is only known by the respondent. 
However, we should have prior knowledge about the probability of Yes/No answer for the alternative question. Therefore, we could have the diagram of probability answering the sensitive question (Figure 4. 2). This alternative question provides more comfort in answering questions compared to other designs; therefore, violations of instructions can be reduced (Blair et al., 2015).

The equation derived from Figure 4. 2 can be seen in Equation 1, where $\rho$ is the probability of a respondent answering question $\mathrm{A}, \pi$ is the probability of a respondent answering "yes" to question $\mathrm{A}$, and $\theta$ is the probability of a respondent answering "yes" to question $\mathrm{B}$. We have found that the value of $\theta$ is $100 \%$ based on a separated question asked at different time. Later, we discovered that the value of $\boldsymbol{\mu}$ is $74.65 \%$. At last, we calculated the value of $\pi$, representing an affirmative answer to the sensitive question, to be $86.62 \%$. Additionally, $82.38 \%$ of all respondents provided credits to suppliers.

$$
\mu=\rho \pi+(1-\rho) \theta
$$

This high number shows that debt indeed affects the basi estimation. However, this calculation cannot capture how much basi traders are willing to charge when a farmer has a certain amount of debt. We will explore this in further sections.

\subsection{Background: Random Utility Model (RUM)}

In daily life, individuals make decisions by comparing possible courses of action, and selecting the best possible outcome. However, understanding which determinants influence the choice outcomes in a population is challenging, because not all related information is always available, and each individual has his/her own preferences. Some of them may have the same level of utility (I) in different combinations, which can be seen by the location of different nodes in Figure 4. 3.

The figure illustrates the assumption of rubber traders' individual preferences, where there exist distinct differences in preferences, in various combinations, for rubber quality and debt value. The combination chosen represents each individual's behavior in maximizing utility (Hensher et al., 2005). Instinctively, traders will choose better quality products and lower farmer debt value to receive higher income or maximize their utility. However, another additional attribute, such as rubber price, may provide another effect in the combination chosen. Within a population, variability in individual preferences leads to 
heterogeneity (Hensher et al., 2005). Maximizing the amount of measured variability can reduce the number of unobserved heterogeneities.

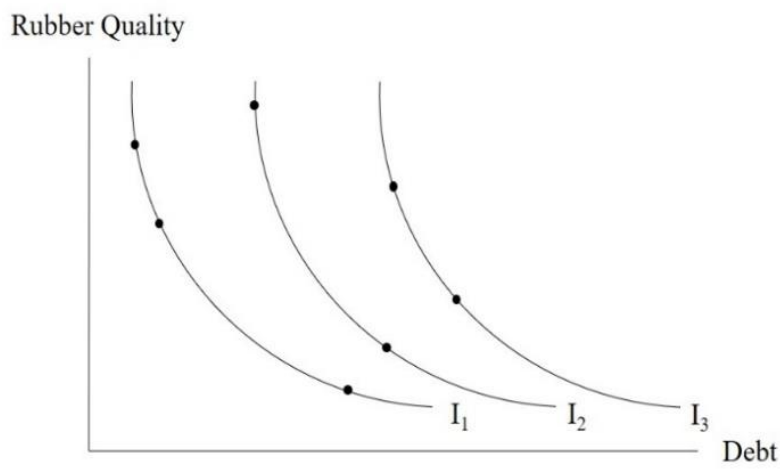

Source: Own illustration based on Hensher, Rose and Greene (2005)

Figure 4. 3 Illustration of rubber trader individual preferences

Equation 2 visualizes the RUM expression, representing the utility $(U)$ of individual $i$ and alternative $j$, where $V_{i j}$ represents the utility component of individual $i$ and alternative $j$, capturing all observed and measured regressors (Eq. 3). $\varepsilon$ refers to the unobserved heterogeneity or error. (Hensher et al., 2005).

$$
\begin{gathered}
U_{i j}=V_{i j}+\varepsilon_{i j} \\
V_{i j}=x_{i j}^{\prime} \beta+z_{i}^{\prime} \gamma_{j}
\end{gathered}
$$

In this situation, regressors are divided into two types, namely case-specific and casevarying (alternative-specific) regressors (Cameron \& Trivedi, 2010). Case-specific regressors, represented by vector $z_{i}$, are regressors which do not alter across alternatives, such as revenue, age, and gender. Meanwhile, alternative-specific regressors, represented by vector $x_{i}$, differ across alternatives $(j)$, such as price and debt. Also, we further consider interaction between both type of regressors. The RUM will be modified as follows (Eq. 4):

$$
U_{i j}=x_{i j}^{\prime} \beta+z_{i}^{\prime} \gamma_{j}+\varepsilon_{i j}
$$

The model above becomes the reference point for analyzing unordered multinomial outcomes resulting from individual choices, with Multinomial Logit (MNL) model (Cameron \& Trivedi, 2010; Greene, 2012). There are three types of MNL models which can be employed through STATA commands (Cameron \& Trivedi, 2010; Greene, 2012). First, the original MNL model is applied when all regressors considered are case-specific type of regressors. Second, the Conditional Logit (CL) model is applied when all regressors are alternative-specific type of regressors. Lastly, Alternative-specific Conditional Logit (ASC- 
L) model is applied when both type of regressors are considered. However, CL model can be applied as ASC-L to simplify the comprehension, in a way which is further explain in the model specification section (Cameron \& Trivedi, 2010; Greene, 2012).

However, these MNL models acknowledge fixed coefficient and maintain some simplifying assumptions, which become their weakness (Rigby \& Burton, 2005). The first assumption is Independence of Choice, which assumes that each choice is independent from the others, as if each was made by a different person (Rigby \& Burton, 2005). For the purpose of our study, we consider repeated choices of data where a respondent answers several choice sets. Answers chosen by one individual are likely to be correlated. The second assumption is that of Independence of Irrelevant Alternatives (IIA), which assumes that the choice probability ratio for each alternative, within a random combination of attributes, is independent from other alternative(s) in the choice set (Hensher et al., 2005). Finally, the third assumption is Homogeneity of Preferences, which assumes that the heterogeneity of attribute preferences is limited only to individual attributes; meanwhile, there exist other attributes which are expected to influence the decision process as well (Rigby \& Burton, 2005).

$$
\begin{gathered}
V_{i j}=x_{i j}^{\prime} \beta_{i}+z_{i}^{\prime} \gamma_{j i} \\
\beta_{i}=\beta+v_{i} \\
\gamma_{i j}=\gamma_{j}+w_{i j} \\
V_{i j}=x_{i j}^{\prime} \beta+x_{i j}^{\prime} v_{i}+z_{i}^{\prime} \gamma_{j}+z_{i}^{\prime} w_{i j} \\
U_{i j}=\left(x_{i j}^{\prime} \beta+z_{i}^{\prime} \gamma_{j}\right)+\left(x_{i j}^{\prime} v_{i}+z_{i}^{\prime} w_{i j}+\varepsilon_{i j}\right)
\end{gathered}
$$

Another approach, the Random Parameter Logit (RPL) model, relaxes these MNL assumptions. The RPL allows for parameter $\beta$ and $\gamma$ to be random across individual $i$, and has stochastic elements that are plausibly heteroskedastic and correlated across alternatives (Cameron \& Trivedi, 2010; Greene, 2012; Hensher et al., 2005). It will be defined by $\beta$ 's and $\gamma$ 's mean, and standard deviation. Equations 5 through 9 outline the modification of the RUM components. Apart from that, even though $\varepsilon_{i j}$ itself has no correlation over alternatives, the current combination of $\boldsymbol{x}_{\boldsymbol{i} \boldsymbol{j}}^{\prime} \boldsymbol{v}_{\boldsymbol{i}}+\boldsymbol{z}_{\boldsymbol{i}}^{\prime} \boldsymbol{w}_{\boldsymbol{i j}}+\boldsymbol{\varepsilon}_{\boldsymbol{i j}}$ as error is correlated over alternatives (Cameron \& Trivedi, 2010). 


\subsection{Model Specification}

In this study, we consider three main attributes as the alternative-specific regressors, i.e. price reduction, rubber quality, and farmers' debt. We also acknowledge six sociodemographic regressors as the case-specific regressors, i.e. trading revenue, credit provision, number of suppliers, number of competitors, trader's status (whether one is a village-level trader or a larger trader), and trans-migration's status (whether one is part of the transmigration scheme or not). Moreover, the interaction of both type of regressors are also taken into account. It is important that no attributes or regressors to be correlated (Hensher et al., 2005). Thus, we perform an initial correlation test for a nonparametric estimator for all regressors (Croux \& Dehon, 2010; Spearman, 1904).

This statistical correlation test, even without a correlation between attributes, may not capture psychological aspect of decision makers, otherwise known as inter-attribute correlation (Hensher et al., 2005). For example, the decision maker may consider that a higher price is associated with a higher quality product. However, in our case, unlike palm oil, which has a clear quality grading system, there is no clear measurement of rubber quality in Jambi. The rubber quality is relatively similar across farmers and areas. Thus, the correlation between price reduction and rubber quality in our study is assumed to not be a major concern. However, considering interaction terms between case- and alternativespecific regressors will initiate another form of correlation in the estimation.

$$
\begin{aligned}
& U 1_{i j}=\beta_{01}+\beta_{1} p_{-} r e d_{i j}+\beta_{2} q u a l_{i j}+\beta_{3} d e b t_{i j}+\varepsilon_{i j} \\
& U 2_{i j}=\beta_{02}+\beta_{4} p_{-} \text {red }_{i j}+\beta_{5} \text { qual }_{i j}+\beta_{6} \text { debt }_{i j}+\beta_{7} \text { dalt_trrev }_{-} \\
& +\beta_{8} \text { dalt_cred }+\beta_{9} \text { dalt_supp }+\beta_{10} \text { dalt_com }+\beta_{11} \text { dalt_stat }+\beta_{12} \text { dalt_trans } \\
& +\beta_{13} \text { trrev_X_qual }+\beta_{14} \text { trrev_X_debt }+\beta_{15} \text { cred_X_qual }+\beta_{16} \text { cred_X_debt } \\
& +\beta_{17} \text { supp_X_qual }+\beta_{18} \text { supp_X_debt }+\beta_{19} \text { com_X_qual }+\beta_{20} \text { com_X_debt } \\
& +\beta_{21} \text { stat_X_qual }+\beta_{22} \text { stat_X_debt }+\beta_{23} \text { trans_X_qual }+\beta_{24} \text { trans_X_debt }+\varepsilon_{i j}
\end{aligned}
$$

Initially, we illustrate our estimation strategy by transforming the RUM function (Eq. 4) into Equation 10. Later, we introduce the additional socio-demographic regressors with the interaction regressors in Equation 11. All $\beta_{0 n}(\mathrm{n}=1, \ldots, 5$, according to the estimated model) refer to dalt or the "none" option. In addition to that, $\beta_{n}(\mathrm{n}=1, \ldots, 48)$ defines all parameters estimated. All variables code used in the equations are defined in Table 4. 1.

Even though we consider both alternative- and case-specific type of regressors, we prefer to employ the CL model instead of the ASC-L model to obtain a simpler interpretation, as mentioned in the previous section. To do so, we are required to interact the case specific regressors with dummies for $m-1$ alternatives, which in this case is the dalti variable 
(Cameron \& Trivedi, 2010). Nonetheless, we have three alternatives in total, consisting of two buying alternatives and an additional "none" option alternative, and we combine the two buying alternatives into one alternative, which we will describe further in the data section (Table 4. 2). dalti itself must be included in the estimation as well.

Table 4. 1 Definition of Variables

\begin{tabular}{|c|c|}
\hline Variables Code & Definition \\
\hline \multicolumn{2}{|c|}{ Alternative-specific Regressors } \\
\hline $\begin{array}{l}\text { p_red } \\
\text { qual } \\
\text { debt }\end{array}$ & $\begin{array}{l}\text { Price reduction } \\
\text { Rubber quality purchased } \\
\text { Farmer's debt }\end{array}$ \\
\hline \multicolumn{2}{|l|}{ Constant } \\
\hline dalt & $\begin{array}{l}\text { Dummy variable where } 1 \text { means that respondents choosing any of alternative, } \\
\text { while } 0 \text { refers to choosing the "none" option alternative }\end{array}$ \\
\hline \multicolumn{2}{|c|}{ Case-specific Regressors } \\
\hline dalt_trrev & Trading Revenue \\
\hline dalt_cred & $\begin{array}{l}\text { Dummy variable of credit provision by traders, whether they are credit provider } \\
\text { (1) or not }(0)\end{array}$ \\
\hline dalt_supp & Number of suppliers \\
\hline dalt_com & Number of competitors \\
\hline dalt_stat & $\begin{array}{l}\text { Dummy variable of trader's status, whether one is a village-level trader }(0) \text { or a } \\
\text { larger trader (1) }\end{array}$ \\
\hline dalt_trans & $\begin{array}{l}\text { Dummy variable of trans-migration's status, whether one is part of the trans- } \\
\text { migration scheme (1) or not }(0)\end{array}$ \\
\hline \multicolumn{2}{|c|}{ Interaction Regressors } \\
\hline trrev_X_qual & Interaction between trading revenue and rubber quality purchased \\
\hline trrev_X_debt & Interaction between trading revenue and farmer's debt \\
\hline cred_X_qual & Interaction between credit provision and rubber quality purchased \\
\hline cred_X_debt & Interaction between credit provision and farmer's debt \\
\hline supp_X_qual & Interaction between number of suppliers and rubber quality purchased \\
\hline supp_X_debt & Interaction between number of suppliers and farmer's debt \\
\hline com_X_qual & Interaction between number of competitors and rubber quality purchased \\
\hline com_X_debt & Interaction between number of competitors and farmer's debt \\
\hline stat_X_qual & Interaction between trader's status and rubber quality purchased \\
\hline stat_X_debt & Interaction between trader's status and farmer's debt \\
\hline $\begin{array}{l}\text { trans_X_qual } \\
\text { trans_X_debt }\end{array}$ & $\begin{array}{l}\text { Interaction between trans-migration's status and rubber quality purchased } \\
\text { Interaction between trans-migration's status and farmer's debt }\end{array}$ \\
\hline
\end{tabular}

The CL model exercised in this study is introduced by McFadden (1973) and Cameron and Trivedi (2010). The general CL estimation is illustrated in Equation 12. When three main alternative-specific regressors are introduced into the equation, it is transformed into Equation 13 by considering the RUM in Equation 10, where the model estimation is later called CL_1. A similar transformation, considering the case-specific and interaction regressors in Equation 11, is also employed, where CL_2 will be the model estimation. 


$$
\begin{gathered}
P_{i j}=\frac{\exp \left(x_{i j}^{\prime} \beta\right)}{\sum_{l=1}^{m} \exp \left(x_{i l}^{\prime} \beta\right)}, \quad j=1, \ldots, m \\
P_{i j}=\operatorname{Pr}\left[y_{i}=j\right]=\frac{\exp \left(\beta_{01}+\beta_{1} p_{-} \text {red }_{i j}+\beta_{2} \text { qual }_{i j}+\beta_{3} \text { debt }_{i j}\right)}{\sum_{l=1}^{3} \exp \left(\beta_{01}+\beta_{1} p_{-} \text {red }_{i j}+\beta_{2} \text { qual }_{i j}+\beta_{3} \text { debt }_{i j}\right)}, \quad j=1, \ldots, 3
\end{gathered}
$$

As a comparison, we exercised the ML model (Eq. 16) (Cameron \& Trivedi, 2010) as part of the RPL, which is expressed in Equation 14 and 15. The difference is that we consider only rubber quality and farmer's debt to be random across individual $i$. This model's objective is to relax the assumptions of fixed coefficient in MNL model (Hensher et al., 2005; Rigby \& Burton, 2005).

$$
\begin{aligned}
& U 3_{i j}=\beta_{03}+\beta_{25} p_{-} \text {red }_{i j}+\beta_{26 i} \text { qual }_{i j}+\beta_{27 i} \text { debt }_{i j}+\varepsilon_{i j} \\
& U 4_{i j}=\beta_{04}+\beta_{28} p_{-} \text {red }_{i j}+\beta_{29 i} \text { qual }_{i j}+\beta_{30 i} \text { debt }_{i j}+\beta_{31} \text { dalt_trrev }_{-} \\
& +\beta_{32} \text { dalt_cred }+\beta_{33} \text { dalt_supp }+\beta_{34} \text { dalt_com }+\beta_{35} \text { dalt_stat }+\beta_{36} \text { dalt_trans } \\
& +\beta_{37} \text { trrev_X_qual }+\beta_{38} \text { trrev_X_debt }+\beta_{39} \text { cred_X_qual }+\beta_{40} \text { cred_X_debt } \\
& +\beta_{41} \text { supp_X_qual }+\beta_{42} \text { supp_X_debt }+\beta_{43} \text { com_X_qual }+\beta_{44} \text { com_X_debt } \\
& +\beta_{45} \text { stat_X_qual }+\beta_{46} \text { stat_X_debt }+\beta_{47} \text { trans_X_qual }+\beta_{48} \text { trans_X_debt }+\varepsilon_{i j}
\end{aligned}
$$

Additionally, we do not consider $p_{-}$red to be random, since it will become an obstacle in measuring WTP when its $\beta$ distribution is close to zero (Rigby \& Burton, 2005). Also, other regressors are not considered to be random. These assumptions might lead to inconsistency in preference heterogeneity. However, model simplicity will be the main reason behind these assumptions (Cameron \& Trivedi, 2010; Hasselbach \& Roosen, 2015).

$$
\begin{gathered}
P_{i j}=\frac{\exp \left(x_{i j}^{\prime} \beta+x_{i j}^{\prime} v_{i}\right)}{\sum_{l=1}^{m} \exp \left(x_{i l}^{\prime} \beta+x_{i j}^{\prime} v_{i}\right)}, \quad j=1, \ldots, m \\
P_{i j}=\operatorname{Pr}\left[y_{i}=j\right]=\frac{\exp \left(\beta_{03}+\beta_{19} p_{-} \text {red }_{i j}+\beta_{20 i} q u a l_{i j}+\beta_{21 i} \operatorname{debt}_{i j}\right)}{\sum_{l=1}^{3} \exp \left(\beta_{03}+\beta_{19} p_{-} \text {red }_{i j}+\beta_{20 i} q u a l_{i j}+\beta_{21 i} \operatorname{debt}_{i j}\right)}, \quad j=1, \ldots, 3
\end{gathered}
$$

Similar regressors are introduced into the equation (Eq. 16), as in Equation 17, by considering the RPL in Equation 14: here the model estimation is called ML_1. A similar transformation considering the interaction regressors in Equation 15 is also employed, where ML_2 will be the model estimation. The last model estimation, called ML_3, introduces cross-correlation among random attribute parameters, in the form of a Cholesky matrix, to the ML_2 estimation. Thus, we would have the true standard deviation of the random parameters (Asante-Addo \& Weible, 2019; Hensher et al., 2005).

The model chosen between CL and ML models will be based on Pseudo- $\mathrm{R}^{2}$ value, the model selection criteria (Akaike and Bayesian information criterion (AIC and BIC)), and 
the log-likelihood values. The log-likelihood based Pseudo- $\mathrm{R}^{2}$ value (Equation 17) provides the interpretation that higher values of Pseudo- $\mathrm{R}^{2}$ mean better improvements in the new model compared to the null model (Hemmert et al., 2018; McFadden, 1973).

$$
\text { Pseudo } R^{2}=1-\left(\frac{l l_{\text {model }}}{l l_{\text {null }}}\right)
$$

Typically, lower criterion values indicate a better model. The difference between criterions lies in how the number of estimated parameters and observations are penalized (Mills \& Prasad, 1992). Meanwhile, even though the general rule is that higher loglikelihood values indicate a better model, we could also apply the Likelihood Ratio (LR) test (Equation 18), wherein $U R$ refers to unrestricted (new) model and $R$ defines otherwise, to be then compared with a chi-square $\left(\chi^{2}\right)$ distribution (Hensher et al., 2005; Wooldridge, 2013). The new model fits best when we reject the null hypothesis, i.e. the computed LR > critical LR. To get the critical value of the chi-square $\left(\chi^{2}\right)$ distribution, we have to define the degree of freedom of the particular model by subtracting the number of observations in a sample by the number of independent constraints or $\beta$-parameters estimated (Hensher et al., 2005).

$$
L R=2\left(L_{U R}-L_{R}\right)
$$

At last, the main objective of this study is to observe how much price reduction traders are willing to charge (WTC) when a farmer with a certain amount of debt or quality offers a product. To do so, we employed a WTP measurement approach (Hensher et al., 2005), derived from choosing the best result between all model estimations. It is based on the ratio of the two parameters involved, where $\beta_{p}$ refers to $p_{-} r e d$ parameter, while $n$ represents parameter of other regressors. It is important to obtain significant regressors to measure the WTC, otherwise no valuable measurement can be determined (Hensher et al., 2005). Additionally, a common supporting Krinsky Robb bootstrap method to measure WTP is employed (Hasselbach \& Roosen, 2015; Hole, 2007a).

$$
W T C_{n}=-\frac{\beta_{n}}{\beta_{p}}
$$

Additional normality and non-parametric equality test are conducted to obtain supporting data based on the socio-demographic respondent characteristics. A Shapiro-Wilk Normality Test is employed to perform normality test for variables required (Royston, 1992), meanwhile Wilcoxon rank-sum (Mann-Whitney) non-parametric test is exercised to obtain equality test between groups based on their median values (Mann \& Whitney, 1947; Wilcoxon, 1947). 


\subsection{Data}

\subsubsection{Data Source}

The data used in this study is part of the data collected from the Collaborative Research Centre (CRC) in Ecological and Socioeconomic Functions of Tropical Lowland Rainforest Transformation Systems in the Jambi province, Indonesia in 2018. Five regencies, namely Sarolangun, Batang Hari, Muaro Jambi, Tebo, and Bungo Regency, were selected purposefully ${ }^{25}$. Then, stratified random sampling was applied in order to select districts and villages. One advantage of using stratified random sampling is that it minimizes survey costs without compromising accuracy (Cameron \& Trivedi, 2010). Next, twenty-two districts and thirty-seven villages were chosen, and respondents were formed by selecting all active, small rubber traders in the selected villages, and excluding those who could not be reached due to absence or rejection. We conducted direct interviews with respondents to gather information about their socio-demographic characterises. Also, we performed an interactive experiment to obtain our DCE data as our main research objectives.

\subsubsection{Choice Experimental Design}

We decided to consider in the study three main attributes related to the core research question: price reduction, rubber quality, and farmer's debt. All were included as alternative specific regressors. Each attribute is presented in different levels. Attributes and levels used in this study are described in Table 4. 2. Combinations of attributes, each with unique levels, are named alternative. There is no label identification for the alternative in this study, commonly called an unlabelled experiment, which is beneficial because there is less of a possibility of a correlation between alternatives and a reduced bias in considering attributes, since decision makers may hold initial assumption by reading the alternative's label (Hensher et al., 2005).

To have an efficient experimental design, all alternatives, attributes, attribute levels and attribute-level labels have to be well-identified and refined before a design is formed (Hensher et al., 2005). It is thought that the presence of too many choice sets may reduce the response reliability. Therefore, even though, theoretically, more information is gained by having more levels of attributes, reducing the number of attribute levels is preferred. Another way is to reduce the size of the experimental design while still considering the concept of

\footnotetext{
${ }^{25}$ Performed by Krishna and Euler, members of CRC's team, and also stated on the EFForTS Discussion Paper by Faust et al. (2013)
} 
orthogonality, where all attributes are statistically independent of one another (Hensher et al., 2005).

Table 4. 2 Attributes, Levels and Descriptions

\begin{tabular}{lll}
\hline Attribute & Level & Description \\
\hline Quality & Bad (0), good (1) & $\begin{array}{l}\text { illustrating the rubber quality whether } \\
\text { it is in bad or good quality. }\end{array}$ \\
Debt & 0 IDR, 350,000 IDR, 750,000 IDR & $\begin{array}{l}\text { illustrating the loan amount borrowed } \\
\text { by the indebted suppliers. } \\
\text { referring the price reduction in } \\
\text { percentage determined by traders. }\end{array}$ \\
\hline
\end{tabular}

In this study, the design of the choice experiment was automatically generated by JMP Statistical Discover from SAS. It will automatically consider the number of alternatives, attributes, attribute levels, and choice sets desired, by still considering the orthogonality concept, called the orthogonal fractional factorial design. We consider a combination of three attributes within a choice set containing two alternatives and a "none" option for each set (Table 4. 3). Also, we include 10 choice sets per survey, from three surveys and over 180 expected respondents. These considerations were then input into the software to randomly generate a design.

Table 4. 3 An example of a Choice Set (simplification)

\begin{tabular}{llll}
\hline Set 1 & Choice A & Choice B & Choice C \\
\hline Quality & Bad Quality & Good Quality & \\
Debt & 750,000 IDR & 0 IDR & Neither \\
Basi & $5 \%$ & $15 \%$ & \\
\hline
\end{tabular}

Note: A sample of choice set is presented in Appendix 4. 1.

A preliminary pilot study was performed where we interviewed actual rubber traders outside the survey area as well as experts who understand the behaviour of traders. Their choice outcomes and feedbacks provided improvement for the final choice design. It is necessary to detect potentially relevant attributes, so that all combination used in the survey are realistic for the respondents. the type of choice data employed in this study is known as 
Revealed Preference $(\mathrm{RP})^{26}$ data, where the choice is based on actual market condition (Hensher et al., 2005).

At the end of survey, we interviewed 210 respondents who were then randomly and evenly divided into three groups to perform different surveys. Each respondent was confronted with choice sets shown in sequence. They were asked to choose one of the alternatives presented in the choice set. The choice concerned $100 \mathrm{~kg}$ of "bokar" and 8,000 $\mathrm{IDR} / \mathrm{kg}$ and was mentioned in the beginning of survey.

To provide a sense of realism, we prefer to use term basi rather than "price reduction" in the choice set, since it is better known by both rubber farmers and traders. Also, it is in the common form of price reduction (in percentage) used on the field. It is then transformed into Indonesian Rupiah (IDR) which must be in accordance with our assumption. Keep in mind that, in the end, we are looking for WTC basi instead of WTP. Additionally, we divide debt by one million to adjust for the many zeros when dealing with IDR currency.

\subsubsection{Descriptive Statistics of Socio-Demographic Characteristic Data}

Descriptive statistics for key socio-demographic variables relating to the respondents are described in Appendix 4. 2. Key variables include the size, number of competitors, sociohuman capital, and credit provision of rubber traders. In an initial assessment of trading activities, of the majority of rubber traders dealt in rubber alone, whereas $12.38 \%$ of respondents reported also trading in oil palm.

Table 4. 4 Village and Larger Traders' Characteristics

\begin{tabular}{|c|c|c|c|c|c|}
\hline \multirow[t]{2}{*}{ Variables } & \multicolumn{2}{|c|}{$\begin{array}{c}\text { Village Trader } \\
\text { actual rank sums }\end{array}$} & \multicolumn{2}{|c|}{$\begin{array}{c}\text { Larger Trader } \\
\text { actual rank sums }\end{array}$} & \multirow{2}{*}{$\begin{array}{r}\text { Sign. } \\
* * *\end{array}$} \\
\hline & 13041.0 & $<$ & 9114.0 & $>$ & \\
\hline Quantity purchased & 12479.5 & $<$ & 9675.5 & $>$ & $* * *$ \\
\hline Number of workers & 13083.5 & $<$ & 9071.5 & $>$ & $* * *$ \\
\hline Number of suppliers & 12459.5 & $<$ & 9695.5 & $>$ & $* * *$ \\
\hline Number of competitors & 15792.5 & $>$ & 6362.5 & $<$ & $* * *$ \\
\hline expected rank sums & & 14559.0 & & & \\
\hline number of obs. & & 138 & & & \\
\hline
\end{tabular}

Source: Own production (Appendix 4. 4)

Note: $* * * \mathrm{p}<0.01, * * \mathrm{p}<0.05, * \mathrm{p}<0.1$

\footnotetext{
${ }^{26}$ Another type of choice data is Stated Preference (SP) data, where a choice is based on hypothetical condition.
} 
To capture the relative "size" of traders, we divide traders into village and larger traders, finding that $65.71 \%$ of respondents are village traders. To compare characteristics between village and larger traders, we performed the Wilcoxon rank-sum (Mann-Whitney) non-parametric test of both groups in total trading revenue, quantity of rubber purchased, number of workers, number of suppliers and number of competitors (Table 4. 4 and Appendix 4. 4). We initially conducted Shapiro-Wilk Normality Test for the variables compared (Appendix 4. 3), however those are not normally distributed thus we considered the rank-sum test to compare variables medians of both groups. Results show that the median of trading revenue, quantity purchased, number of workers, and number of suppliers variables of larger traders are significantly higher than those of village traders, but otherwise for the number of competitors variable. This is very plausible, because when there is a larger trader in an area, the challenge to become a competitor in that region will be greater due to capital required.

In terms of measuring traders' competition, $54.75 \%$ of respondents reported having 10-16 competitors in their village. Furthermore, when analysing socio-human capital characteristics of traders, we determined that $7.14 \%$ of respondents reported having a leadership title within the village, like village official, teenage leader, or religious leader; $14.76 \%$ of respondents reported being transmigrant ${ }^{27}$, and $84.26 \%$ of respondents attained a basic education, and were at least primary or secondary school graduates.

Table 4. 5 Credit Providers and Traders not Providing Credit Characteristics

\begin{tabular}{|c|c|c|c|c|c|}
\hline Variables & \multicolumn{2}{|c|}{$\begin{array}{l}\text { Provide no Credit } \\
\text { actual rank sums }\end{array}$} & \multicolumn{2}{|c|}{$\begin{array}{l}\text { Provide Credit } \\
\text { actual rank sums }\end{array}$} & \multirow[t]{2}{*}{ Sign. } \\
\hline Trading revenue & 3612.5 & $<$ & 18542.5 & $>$ & \\
\hline Quantity purchased & 3501.0 & $<$ & 18654.0 & $>$ & \multirow{6}{*}{$* * *$} \\
\hline Number of workers & 3391.0 & $<$ & 18764.0 & $>$ & \\
\hline Number of suppliers & 2845.0 & $<$ & 19310.0 & $>$ & \\
\hline Number of competitors & 4164.5 & $>$ & 17990.5 & $<$ & \\
\hline expected rank sums & & 390 & & 1825 & \\
\hline number of obs. & & & & & \\
\hline
\end{tabular}

Source: Own production (Appendix 4. 4)

Note: $* * * \mathrm{p}<0.01,{ }^{* *} \mathrm{p}<0.05, * \mathrm{p}<0.1$

At last, we observed the traders' credit provision, where $82.38 \%$ of respondents provided credits to suppliers, and $79.77 \%$ of them felt that indebted suppliers had the

27 Those have followed a transmigration program from Indonesian government, with the aim of equal distribution of Indonesian population. The program is fully subsidized by the government. 
obligation to sell their rubber to them. We also divide the respondents into two groups based on credit availability (Table 4. 5 and Appendix 4. 4). To compare both groups, we also performed the Wilcoxon rank-sum (Mann-Whitney) non-parametric test for median difference of the same variables as in Table 4. 4. Results show that the "median number of supplier" variable is significantly higher among credit providers than those traders not providing credit. One plausible reason for this is that more suppliers depend on credits offered by traders.

\subsection{Result and Discussion}

We analysed the choice experiment data using conditional and mixed logit model in STATA 14.2. Three main alternative-specific attributes and six additional sociodemographic regressors are considered, as well as their interaction. A separate initial Spearman's rank correlation test (Appendix 4. 5) was carried out for all variables in all estimations where there is no correlation among three main attributes found; meanwhile, some interaction variables indicate otherwise. These are understandable since main attributes are counted in the interaction variables. However, we also considered cross-correlation among random attribute parameters in the last model estimation to anticipate different responses once random characteristics are introduced for some main attributes.

There are five models we considered in obtaining the best fitted model (Appendix 4. 6). The most general model represented by $C L \_1$ introduced fixed coefficients for the main attributes, which do not vary across respondents, while CL_2 introduced additional sociodemographic characteristics and their interaction regressors to $\mathrm{CL}_{-} 1$. Both models were estimated using conditional logit estimation. The last three models were estimated using a mixed logit model, allowing for variation in the main attribute's coefficients, except for the price reduction and "none" option. ML_1 considers only main attributes in the estimation, while ML_2 considers main attributes as well as additional socio-demographic characteristics and their interaction regressors. We then introduced cross-correlation to ML_3 to ensure that the random attributes are still random after allowing for correlation among them. The cross-correlation information is captured as Cholesky Matrix (Hole, 2007b) which is represented by the lower-triangular matrix in ML_3. The matrix is part of the covariance matrix in Appendix 4. 13. Additionally, all mixed logit models are estimated using 500 Halton draws to find better result accuracy (Hole, 2007b). 
We compare the goodness of fit measures in order to find the best model. Estimation statistics of all model estimations are shown in Table 4. 6. The first measure is the loglikelihood measure, where, generally, a higher log-likelihood value indicates a better model, shown by ML_3. However, it is also necessary to prove this with a log-likelihood ratio test, which determines the ML_2 model to be the best fit (Table 4. 7). The second measure utilized is the pseudo- $\mathrm{R}^{2}$ by McFadden (1973), wherein a higher value of Pseudo- $\mathrm{R}^{2}$ indicates a better improvement of the new model compared with the null modeln (Hemmert et al., 2018; McFadden, 1973). It can be seen that the ML_2 and ML_3 have similar and high Pseudo-R ${ }^{2}$ values. The last measures considered are the AIC and BIC value, where a lower value indicates a better model. ML models provide lower criterion values than those of CL models. It was determined that the ML_2 model fit best based on AIC while ML_1 fit best based on BIC. Overall, ML models improve the model estimation, especially the model ML_2.

Table 4. 6 Estimation Statistics of All Model Estimations

\begin{tabular}{cccccccc}
\hline \multirow{2}{*}{ Model } & \multirow{2}{*}{ Obs } & \multicolumn{2}{c}{ Log-likelihood Value } & \multirow{2}{*}{ df } & AIC & BIC & \multirow{2}{*}{ Pseudo R ${ }^{2}$ b) } \\
\cline { 3 - 6 } & & ll-null a) & ll-model & & & & \\
\hline CL_1 & 6300 & -2307.09 & -1450.42 & 4 & 2908.84 & 2935.83 & 0.37 \\
CL_2 & 6300 & -2307.09 & -1396.03 & 22 & 2836.07 & 2984.53 & 0.39 \\
ML_1 & 6300 & -1450.42 & -1179.90 & 6 & 2371.81 & 2412.29 & 0.49 \\
ML_2 & 6300 & -1396.03 & -1154.40 & 24 & 2356.81 & 2518.77 & 0.50 \\
ML_3 & 6300 & -1396.03 & -1153.59 & 25 & 2357.18 & 2525.88 & 0.50 \\
\hline
\end{tabular}

Source: Own production (Appendix 4. 7-4.11)

Note: ${ }^{\text {a) }}$ The ll-null values for ML estimations equal to ll-model values for CL estimations, thus we replace the 11-null values for ML estimations with ll-null values for CL estimations to calculate the true Pseudo $\mathrm{R}^{2}$.

b) Calculation is based on Equation 17.

Even though model ML_3 is not the best model, the estimation result appears similar, which can reflect a quite robust result. All models provide consistent result in term of parameter signs, although number of significant regressors are reduced (Appendix 4. 6). However, the main three attributes are all significant and specify persistent parameter signs.

Based on the ML_2 model estimation, as expected, respondents tend to obtain higher price reductions to increase their utility (Table 4. 8). Theoretically, price attributes should be statistically significant and negative (Elshiewy et al., 2017; Hensher et al., 2005), while in our study, we replace the price attribute with the price reduction attribute which should respond in the opposite direction. Having a higher price reduction allows rubber traders to increase their profit per unit. 
Table 4. 7 Log-likelihood Ratio Test

\begin{tabular}{lcrrrr}
\hline $\begin{array}{c}\text { Models } \\
\text { Compared }\end{array}$ & Computed Value b) & Critical Value & $\begin{array}{c}\text { Model } \\
\text { Chosen }\end{array}$ \\
\hline ML_3 vs ML_2 & $2(-1153.59-(-1154.40))=$ & 1.64 & $\chi 2(0.95,1)=$ & 3.84 & ML_2 \\
ML_3 vs ML_1 & $2(-1153.59-(-1179.90))=$ & 52.62 & $\chi 2(0.95,37)=$ & 52.19 & ML_3 \\
ML_3 vs CL_2 & $2(-1153.59-(-1396.03))=$ & 484.88 & $\chi 2(0.95,25)=$ & 37.65 & ML_3 \\
ML_3 vs CL_1 & $2(-1153.59-(-1450.42))=$ & 593.66 & $\chi 2(0.95,43)=$ & 59.30 & ML_3 \\
ML_2 vs ML_1 & $2(-1154.40-(-1179.90))=$ & 51.00 & $\chi 2(0.95,36)=$ & 50.99 & ML_2 \\
ML_2 vs CL_2 & $2(-1154.40-(-1396.03))=$ & 483.24 & $\chi 2(0.95,24)=$ & 36.42 & ML_2 \\
ML_2 vs CL_1 & $2(-1154.40-(-1450.42))=$ & 592.02 & $\chi 2(0.95,42)=$ & 58.12 & ML_2 \\
ML_1 vs CL_2 & $2(-1179.90-(-1396.03))=$ & 432.26 & & - & ML_1 \\
ML_1 vs CL_1 & $2(-1179.90-(-1450.42))=$ & 541.04 & $\chi 2(0.95,6)=$ & 12.59 & ML_1 \\
CL_2 vs CL_1 & $2(-1396.12-(-1450.42))=$ & 108.60 & $\chi 2(0.95,18)=$ & 28.87 & CL_2 \\
\hline SL
\end{tabular}

Source: Own production (Appendix 4. 8-4. 12)

Note: ${ }^{\text {a) }}$ Degree of freedom (df) of ML_1 is less than that of CL_2, thus critical value is unmeasured. However, we consider both models are not better than ML_2 and ML_3 based on other calculations. ${ }^{\text {b) }}$ Based on Equation 18. ${ }^{\text {c) }}$ The new model fits best when we reject the null hypothesis, i.e. the computed value > critical value.

Further, the results indicate that respondents tend to choose higher rubber quality to increase their utility. Having a higher quality product surely increases the probability to obtain higher selling price. Also, it shows that respondents tend to select lower farmer's debt to minimize the risk of losing money to suppliers who default on their debt. Based on ML_2 model, farmer's debt has the highest marginal utility among main attributes. On the other hand, "none" option parameter turns to be not significant, since it is currently interacted with the socio-demographic regressors, unlike in the model ML_1.

Evidently, traders having higher trading revenue, credit provision, less suppliers and transmigrant traders prefer to choose any alternative option to the "none" option. It implies that attributes presented in alternatives matter for those criteria. Regarding the interaction regressors, good quality is preferred over bad quality for larger traders and traders having higher number of competitors.

Additionally, Table 4.8 presents the significance outcomes for random parameters. It implies that there exits heterogeneity among traders for the related attributes, since their estimates are significantly different from zero. Each trader preference differs from others as well as their WTC. Table 4. 9 shows the ML_2 WTC value which influences the respondents' utility. It can be deduced that there is no WTC for any non-significant regressors. WTC value comparisons among all models are presented in Appendix 4. 14. We 
assumed a prevailing rubber price of $8,000 \mathrm{IDR} / \mathrm{kg}$ and divided the debt value by one million to provide a more intuitive interpretation.

Table 4. 8 Parameter Estimates from the ML_2 Model Estimation

\begin{tabular}{|c|c|c|c|}
\hline Attributes & Coefficient a) & & $\mathrm{SE}$ \\
\hline \multicolumn{4}{|l|}{ Mean Estimates } \\
\hline p_red & 0.0007 & $* * *$ & $(0.0001)$ \\
\hline qual & 1.6480 & $*$ & $(0.9059)$ \\
\hline debt & -1.9086 & $* *$ & (0.9488) \\
\hline dalt b) & -0.1110 & & $(0.4054)$ \\
\hline dalt_trrev & 0.0094 & $*$ & $(0.0050)$ \\
\hline dalt_cred & 0.8596 & $* * *$ & $(0.2840)$ \\
\hline dalt_supp & -0.0085 & $* * *$ & $(0.0032)$ \\
\hline dalt_com & 0.0215 & & $(0.0253)$ \\
\hline dalt_stat & -0.3790 & & $(0.2636)$ \\
\hline dalt_trans & 0.6552 & $*$ & $(0.3402)$ \\
\hline trrev_x_qual & -0.0124 & & $(0.0109)$ \\
\hline trrev_x_debt & 0.0052 & & $(0.0105)$ \\
\hline cred_x_qual & -0.0272 & & $(0.6658)$ \\
\hline cred_x_debt & 1.0145 & & $(0.6876)$ \\
\hline supp_x_qual & 0.0126 & & $(0.0077)$ \\
\hline supp_x_debt & -0.0036 & & $(0.0071)$ \\
\hline com_x_qual & 0.1018 & $*$ & $(0.0550)$ \\
\hline com_x_debt & 0.0294 & & $(0.0555)$ \\
\hline stat_x_qual & 1.9702 & $* * *$ & $(0.6022)$ \\
\hline stat_x_debt & -0.0283 & & $(0.5876)$ \\
\hline trans_x_ $x$ _qual & -1.0488 & & $(0.7122)$ \\
\hline trans_ $x \_$debt & -0.3422 & & $(0.7190)$ \\
\hline \multicolumn{4}{|c|}{ Standard Deviation of Random Parameter Distributions } \\
\hline qual & 2.8441 & $* * *$ & $(0.2936)$ \\
\hline debt & 2.6058 & $* * *$ & (0.2755) \\
\hline \multicolumn{4}{|l|}{ Goodness of Fit Measures } \\
\hline Log-likelihood & -1154.4063 & & \\
\hline Pseudo- $\mathrm{R}^{2}$ & 0.4996 & & \\
\hline AIC & 2356.8130 & & \\
\hline BIC & 2518.7720 & & \\
\hline Number of observations & 6300 & & \\
\hline Number of respondents & 210 & & \\
\hline
\end{tabular}

Source: Own production (Appendix 4.10)

Note: ${ }^{\text {a) }} * * * \mathrm{p}<0.01,{ }^{* *} \mathrm{p}<0.05,{ }^{*} \mathrm{p}<0.1 ;{ }^{\text {b) }}$ Dummy variable for choosing any alternative (1) or "none" opt (0)

An increase in quality from bad to good, is followed by a decrease in price reduction by $2,397.48 \mathrm{IDR} / \mathrm{kg}$, ceteris paribus, which is $29.97 \%$ of the assumed price. This is in accordance with our expectation, because the price of bokar of very poor quality can reach $40 \%$ of the prevailing price. Meanwhile, bokar with prices of up to $10 \%$ of the prevailing 
price are considered to be of good quality ${ }^{28}$. Furthermore, an increase in farmer's debt by 1 million IDR leads to an increase in price reduction by $2,776.54 \mathrm{IDR} / \mathrm{kg}$, ceteris paribus, which is $34.71 \%$ of the assumed price. The most common farmer's debt values are below 1 million IDR, with an average of 0.5 million IDR $^{29}$, and these loans are often used for daily needs. In other words, mostly price reduction due to farmer's debt value is below 2,776.54 IDR $/ \mathrm{kg}$. Also, the farmer's reason for having the debt is in accordance with a study finding that informal loans are mostly spent on food (Carranza \& Niles, 2019).

Table 4. 9 Rubber Traders' Willingness to Charge Price Reduction for Rubber Attributes

\begin{tabular}{|c|c|c|c|c|}
\hline Attributes & WTC a) & & Min. & Max. \\
\hline \multicolumn{5}{|c|}{ Alternative-specific regressors } \\
\hline qual & $-2,397.48$ & $*$ & $-5,763.19$ & -149.19 \\
\hline debt & $2,776.54$ & $* *$ & -84.55 & $6,285.63$ \\
\hline \multicolumn{5}{|c|}{ Socio-demographic regressors } \\
\hline dalt_trrev & -13.64 & $*$ & -32.62 & 0.73 \\
\hline dalt_cred & $-1,250.49$ & $* * *$ & $-2,538.36$ & -410.00 \\
\hline dalt_supp & 12.42 & $* * *$ & 3.33 & 25.88 \\
\hline dalt_com & -31.24 & & -115.25 & 40.39 \\
\hline dalt_stat & 551.36 & & -200.98 & $1,514.28$ \\
\hline dalt_trans & -953.11 & $*$ & $-2,222.23$ & 25.99 \\
\hline \multicolumn{5}{|c|}{ Interaction regressors } \\
\hline trrev_x_qual & 18.03 & & -13.82 & 55.70 \\
\hline trrev_x_debt & -7.62 & & -41.76 & 23.84 \\
\hline cred_x_qual & 39.51 & & $-2,007.59$ & $2,146.49$ \\
\hline cred_x_debt & $-1,475.85$ & & $3,992.40$ & 510.05 \\
\hline supp_x_qual & -18.38 & & -46.99 & 4.15 \\
\hline $\operatorname{supp}_{-} x \_$debt & 5.23 & & -16.11 & 28.13 \\
\hline com_x_qual & -148.05 & $*$ & -356.51 & 7.32 \\
\hline com_x_debt & -42.83 & & -221.74 & 126.85 \\
\hline stat_x_qual & $-2,866.18$ & $* * *$ & $-5,620.40$ & $-1,106.14$ \\
\hline stat_ $x$ _debt & 41.19 & & $-1,757.88$ & $1,860.62$ \\
\hline trans_ $x$ _qual & $1,525.72$ & & -473.64 & $4,118.37$ \\
\hline trans_ $x$ _debt & 497.85 & & $-1,622.50$ & $2,812.17$ \\
\hline
\end{tabular}

Source: Own production (Appendix 4. 18), with Confidence Interval 95\%

Note: ${ }^{\text {a) }} * * * \mathrm{p}<0.01,{ }^{* *} \mathrm{p}<0.05,{ }^{*} \mathrm{p}<0.1$

As the second part of the WTC result, from the socio-demographic characteristic perspective, we observe a positive WTC for the "number of suppliers" regressor as well as

\footnotetext{
${ }^{28}$ Based on interview with one of the rubber factories in Jambi.

${ }^{29}$ Based on interview with rubber traders in Jambi.
} 
negative WTC for the "trader revenue", "credit provision", and "transmigrant status" regressors. The average buyer respondent is willing to increase his/her price reduction by $12.42 \mathrm{IDR} / \mathrm{kg}$ for an increase of one unit of suppliers, ceteris paribus, which is $0.16 \%$ of the assumed price. A plausible reason for this phenomenon is that traders with more suppliers feel less at risk of supply shortages resulting from increasing price reduction.

The average buyer respondent is willing to reduce his price reduction by 13.64 IDR $/ \mathrm{kg}$ for an increase of a million-trading revenue, ceteris paribus, which is $0.17 \%$ of the assumed price. With higher trading revenue, the trader can loosen his desire to take advantage of price reduction, which makes perfect sense. Further, a buyer respondent with credit provision has his WTC unexpectedly decrease by 1,250.49 IDR/kg, ceteris paribus, which is $15.63 \%$ from the assumed price. This means that traders providing credit offer higher prices for their rubber than traders providing no credit. The plausible reason is that they would like to provide credit to maintain supply continuity from farmers. That is also one of the factors influencing the trader to remain in the market, based on the previous chapter. Meanwhile, transmigrant trader's WTC decreases by $953.11 \mathrm{IDR} / \mathrm{kg}$, which is $11.91 \%$ of the assumed price, ceteris paribus. We found that transmigrant traders purchase more rubber than non-transmigrant traders in term of quantity (Appendix 4. 20). This can explain that the transmigrant traders may focus more in purchasing rubber rather than pursuing higher margin gained from price reduction.

At last, there are two interaction regressors providing significant effects on the respondent's utility. An initial interpretation for this is that having one additional competitor leads to a respondent's WTC for quality decreasing by $148.05 \mathrm{IDR} / \mathrm{kg}$, which is $1.85 \%$ of the assumed price. A trader with more competitors seeks to achieve higher quality by reducing price reduction, to attract suppliers selling their better-quality rubber to them instead of their competitors. Secondly, a larger trader's WTC decreases by $2,866.18$ IDR/kg for good quality, which is $35.83 \%$ of the assumed price, ceteris paribus. The plausible reason is that they may be more efficient in trading activity than the village traders and thus are able to give more incentive to suppliers selling high quality rubber. 


\subsection{Conclusion}

The Discrete Choice Experiment (DCE) method has successfully helped us to answer the research questions of this study. We found that a mixed logit model, which considers heterogeneity of the random parameters, provides the best fitted model with the highest value of log-likelihood and the lowest value of AIC.

There are significant results showing that price reduction, rubber quality and farmer's debt influence traders' preference in buying rubber, where increased price reduction, higher rubber quality, and lower farmer's debt will increase the trader's utility. Some interaction variables between those main attributes and some respondents' sociodemographic characteristics also influence the traders' preference. These include the interaction between number of competitors and rubber quality, and whether a trader is a larger trader or village trader and rubber quality. Afterwards, we employ a WTP measurement approach and find a WTC by traders for all significant regressors. An increase in quality from bad to good is associated with a $29.97 \%$ price reduction from the assumed price. Further, an increase in farmer's debt of 1 million IDR is followed by an increase in $34.71 \%$ price reduction off of the assumed price. 
Chapter 5

General Conclusion 
Based on results of all chapters regarding the initial research objectives, we can conclude that there are effects of an importing country trade policy to price in a targeted exporting country, which in this case the EU AD duty affects the Indonesian CPO and local Jambi FFB price. Also, we found that there are factors affecting OPFFB and rubber local traders to remain in or exit the market. Those are human capital, trading structure, structural environment, and socioeconomic factors. Lastly, we found that rubber farmer's debt influences the rubber traders' preference in buying rubber. The summary of each chapter's conclusion is presented as follows.

The first paper explains that the imposition of the EU biodiesel AD generated a SB in the cointegration estimation between Indonesian and world CPO prices, and between Jambi FFB and Indonesian CPO prices. This could indicate that the duty had an effect on the price after the breakpoint. Results show that the duty negatively affected the Indonesian CPO and local Jambi FFB price, whereas the world CPO market gained more power after the duty implementation. Decreases in Indonesian CPO demand due to decreased demand for imported biodiesel by the EU lead to a price reduction caused by a shifting of demand.

From the second paper we could summarize that many traders leave their activities due to falling oil palm and rubber prices in the period of study. This price fluctuation raise uncertainty to traders to remain in the market. In light of this evidence, it is clear that human capital, trading structure, structural environment, and socioeconomic factors affect the decision of traders in remaining in or exiting the market. It is also interesting that some variables are only significant in particular period but not significant in the other, due to different situation and behavior, formed over time.

Lastly, the third paper concludes that there are significant results showing that price reduction, rubber quality and farmer's debt influence traders' preference in buying rubber, where increased price reduction, higher rubber quality, and lower farmer's debt will increase the trader's utility. Some interaction variables between those main attributes and some respondents' socio-demographic characteristics also influence the traders' preference. These include the interaction between number of competitors and rubber quality, and whether a trader is a larger trader or village trader and rubber quality. Afterwards, we employ a WTP measurement approach and find a WTC by traders for all significant regressors. An increase in quality from bad to good is associated with a decrease of $29.97 \%$ price reduction of the assumed price. Further, an increase of farmer's debt by 1 million IDR, is followed by an increase in $34.71 \%$ price reduction of the assumed price. 


\section{Bibliography}

Abd, A., Nambiappan, B., Palm, M., \& Board, O. (2013). Impact of Palm Oil Supply and Demand on Palm Oil Price Behaviour. Oil Palm Industry Economic Journal, 13(1). Retrieved from https://www.researchgate.net/publication/324561688_Impact_of_Palm_Oil_Supply_a nd_Demand_on_Palm_Oil_Price_Behaviour

Aidenvironment. (2016). Low Prices Drive Natural Rubber Producers into Poverty. Retrieved from http://www.aidenvironment.org/wp-content/uploads/2016/10/Rubberstudy-FRA.pdf

Andarani, P., Nugraha, W. D., \& Wieddya. (2017). Energy balances and greenhouse gas emissions of crude palm oil production system in Indonesia (Case study: Mill P, PT X, $\begin{array}{llll}\text { Sumatera Island). AIP Conference } & \text { Proceedings, } 1823 .\end{array}$ https://doi.org/10.1063/1.4978137

Asante-Addo, C., \& Weible, D. (2019). Is there hope for domestically produced poultry meat? A choice experiment of consumers in Ghana. Agribusiness, (July). https://doi.org/10.1002/agr.21626

Asche, F. (2001). Testing the effect of an anti-dumping duty: The US salmon market. Empirical Economics, 26(2), 343-355. https://doi.org/10.1007/s001810000043

Asteriou, D., \& Hall, S. G. (2016). Applied Econometrics (3rd Ed). London: Macmillan Publishers Ltd.

Avşar, V. (2013). Trade Effects of Turkey's Antidumping Duties. XXXII(1), 1-10.

Bennett, J., \& Birol, E. (2010). The roles and significance of choice experiments in developing country contexts. In J. Bennett \& E. Birol (Eds.), Choice Experiments in Developing Countries (pp. 1-13). Cheltenham: Edward Elgar Publishing Limited.

Benos, A. V. (1998). Aggressiveness and survival of overconfident traders. International Social Work, 353-383. https://doi.org/10.1177/002087288602900206

Blair, G., Imai, K., \& Zhou, Y. Y. (2015). Design and Analysis of the Randomized Response Technique. Journal of the American Statistical Association, 110(511), 1304-1319. https://doi.org/10.1080/01621459.2015.1050028

Bou Dib, J., Krishna, V. V., Alamsyah, Z., \& Qaim, M. (2018). Land-use change and livelihoods of non-farm households: The role of income from employment in oil palm and rubber in rural Indonesia. Land Use Policy, 76(March), 828-838. https://doi.org/10.1016/j.landusepol.2018.03.020

Bourguignon, D. (2015). Briefing EU biofuels policy. In European Parliamentary Research Service.

BPS-Statistics of Jambi Province. (2018). Jambi Province in Figures 2018. Jambi: BPSStatistics of Jambi Province.

Bragg, L. A., \& Dalton, T. J. (2004). Factors affecting the decision to exit dairy farming: A two-stage regression analysis. Journal of Dairy Science, 87(9), 3092-3098. https://doi.org/10.3168/jds.S0022-0302(04)73444-X

Brambilla, I., Porto, G., \& Tarozzi, A. (2012). Adjusting to Trade Policy: Evidence from 
U.S. Antidumping Duties on Vietnamese Catfish. The Review of Economics and Statistics, 94(1), 304-319.

Breustedt, G., \& Glauben, T. (2007). Driving forces behind exiting from farming in Western Europe. Journal of Agricultural Economics, 58(1), 115-127. https://doi.org/10.1111/j.1477-9552.2007.00082.x

Cameron, A. C., \& Trivedi, P. K. (2005). Microeconometrics, Methods and Applications. Cambridge: Cambridge University Press.

Cameron, A. C., \& Trivedi, P. K. (2010). Microeconometrics Using Stata (Revised). Texas: Stata Press.

Carranza, M., \& Niles, M. T. (2019). Smallholder Farmers Spend Credit Primarily on Food: Gender Differences and Food Security Implications in a Changing Climate. Frontiers in Sustainable Food Systems, 3(July). https://doi.org/10.3389/fsufs.2019.00056

Chandra, P., \& Long, C. (2013). Anti-dumping Duties and their Impact on Exporters: Firm Level Evidence from China. World Development, 51, 169-186. https://doi.org/10.1016/j.worlddev.2013.05.018

Cheong, D. (2007). The impact of Antidumping on EU Trade. Retrieved from http://citeseerx.ist.psu.edu/viewdoc/summary?doi=10.1.1.575.3592

Corzine, M. N. (2008). An Analysis of Import Tariff Escalation: A Case of Maize Trade between Sout Africa and Mozambique (Michigan State University). https://doi.org/10.1017/CBO9781107415324.004

Coughlan, A. T., Anderson, E., Stern, L. W., \& El-Ansary, A. I. (2006). Marketing Channel (7th ed.). New Jersey: Pearson Prentice Hall.

Croezen, H. J., Bergsma, G. C., Otten, M. B. J., \& van Valkengoed, M. P. J. (2010). Biofuels: Indirect land use change and climate impact. Retrieved from https://www.ce.nl/publicaties/download/944

Croux, C., \& Dehon, C. (2010). Influence functions of the Spearman and Kendall correlation measures. Statistical Methods and Applications, 19(4), 497-515. https://doi.org/10.1007/s10260-010-0142-z

Cuyvers, L., \& Dumont, M. (2005). EU anti-dumping measures against ASEAN countries: Impact on trade flows. Asian Economic Journal, 19(3), 249-271. https://doi.org/10.1111/j.1467-8381.2005.00212.x

Directorate General of Customs and Excise. (2015, September). Export Tariff and Levy for CPO and Its Derivative Products (in Indonesian). Warta Bea Cukai (Customs News), Directorate General of Customs and Excise of the Republic of Indonesia, 47(9), 1-64.

Directorate General of Estate Crops. (2015). Tree Crop Estate Statistics Of Indonesia 20132015 Palm Oil (Y. Soependi \& Y. Arianto, Eds.). Retrieved from http://ditjenbun.pertanian.go.id

Directorate General of Estate Crops. (2016a). Tree Crop Estate Statistics Of Indonesia 20152017 Palm Oil (D. Hendaryati \& Y. Arianto, Eds.). Retrieved from http://ditjenbun.pertanian.go.id

Directorate General of Estate Crops. (2016b). Tree Crop Estate Statistics of Indonesia 20152017 Rubber (D. Hendaryati \& Y. Arianto, Eds.). Retrieved from 
http://ditjenbun.pertanian.go.id

Directorate General of Estate Crops. (2017a). Tree Crop Estate Statistics Of Indonesia 20162018 Palm Oil (D. Hendaryati \& Y. Arianto, Eds.). Retrieved from http://ditjenbun.pertanian.go.id

Directorate General of Estate Crops. (2017b). Tree Crop Estate Statistics of Indonesia 20162018 Rubber (D. Hendaryati \& Y. Arianto, Eds.). Retrieved from http://ditjenbun.pertanian.go.id

Directorate General of Estate Crops. (2018). Tree Crop Estate Statistics of Indonesia 20172019 Rubber (D. Hendaryati \& Y. Arianto, Eds.). Retrieved from http://ditjenbun.pertanian.go.id

Elamin, N., \& Khaira, H. (2003). Tariff Escalation in Agricultural Commodity Markets. In Commodity Market Review 2003-2004. Retrieved from http://www.fao.org/3/ay5117e.pdf\#page $=107$

Elshiewy, O., Guhl, D., \& Boztug, Y. (2017). Multinomial Logit Models in Marketing From Fundamentals to State-of-the-Art. Marketing ZFP, 39(3), 32-49. https://doi.org/10.15358/0344-1369-2017-3-32

Estate Crops Office. (2019). Oil Palm Fresh Fruit Bunch Price Data - requested data.

European Commission. Directive 2003/30/EC pf the European Parliament and of the Council. , Pub. L. No. 2003/30/EC, Official Journal of the European Union 42 (2003).

European Commission. Procedures Relating to the Implementation of the Common Commercial Policy. , Pub. L. No. 2012/C 260/04, 8 (2012).

European Commission. Council Implementing Regulation (EU) No 1194/2013. , Pub. L. No. 1194/2013, 2 (2013).

European Commission. (2013b). EU to impose definitive anti-dumping duties on biodiesel from Argentina and Indonesia. Retrieved from http://europa.eu/rapid/press-release_IP13-1140_en.htm

European Commission. Directive (EU) 2018/2001 of the European Parliament and of the Council. , Pub. L. No. 2018/2001, Official Journal of the European Union 82 (2018).

European Commission. Commssion Delegated Regulation (EU) 2019/807. , Pub. L. No. 2019/807, L133 Official Journal of the European Union 1 (2019).

European Union External Action. (2018). EU Anti-Dumping Duties on Biodiesel from Indonesia. https://eeas.europa.eu/sites/eeas/files/20180323_biodiesel_fact_sheet_en_1.pdf

Faust, H., Schwarze, S., Beckert, B., Brümmer, B., Dittrich, C., Euler, M., ... Wollni, M. (2013). Assessment of socio-economic functions of tropical lowland transformation systems in Indonesia - sampling framework and methodological approach. Göttingen.

Feenstra, R. C., \& Taylor, A. C. (2014). International Trade (3rd Ed). Ney York: Worth Publishers.

Ferjani, A., Zimmermann, A., \& Roesch, A. (2015). Determining factors of farm exit in agriculture in Switzerland. Agricultural Economics Review, 16(1), 59-72. 
Flach, B., Lieberz, S., Lappin, J., \& Bolla, S. (2018). EU Biofuels Annual 2018. The Hague.

Flach, B., Lieberz, S., Rondon, M., Williams, B., \& Wilson, C. (2016). EU Biofuels Annual 2016. Retrieved from http://gain.fas.usda.gov/Recent GAIN Publications/Biofuels Annual_Buenos Aires_Argentina_7-6-2012.pdf

Gao, Z., \& Schroeder, T. C. (2009). Effects of label information on consumer willingnessto-pay for food attributes. American Journal of Agricultural Economics, 91(3), 795809. https://doi.org/10.1111/j.1467-8276.2009.01259.x

Greenberg, B. G., Abul-Ela, A.-L. A., Simmons, W. R., \& Horvitz, D. G. (1969). The Unrelated Question Randomized Response Model: Theoretical Framework. 64(326), 520-539.

Greene, W. H. (2012). Econometric Analysis (7th ed.). Boston: Pearson Education Limited.

Gregory, A. W., \& Hansen, B. E. (1996). Residual-based tests for cointegration with regime shifts in models with regime shifts. Journal of Econometrics, 70, 99-126. Retrieved from file:///C:/Users/ellasujarwo/Downloads/1-s2.0-0304407669416857-main (1).pdf

Guirkinger, C. (2008). Understanding the Coexistence of Formal and Informal Credit Markets in Piura, Peru. World Development, 36(8), 1436-1452. https://doi.org/10.1016/j.worlddev.2007.07.002

Hasselbach, J. L., \& Roosen, J. (2015). Consumer Heterogeneity in the Willingness to Pay for Local and Organic Food. Journal of Food Products Marketing, 21(6), 608-625. https://doi.org/10.1080/10454446.2014.885866

Hemmert, G. A. J., Schons, L. M., Wieseke, J., \& Schimmelpfennig, H. (2018). Loglikelihood-based Pseudo-R2 in Logistic Regression: Deriving Sample-sensitive Benchmarks. Sociological Methods and Research, 47(3), 507-531. https://doi.org/10.1177/0049124116638107

Hensher, D. A., Rose, J. M., \& Greene, W. H. (2005). Applied Choice Analysis A Primer (1st ed.). Cambridge: Cambridge University Press.

Hole, A. R. (2007a). A Comparison of Approaches to Estimating Confidence Intervals for Willingness to Pay Measures. Health Economics, 16, 827-840. https://doi.org/10.1002/hec

Hole, A. R. (2007b). Fitting mixed logit models by using maximum simulated likelihood. Stata Journal, 7(3), 388-401. https://doi.org/10.1177/1536867x0700700306

Jabbour, L., Tao, Z., Vanino, E., \& Zhang, Y. (2009). The good, the bad and the ugly: Chinese import, EU anti-dumping measurs and firm performance. Research Paper Series. Globalisation, Productivity and Technology.

Jegede, A. (2019). Top 10 Largest Farmers Producing Countries in the World. Retrieved February 27, 2020, from The Daily Records website: http://www.thedailyrecords.com/2018-2019-2020-2021/world-famous-top-10list/world/largest-rubber-producing-countries-world-10-top/6857/

Johansen, S. (1988). Statistical analysis of cointegration vectors. Journal of Economic Dynamics and Control, 12, 231-254. https://doi.org/10.1016/0165-1889(88)90041-3

Kerin, R. A., Hartley, S. W., \& Rudelius, W. (2013). Marketing (11th ed.). USA: McGrawHill Irwin. 
Kimhi, A., \& Bollman, R. (1999). Family farm dynamics in Canada and Israel: The case of farm exits. Agricultural Economics, 21(1), 69-79. https://doi.org/10.1016/S01695150(99)00015-8

Kogan, L., Ross, S. A., \& Westerfield, M. M. (2006). The Price Impact and Survival of Irrational Traders. The Journal of Finance, LXI(1), 1-35. Retrieved from https://onlinelibrary.wiley.com/doi/epdf/10.1111/j.1540-6261.2006.00834.x

Konings, J., \& Vandenbussche, H. (2013). Antidumping protection hurts exporters: Firmlevel evidence. Review of World Economics, 149(2), 295-320. https://doi.org/10.1007/s10290-013-0151-8

Kopp, T., Alamsyah, Z., Fatricia, R. S., \& Brümmer, B. (2014). Have Indonesian Rubber Processors Formed a Cartel? Analysis of Intertemporal Marketing Margin Manipulation (No. EFForTS Discussion Paper Series, No. 3). Retrieved from https://econpapers.repec.org/paper/zbwcrc990/3.htm

Kopp, T., \& Brümmer, B. (2017). Traders' market power along Indonesian rubber value chains. China Agricultural Economic Review, 9(2), 169-187. https://doi.org/10.1108/CAER-07-2015-0080

Lancaster, K. (1966). A New Approach to Consumer Theory. 74(2), 132-157.

Leinbach, T. R., \& Smith, A. (1994). Off-Farm Employment, Land, and Life Cycle: Transmigrant Households in South Sumatra , Indonesia. Economic Geography, 70(3), 273-296.

Lindsey, B., \& Ikenson, D. J. (2003). Antidumping Exposed: the devilish details of unfair trade law. Washington D.C.: The Cato Institute.

Louviere, J. J., \& Hensher, D. A. (1982). Design and Analysis of Simulated Choice or Allocation Experiments in Travel Choice Modelling. In Attitudes, Perceptions, and Constraints on Travel (pp. 11-17). Washington, D.C.: National Academy of Sciences.

Louviere, J. J., \& Woodworth, G. (1983). Design and Analysis of Simulated Consumer Choice Experiments or Allocation Experiments: An Approach Based on Aggregate Data. Journal of Marketing Research, 20, 350-367.

Lu, Y., Tao, Z., \& Zhang, Y. (2013). How do exporters respond to antidumping investigations? Journal of International Economics, 91, 290-300. https://doi.org/10.1016/j.jinteco.2013.08.005

Mann, H. B., \& Whitney, D. R. (1947). On a Test of Whether one of Two Random Variables is Stochastically Larger than the Other. The Annals of Mathematical Statistics, 18(1), $50-60$.

Manski, C. F. (1977). The Structure of Random Ultility Models. ProQuest, 8(3), 229. Retrieved from https://search.proquest.com/docview/1303217712/fulltextPDF/D4F85BFF40AE403A $\mathrm{PQ} / 1$ ?accountid=11144

Mas-Colell, A., Whinston, M. D., \& Green, J. R. (1995). Microeconomic Theory. New York: Oxford University Press, Inc.

Matsuda, H., \& Takeuchi, K. (2018). Biofuels and Approach to Biofuel Issues from the Perspective of Sustainability Science Studies. In K. Takeuchi, H. Shiroyama, O. Saito, 
\& M. Matsuura (Eds.), Biofuels and Sustainability (pp. 11-15). Japan: Springer Open.

McFadden, D. (1973). Conditional logit analysis of quality choice behaviour. In P. Zarembka (Ed.), Frontiers in Econometrics (pp. 105-142). https://doi.org/10.1080/07373937.2014.997882

Mills, J. A., \& Prasad, K. (1992). A comparison of model selection criteria. Econometric Reviews, 11(2), 201-234. https://doi.org/10.1080/07474939208800232

Minister of Finance of the Republic of Indonesia. Regulation of the Minister of Finance concerning the Stipulation of Export Goods subject to Export Duties and Export Duty Tariff. , Pub. L. No. 128 / PMK.011 / 2011 (2011).

Minister of Finance of the Republic of Indonesia. Regulation of the Minister of Finance concerning the Stipulation of Export Goods subject to Export Duties and Export Duty Tariff. , Pub. L. No. 136 / PMK.010 / 2011 (2015).

Minister of Finance of the Republic of Indonesia. Regulation of the Minister of Finance of the Republic of Indonesia concerning Service Tariff of the General Service Board, the Oil Palm Plantation Fund Management Board in the Ministry of Finance (in Indonesian). , Pub. L. No. 133/PMK.05/2015 (2015).

Minister of Trade of the Republic of Indonesia. (2019). Regulation of the Minister of Trade of the Republic of Indonesia concerning the Designation on Export Standard Price of Exported Goods Charged with Export Duty in 2009-2018 (in Indonesian). Retrieved November 25, 2019, from Documentation Network and Legal Information website: http://jdih.kemendag.go.id/peraturan

Ministry of Finance of the Republic of Indonesia. (2019). Decree of the Minister of Finance of the Republic of Indonesia concerning the Designation on Export Standard Price for Export Duty Determination of Agricultural and Forestry Products in 2009-2018 (in Indonesian). Retrieved November 25, 2019, from Documentation Network and Legal Information website: https://jdih.kemenkeu.go.id/\#/

Nag, A., Jha, S. K., Mohammad, A., Maiti, S., Gupta, J., Gosain, D. K., ... Mohanty, T. K. (2018). Predictive factors affecting Indian rural farm youths' decisions to stay in or leave agriculture sector. Journal of Agricultural Science and Technology, 20(2), 221234.

Nogués, J. (2011). Agricultural Export Barriers and Domestic Prices: Argentina during the last Decade. (June), 1-49. Retrieved from http://www.ucema.edu.ar/conferencias/download/2012/06.15AN.pdf

Oni, O. A., Oladele, O. I., \& Oyewole, I. K. (2005). Analysis of Factors Influencing Loan Default Among Poultry Farmers in Ogun State Nigeria. Journal of Central European Agriculture, 6(4), 619-624. https://doi.org/10.5513/jcea.v6i4.344

Patterson, K. (2000). An Introduction to Applied Econometrics: a time series approach. London: Macmillan Press Ltd.

Pierce, J. R. (2011). Plant-level responses to antidumping duties: Evidence from U.S. manufacturers. Journal of International Economics, 85(2), 222-233. https://doi.org/10.1016/j.jinteco.2011.07.006

Reed, R. R. (2001). International Trade in Agricultural Products (1st ed.). New Jersey: Prentice Hall. 
Rigby, D., \& Burton, M. (2005). Preference heterogeneity and GM food in the UK. European Review of Agricultural Economics, 32(2), 269-288. https://doi.org/10.1093/eurrag/jbi009

Royston, P. (1992). Approximating the Shapiro-Wilk W-test for non-normality. Statistics and Computing, 2(3), 117-119. https://doi.org/10.1007/BF01891203

Sheehan, J., Camobreco, V., Duffield, J., Graboski, M., \& Shapori, H. (1998). An Overview of Biodiesel and Petroleum Diesel Life Cycles. Retrieved from https://www.nrel.gov/docs/legosti/fy98/24772.pdf

Smith, P. L. (2018). Biodiesel From Argentina and Indonesia: Antidumping Duty Orders. Federal Register, 83(81), 18278-18279. https://doi.org/10.1016/0196-335x(80)900588

Spearman, C. (1904). The Proof and Measurement of Association between Two Things. The American Journal of Psychology, 15(1), 72-101. https://doi.org/10.1037/h0065390

Statistics Indonesia. (2018). Export Dataset - purchased data.

Statistics Indonesia. (2019). Indonesian Gross Domestic Product according to Business Sector, 2014-2019. Retrieved from https://www.bps.go.id/dynamictable/2015/05/06/826/-seri-2010-pdb-triwulanan-atasdasar-harga-berlaku-menurut-lapangan-usaha-miliar-rupiah-2014-2019.html

Statistics Jambi Province. (2019). The status of employment in Jambi province in August 2019. Jambi.

Stiglbauer, A., \& Weiss, C. R. (2000). Family and Non-Family Succession in the UpperAustrian Farm Sector Family and Non-Family Succession. Cahiers d'Economie et de Sociologie Rurales, 54, 6-26.

Thomson Reuters. (2019a). Palm Oil, ID CPO Free on Board United States Dollar per Metric Tonne - Datastream.

Thomson Reuters. (2019b). Palm Oil Crude MAL Cost Insurance Freight Rotterdam United States Dollar per Metric Tonne - Datastream.

Thomson Reuters. (2019c). Rubber, Indonesia Origin Technically Specified Rubber Grade 20 New York UC/Pound - Datastream.

Tiseo, I. (2019). Biofuels consumption for transport in the European Union (EU-28) 20152018. Retrieved November 13, 2019, from https://www.statista.com/statistics/613238/biofuels-consumption-transport-eu/

Trade Map. (2019). List of importing markets for a product exported by Indonesia Biodiesel. Retrieved November 13, 2019, from https://www.trademap.org/Index.aspx

UCLA. (2020a). Lesson 3 Logistic Regression Diagnostics. Retrieved April 15, 2020, from Institute for Digital Research and Education, Statistical Consulting website: https://stats.idre.ucla.edu/stata/webbooks/logistic/chapter3/lesson-3-logisticregression-diagnostics-2/

UCLA. (2020b). What Statistical Analysis Should I Use? Statistical Analyses Using Stata. Retrieved April 15, 2020, from Institute for Digital Research and Education, Statistical Consulting website: https://stats.idre.ucla.edu/stata/whatstat/what-statistical-analysisshould-i-usestatistical-analyses-using-stata/ 
UFOP. (2017, September). EU-28 Biodiesel Imports Likely to Increase Significantly. Retrieved from Biodiesel Magazine website: http://biodieselmagazine.com/articles/2516142/eu-28-biodiesel-imports-likely-toincrease-significantly

UN Comtrade. (2019). List of importing markets for a product exported by Indonesia. Retrieved November 13, 2019, from https://comtrade.un.org/data/

Waheed, M., Alam, T., \& Ghauri, S. P. (2007). Structural breaks and unit root : evidence from Pakistani macroeconomic time series. Retrieved from https://mpra.ub.unimuenchen.de/1797/1/mpra_paper_1797.pdf?origin=publication_detail

Warner, S. L. (1965). Randomized Response : A Survey Technique for Eliminating Evasive Answer Bias. Journal of the American Statistical Association, 60(309), 63-69.

Weiss, C. R. (1997). Do they come back again? The symmetry and reversibility of off-farm employment. European Review of Agricultural Economics, 24(1), 65-84. https://doi.org/10.1093/erae/24.1.65

Wilcoxon, F. (1947). Probability Tables for Individual Comparisons by Ranking Methods. Biometrics, 3(3), 119-122.

Wooldridge, J. M. (2013). Introductory Econometrics A Modern Approach (5th ed.). SouthWestern, Cengage Learning.

World Trade Organization. Article VI Anti-dumping and Countervailing Duties. , Pub. L. No. The General Agreement on Tariffs and Trade (GATT), 219 (1994).

World Trade Organization. (2018). European Union - Anti-Dumping Measures on Biodiesel from Indonesia. In WTO Report of the Panel. https://doi.org/10.1017/s1474745617000106

World Trade Organization. (2019). Anti-dumping Initiations: By Reporting Member 01/01/1995 - 31/12/2018. Retrieved from https://www.wto.org/english/tratop_e/adp_e/AD_InitiationsByRepMem.pdf

Zivot, E., \& Andrews, D. W. K. (1992). Further evidence on the great crash, the oil-price shock, and the unit-root hypothesis. Journal of Business and Economic Statistics, 10(3), 251-270. https://doi.org/10.1080/07350015.1992.10509904

Zúñiga-Arias, G. E. (2007). Quality management and strategic alliances in the mango supply chain from Costa Rica (Wageningen University). Retrieved from https://edepot.wur.nl/2476 


\section{Appendices}

Appendix 2. 1 Unit Root Tests

\begin{tabular}{|c|c|c|c|c|c|c|c|c|}
\hline \multirow{3}{*}{$\begin{array}{c}\text { Price } \\
\text { Variables }\end{array}$} & \multicolumn{2}{|c|}{ ADF test } & \multicolumn{2}{|c|}{ PP test } & \multicolumn{4}{|c|}{ ZA test } \\
\hline & \multirow{2}{*}{ Level } & \multirow{2}{*}{$1^{\text {st }}$ Diff } & \multirow{2}{*}{ Level } & \multirow{2}{*}{$1^{\text {st }}$ Diff } & \multicolumn{2}{|c|}{ Level } & \multicolumn{2}{|c|}{$1^{\text {st }}$ Diff } \\
\hline & & & & & Break & Min t-stat & Break & Min t-stat \\
\hline $\ln P_{W}$ & -0.910 & $-19.744 * * *$ & -0.812 & $-19.767 * * *$ & 21Jan 16 & -4.206 & 3Sep15 & $-20.145^{* * *}$ \\
\hline $\ln P_{I D}$ & -0.499 & $-16.992 * * *$ & -0.836 & $-17.090 * * *$ & 28Jan 16 & -4.051 & 3Sep15 & $-17.560 * * *$ \\
\hline $\ln P_{J B}$ & -0.201 & $-12.300 * * *$ & -1.195 & $-12.383^{* * *}$ & 4Feb16 & -3.574 & 10Sep 15 & $-9.339 * * *$ \\
\hline
\end{tabular}

Note: ADF dan PP (Z(t)) test Critical Values: 1\%: -3.450, 5\%: -2.875, 10\%: -2.570; ZA test Critical Values: 1\%: $-5.34,5 \%:-4.80,10 \%: 4.58$ via TTest

Appendix 2. 2 Johansen Cointegration Test between Indonesian and World CPO Prices

\begin{tabular}{|c|c|c|c|c|c|c|c|}
\hline \multirow{2}{*}{ Max Rank } & \multirow{2}{*}{ Eigenvalue } & \multirow{2}{*}{ Trace statistics } & \multicolumn{2}{|c|}{ Critical Values } & \multirow{2}{*}{ Max Statistics } & \multicolumn{2}{|c|}{ Critical Values } \\
\hline & & & $5 \%$ & $1 \%$ & & $5 \%$ & $1 \%$ \\
\hline 0 & $\cdot$ & 66.344 & 15.410 & 20.040 & 66.086 & 14.070 & 18.630 \\
\hline 1 & 0.163 & $0.258 * *$ & 3.760 & 6.65 & 0.258 & 3.760 & 6.650 \\
\hline 2 & 0.001 & & & & & & \\
\hline
\end{tabular}

Note: lags $=1$

Appendix 2. 3 Johansen Cointegration Test between Jambi FFB and Indonesian CPO Prices

\begin{tabular}{|c|c|c|c|c|c|c|c|}
\hline \multirow{2}{*}{ Max Rank } & \multirow{2}{*}{ Eigenvalue } & \multirow{2}{*}{ Trace statistics } & \multicolumn{2}{|c|}{ Critical Values } & \multirow{2}{*}{ Max Statistics } & \multicolumn{2}{|c|}{ Critical Values } \\
\hline & & & $5 \%$ & $1 \%$ & & $5 \%$ & $1 \%$ \\
\hline 0 & & 32.379 & 15.410 & 20.040 & 31.765 & 14.070 & 18.630 \\
\hline 1 & 0.082 & $0.614 * *$ & 3.760 & 6.65 & 0.614 & 3.760 & 6.650 \\
\hline 2 & 0.002 & & & & & & \\
\hline
\end{tabular}

Note: Lags $=1$ 
Appendix 2. 4 Gregory-Hansen Cointegration Test between Indonesian and World CPO Prices

\begin{tabular}{lrrrrr}
\hline \multicolumn{2}{c}{ GH Test } & \multirow{2}{*}{ Test Statistics } & \multirow{2}{*}{ Breakpoint } & \multicolumn{3}{c}{ Asymptotic Critical Value } \\
& & $1 \%$ & $5 \%$ & $10 \%$ \\
\hline \multicolumn{4}{l}{ Model: Change in Level (lags = 1, AIC \& BIC) } \\
ADF & $-7.57^{* * *}$ & Feb 20, 2014 & -5.13 & -4.61 & -4.34 \\
Zt & $-9.30^{* * *}$ & Jan 02, 2014 & -5.13 & -4.61 & -4.34 \\
Za & $-147.38^{* * *}$ & Jan 02, 2014 & -50.07 & -40.48 & -36.19 \\
Model: Change in Regime (lags = 1, AIC) & & & \\
ADF & $-7.94^{* * *}$ & Jan 16, 2014 & -5.47 & -4.95 & -4.68 \\
Zt & $-9.72^{* * *}$ & Dec 19, 1013 & -5.47 & -4.95 & -4.68 \\
Za & $-157.73^{* * *}$ & Dec 19, 1013 & -57.17 & -47.04 & -41.85 \\
\hline
\end{tabular}

Appendix 2. 5 Gregory-Hansen Cointegration Test between Jambi FFB and Indonesian CPO Prices

\begin{tabular}{|c|c|c|c|c|c|}
\hline \multirow{2}{*}{ GH Test } & \multirow{2}{*}{ Test Statistics } & \multirow{2}{*}{ Breakpoint } & \multicolumn{3}{|c|}{ Asymptotic Critical Value } \\
\hline & & & $1 \%$ & $5 \%$ & $10 \%$ \\
\hline \multicolumn{6}{|c|}{ Model: Change in Level (lags = 1, BIC) } \\
\hline $\mathrm{ADF}$ & $-5.93 * * *$ & Oct 21, 2013 & -5.13 & -4.61 & -4.34 \\
\hline $\mathrm{Zt}$ & $-6.56 * * *$ & Dec 19, 1013 & -5.13 & -4.61 & -4.34 \\
\hline $\mathrm{Za}$ & $-83.18 * * *$ & Dec 19, 1013 & -50.07 & -40.48 & -36.19 \\
\hline \multicolumn{6}{|c|}{ Model: Change in Regime (lags = 1, BIC) } \\
\hline $\mathrm{ADF}$ & $-6.51 * * *$ & Dec 26, 1013 & -5.47 & -4.95 & -4.68 \\
\hline $\mathrm{Zt}$ & $-7.30 * * *$ & Dec 19, 1013 & -5.47 & -4.95 & -4.68 \\
\hline $\mathrm{Za}$ & $-97.25 * * *$ & Dec 19, 1013 & -57.17 & -47.04 & -41.85 \\
\hline
\end{tabular}


Appendix 2. 6 Johansen Cointegration Test between Indonesian and World CPO Prices before the Breakpoint

\begin{tabular}{|c|c|c|c|c|c|c|c|}
\hline \multirow{2}{*}{ Max Rank } & \multirow{2}{*}{ Eigenvalue } & \multirow{2}{*}{ Trace statistics } & \multicolumn{2}{|c|}{ Critical Values } & \multirow{2}{*}{ Max Statistics } & \multicolumn{2}{|c|}{ Critical Values } \\
\hline & & & $5 \%$ & $1 \%$ & & $5 \%$ & $1 \%$ \\
\hline 0 & . & 66.697 & 15.410 & 20.040 & 66.214 & 14.070 & 18.630 \\
\hline 1 & 0.228 & $0.484 * *$ & 3.760 & 6.65 & 0.484 & 3.760 & 6.650 \\
\hline 2 & 0.002 & & & & & & \\
\hline
\end{tabular}

Note: lags $=1$

Appendix 2. 7 Johansen Cointegration Test between Indonesian and World CPO Prices after the Breakpoint

\begin{tabular}{|c|c|c|c|c|c|c|c|}
\hline \multirow{2}{*}{ Max Rank } & \multirow{2}{*}{ Eigenvalue } & \multirow{2}{*}{ Trace statistics } & \multicolumn{2}{|c|}{ Critical Values } & \multirow{2}{*}{ Max Statistics } & \multicolumn{2}{|c|}{ Critical Values } \\
\hline & & & $5 \%$ & $1 \%$ & & $5 \%$ & $1 \%$ \\
\hline 0 & . & 31.456 & 15.410 & 20.040 & 30.205 & 14.070 & 18.630 \\
\hline 1 & 0.146 & $1.251 * *$ & 3.760 & 6.65 & 1.251 & 3.760 & 6.650 \\
\hline 2 & 0.005 & & & & & & \\
\hline
\end{tabular}

Note: lags $=1$

Appendix 2. 8 Johansen Cointegration Test between Jambi FFB and Indonesian CPO Prices before the Breakpoint

\begin{tabular}{|c|c|c|c|c|c|c|c|}
\hline \multirow{2}{*}{ Max Rank } & \multirow{2}{*}{ Eigenvalue } & \multirow{2}{*}{ Trace statistics } & \multicolumn{2}{|c|}{ Critical Values } & \multirow{2}{*}{ Max Statistics } & \multicolumn{2}{|c|}{ Critical Values } \\
\hline & & & $5 \%$ & $1 \%$ & & $5 \%$ & $1 \%$ \\
\hline 0 & $\cdot$ & 75.732 & 15.410 & 20.040 & 74.730 & 14.070 & 18.630 \\
\hline 1 & 0.082 & $1.002 * *$ & 3.760 & 6.65 & 1.002 & 3.760 & 6.650 \\
\hline 2 & 0.002 & & & & & & \\
\hline
\end{tabular}

Note: Lags $=1$

Appendix 2. 9 Johansen Cointegration Test between Jambi FFB and Indonesian CPO Prices after the Breakpoint

\begin{tabular}{|c|c|c|c|c|c|c|c|}
\hline \multirow{2}{*}{ Max Rank } & \multirow{2}{*}{ Eigenvalue } & \multirow{2}{*}{ Trace statistics } & \multicolumn{2}{|c|}{ Critical Values } & \multirow{2}{*}{ Max Statistics } & \multicolumn{2}{|c|}{ Critical Values } \\
\hline & & & $5 \%$ & $1 \%$ & & $5 \%$ & $1 \%$ \\
\hline 0 & $\cdot$ & $17.954 *$ & 15.410 & 20.040 & 16.940 & 14.070 & 18.630 \\
\hline 1 & 0.082 & $1.015^{* *}$ & 3.760 & 6.65 & 1.015 & 3.760 & 6.650 \\
\hline 2 & 0.002 & & & & & & \\
\hline
\end{tabular}

Note: Lags $=1$ 


\section{Appendix 2. 10. VECM Estimation between Indonesian and World CPO Prices}

VECM system, lag order 2

Maximum likelihood estimates, observations 2011-11-02-2018-12-05 ( $\mathrm{T}=371$ )

Cointegration rank $=1$

Case 2: Restricted constant

beta (cointegrating vectors, standard errors in parentheses)

$\begin{array}{ll}\text { lnP_ID } & 1.0000 \\ & (0.00000) \\ \text { lnP_W } & -1.0179 \\ & (0.019549) \\ \text { const } & 0.058648 \\ & (0.0066206)\end{array}$

alpha (adjustment vectors)

lnP_ID $\quad-0.062430$

$\ln \mathrm{P}$ W $\quad 0.18768$

Log-likelihood $=1768.6987$

Determinant of covariance matrix $=2.4783124 \mathrm{e}-007$

$\mathrm{AIC}=-9.4916$

$\mathrm{BIC}=-9.4072$

$\mathrm{HQC}=-9.4581$

Equation 1: d_lnP_ID

$\begin{array}{lcccc} & 0.0678890 & 0.0877177 & 0.7739 & 0.4395 \\ \text { d_lnP_ID_1 } & 0.0682527 & 0.0789647 & 0.8643 & 0.3880 \\ \text { d_lnP_W_1 } & -0.0624297 & 0.0611156 & -1.022 & 0.3077 \\ \text { EC1 } & & \end{array}$

Mean dependent var

Sum squared resid

R-squared

rho

d_lnP_ID_1

EC1

Mean dependent var

Sum squared resid

R-squared

rho

$\begin{array}{rlr}-0.002030 & \text { S.D. dependent var } & 0.027859 \\ 0.281688 & \text { S.E. of regression } & 0.027705 \\ 0.024262 & \text { Adjusted R-squared } & 0.016286 \\ -0.007055 & \text { Durbin-Watson } & 2.010929\end{array}$

Equation 2: d_lnP_W

$\begin{array}{ccccl}\text { Coefficient } & \text { Std. Error } & \text { t-ratio } & p \text {-value } & \\ 0.230024 & 0.0995170 & 2.311 & 0.0214 & * * \\ -0.150547 & 0.0895866 & -1.680 & 0.0937 & * \\ 0.187677 & 0.0693365 & 2.707 & 0.0071 & * * *\end{array}$

$-0.001994 \quad$ S.D. dependent var

0.032059

0.362567

S.E. of regression

0.031431

0.050246

Adjusted R-squared

0.042482

$-0.013784$

Durbin-Watson

2.019377

Cross-equation covariance matrix:

\begin{tabular}{llr} 
& \multicolumn{1}{c}{ lnP_ID } & lnP_W \\
lnP_ID & 0.00075927 & 0.00070298 \\
lnP_W & 0.00070298 & 0.00097727
\end{tabular}

determinant $=2.47831 \mathrm{e}-007$ 
Appendix 2. 11 VECM Estimation between Indonesian and World CPO Prices allowing Structural Break

VECM system, lag order 2

Maximum likelihood estimates, observations 2011-11-02-2018-12-05 (T = 371)

Cointegration rank $=1$

Case 2: Restricted constant

beta (cointegrating vectors, standard errors in parentheses)

$\begin{array}{ll}\text { lnP_ID } & 1.0000 \\ & (0.00000) \\ \text { lnP_W } & -1.3667 \\ & (0.032649) \\ \text { const } & 0.045589 \\ & (0.0048494) \\ \text { SB } & 0.011194 \\ & (0.0090282) \\ \text { SBxlnP_W } & 0.36334 \\ & (0.036856)\end{array}$

alpha (adjustment vectors)

lnP_ID 0.23468

lnP_W 0.53378

Log-likelihood $=1811.8278$

Determinant of covariance matrix $=1.9641815 \mathrm{e}-007$

$\mathrm{AIC}=-9.7241$

$\mathrm{BIC}=-9.6397$

$\mathrm{HQC}=-9.6906$

Equation 1: d_lnP_ID

\begin{tabular}{|c|c|c|c|c|c|}
\hline & Coefficient & & t-ratio & p-value & \\
\hline d_lnP_ID_1 & -0.0947447 & 306 & -1.114 & 0.2662 & \\
\hline d_lnP_W_1 & 0.242923 & & 3.177 & 0.0016 & $* * *$ \\
\hline $\mathrm{EC} 1$ & 0.234683 & 388 & 4.728 & $<0.0001$ & $* * *$ \\
\hline Mean dependent var & -0.002030 & \multicolumn{2}{|c|}{ S.D. dependent var } & & 0.027859 \\
\hline Sum squared resid & 0.266230 & \multicolumn{2}{|c|}{ S.E. of regression } & & 0.026970 \\
\hline R-squared & 0.077807 & \multicolumn{2}{|c|}{ Adjusted R-squared } & & 0.067728 \\
\hline rho & 0.033346 & \multicolumn{2}{|c|}{ Durbin-Watson } & & 1.931993 \\
\hline
\end{tabular}

Equation 2: d_lnP_W

$\begin{array}{lcccc}\text { d_lnP_ID_1 } & 0.0203581 & 0.0881360 & 0.2310 & 0.8175 \\ \text { d_lnP_W_1 } & 0.0746029 & 0.0792143 & 0.9418 & 0.3469 \\ \text { EC1 } & 0.533776 & 0.0514214 & 10.38 & <0.0001\end{array}$

Mean dependent var

Sum squared resid

R-squared

rho

$\begin{array}{rlr}-0.001994 & \text { S.D. dependent var } & 0.032059 \\ 0.285694 & \text { S.E. of regression } & 0.027939 \\ 0.251615 & \text { Adjusted R-squared } & 0.243436 \\ 0.131929 & \text { Durbin-Watson } & 1.730852\end{array}$

Cross-equation covariance matrix:

$$
\text { lnP_ID lnP_W }
$$

lnP_ID $0.00071760 \quad 0.00059681$

lnP_W $0.00059681 \quad 0.00077007$

determinant $=1.96418 \mathrm{e}-007$

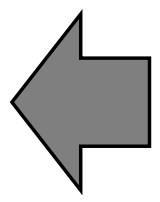

1.931993

1.730852 
Appendix 2. 12 VECM Estimation between Indonesian and World CPO Prices before the Breakpoint

VECM system, lag order 2

Maximum likelihood estimates, observations 2011-11-02-2014-01-01 $(\mathrm{T}=114)$

Cointegration rank $=1$

Case 2: Restricted constant

beta (cointegrating vectors, standard errors in parentheses)

$\begin{array}{ll}\text { lnP_ID } & 1.0000 \\ & (0.00000) \\ \text { lnP_W } & -1.1660 \\ & (0.029409) \\ \text { const } & 0.060600 \\ & (0.0041074)\end{array}$

alpha (adjustment vectors)

lnP_ID $\quad 0.082717$

$\ln \mathrm{P}$ W 0.39578

Log-likelihood $=583.80093$

Determinant of covariance matrix $=1.2216715 \mathrm{e}-007$

$\mathrm{AIC}=-10.1018$

$\mathrm{BIC}=-9.9098$

$\mathrm{HQC}=-10.0238$

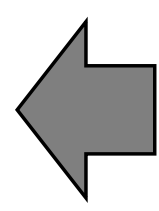

Equation 1: d_lnP_ID

$\begin{array}{lcccc} & \text { Coefficient } & \text { Std. Error } & \text { t-ratio } & p \text {-value } \\ \text { d_lnP_ID_1 } & -0.108847 & 0.218097 & -0.4991 & 0.6187 \\ \text { d_lnP_W_1 } & 0.161486 & 0.228673 & 0.7062 & 0.4816 \\ \text { EC1 } & 0.0827171 & 0.189608 & 0.4363 & 0.6635\end{array}$

Mean dependent var

Sum squared resid

R-squared

rho

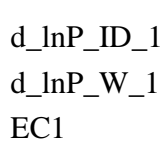

Mean dependent var

Sum squared resid

R-squared

rho$$
-0.001045
$$$$
\text { S.D. dependent var }
$$$$
0.096425
$$$$
\text { S.E. of regression }
$$

0.005509

Adjusted R-squared

0.004652

Durbin-Watson

\section{Equation 2: d_lnP_W}

$\begin{array}{cccc}\text { Coefficient } & \text { Std. Error } & \text { t-ratio } & p \text {-value } \\ 0.0724771 & 0.209683 & 0.3457 & 0.7303 \\ -0.0464685 & 0.219851 & -0.2114 & 0.8330 \\ 0.395777 & 0.182293 & 2.171 & 0.0321\end{array}$
0.029274
0.029607
$-0.021614$
1.982445

-0.001089
0.089128
0.058918
-0.006070

S.D. dependent var

0.028930

0.028465

0.033253

1.991635

Cross-equation covariance matrix:

$$
\begin{aligned}
& \text { lnP_ID } 0.00084583 \stackrel{\text { lnP_ID } 1 \text { lnP_W }}{0.00073425} \\
& \text { lnP_W } \quad 0.00073425 \quad 0.00078183
\end{aligned}
$$

determinant $=1.22167 \mathrm{e}-007$ 
Appendix 2. 13 VECM Estimation between Indonesian and World CPO Prices after the Breakpoint

VECM system, lag order 2

Maximum likelihood estimates, observations 2014-01-22-2018-12-05 ( $\mathrm{T}=255$ )

Cointegration rank $=1$

Case 2: Restricted constant

beta (cointegrating vectors, standard errors in parentheses)

$\begin{array}{ll}\text { P_ID } & 1.0000 \\ & (0.00000) \\ \text { P_W } & -0.99705 \\ & (0.021038) \\ \text { const } & 0.037280 \\ & (0.014820)\end{array}$

alpha (adjustment vectors)

P_ID $\quad-0.018372$

P_W 0.37791

Log-likelihood $=1415.2962$

Determinant of covariance matrix $=5.1787548 \mathrm{e}-008$

$\mathrm{AIC}=-11.0376$

$\mathrm{BIC}=-10.9265$

$\mathrm{HQC}=-10.9929$

Equation 1: d_P_ID

$\begin{array}{lcccr} & \text { Coefficient } & \text { Std. Error } & \text { t-ratio } & \text { p-value } \\ \text { d_P_ID_1 } & 0.0597548 & 0.0995838 & 0.6000 & 0.5490 \\ \text { d_P_W_1 } & 0.0996565 & 0.0817413 & 1.219 & 0.2239 \\ \text { EC1 } & -0.0183715 & 0.0769050 & -0.2389 & 0.8114\end{array}$

Mean dependent var

Sum squared resid

R-squared

rho

d_P_ID_1

d_P_W_1

EC1

Mean dependent var

Sum squared resid

R-squared

rho

$\begin{aligned}-0.001564 & \text { S.D. dependent var } \\ 0.075347 & \text { S.E. of regression } \\ 0.033224 & \text { Adjusted R-squared } \\ -0.006639 & \text { Durbin-Watson }\end{aligned}$

Equation 2: d_P_W

$\begin{array}{cccc}\text { Coefficient } & \text { Std. Error } & \text { t-ratio } & p \text {-value } \\ 0.160427 & 0.125197 & 1.281 & 0.2012 \\ -0.0170034 & 0.102765 & -0.1655 & 0.8687 \\ 0.377912 & 0.0966851 & 3.909 & 0.0001\end{array}$

$-0.001647$

S.D. dependent var

0.022589

0.119091

S.E. of regression

0.021782

0.086014

Adjusted R-squared

0.075090

$-0.004889$

Durbin-Watson

1.997934

Cross-equation covariance matrix:

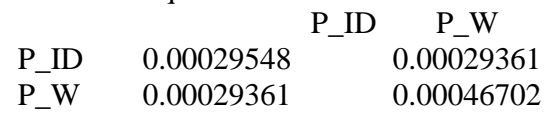

determinant $=5.17875 \mathrm{e}-008$ 
Appendix 2. 14 VECM Estimation between Jambi FFB and Indonesian CPO prices

VECM system, lag order 2

Maximum likelihood estimates, observations 2011-11-02-2018-12-05 $(\mathrm{T}=371)$

Cointegration rank $=1$

Case 2: Restricted constant

beta (cointegrating vectors, standard errors in parentheses)

$\begin{array}{ll}\text { lnP_JB } & 1.0000 \\ & (0.00000) \\ \text { lnP_ID } & -1.3558 \\ & (0.063101) \\ \text { const } & 1.4346 \\ & (0.032321) \\ \text { ET } & 1.7910 \\ & (0.22217) \\ \text { TL } & 0.022204 \\ & (0.016798)\end{array}$

alpha (adjustment vectors)

lnP_JB $\quad-0.15886$

lnP ID $\quad 0.020219$

d_lnP_JB_1

$\mathrm{EC} 1$

d_lnP_JB_1

d_lnP_ID_1

EC1

Mean dependent var

Sum squared resid

R-squared

rho
Log-likelihood $=1745.9297$

Determinant of covariance matrix $=2.8019667 \mathrm{e}-007$

$\mathrm{AIC}=-9.3689$

$\mathrm{BIC}=-9.2844$

$\mathrm{HQC}=-9.3354$

Equation 1: d_lnP_JB

Std. Error

t-ratio $\quad p$-value

Coefficient

0.0408673

4.353

$<0.0001$

0.177914

0.0526689

8.366

$<0.0001$

$-0.158856$

0.0285240

$-5.569$

$<0.0001$

$\begin{array}{rlr}-0.001851 & \text { S.D. dependent var } & 0.029854 \\ 0.169197 & \text { S.E. of regression } & 0.021501 \\ 0.488879 & \text { Adjusted R-squared } & 0.483293 \\ -0.142773 & \text { Durbin-Watson } & 2.283819\end{array}$

Equation 2: d_lnP_ID

$\begin{array}{lcc}\text { Std. Error } & \text { t-ratio } & p \text {-value } \\ 0.0526172 & 2.103 & 0.0362 \\ 0.0678119 & 1.514 & 0.1310 \\ 0.0367250 & 0.5505 & 0.5823\end{array}$

Coefficient

0.110650

0.102648

0.0367250

0.5505

0.5823

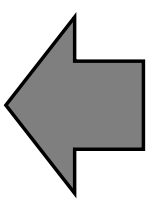

2.283819

$\begin{array}{rll}-0.002030 & \text { S.D. dependent var } & 0.027859 \\ 0.280476 & \text { S.E. of regression } & 0.027683 \\ 0.028458 & \text { Adjusted R-squared } & 0.017840 \\ -0.008245 & \text { Durbin-Watson } & 2.014206\end{array}$

Cross-equation covariance matrix:

$$
\begin{aligned}
& \ln \mathrm{P} \text { JB } \ln \mathrm{P} \text { ID } \\
& \text { lnP_JB } 0.00045606 \quad 0.00025413 \\
& \text { lnP_ID } 0.00025413 \quad 0.00075600
\end{aligned}
$$

determinant $=2.80197 \mathrm{e}-007$ 
Appendix 2. 15 VECM Estimation between Jambi FFB and Indonesian CPO allowing Structural Break

VECM system, lag order 2

Maximum likelihood estimates, observations 2011-11-02-2018-12-05 $(\mathrm{T}=371)$

Cointegration rank $=1$

Case 2: Restricted constant

beta (cointegrating vectors, standard errors in parentheses)

$\begin{array}{ll}\text { lnP_JB } & 1.0000 \\ & (0.00000) \\ \text { lnP_ID } & -1.4356 \\ & (0.062597) \\ \text { const } & 1.4839 \\ & (0.025909) \\ \text { ET } & 1.4846 \\ & (0.15469) \\ \text { TL } & 0.042258 \\ & (0.010304) \\ \text { SB } & -0.065405 \\ & (0.018591) \\ \text { SBx lnP_ID } & 0.090191 \\ & (0.056691)\end{array}$

alpha (adjustment vectors)

lnP_JB $\quad-0.22305$

lnP_ID 0.12994

Log-likelihood $=1761.7651$

Determinant of covariance matrix $=2.5726986 \mathrm{e}-007$

$\mathrm{AIC}=-9.4543$

$\mathrm{BIC}=-9.3698$

$\mathrm{HQC}=-9.4207$

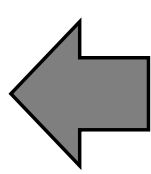

Equation 1: d_lnP_JB

d_lnP_JB_1

Std. Error

t-ratio

p-value

d_lnP_ID_1

Coefficient

0.0405341

4.622

$<0.0001$

0.187357

0.0567833

6.744

$<0.0001$

$-0.223049$

0.0368110

$-6.059$

$<0.0001$

$\begin{array}{rll}-0.001851 & \text { S.D. dependent var } & 0.029854 \\ 0.166761 & \text { S.E. of regression } & 0.021375 \\ 0.496237 & \text { Adjusted R-squared } & 0.489337 \\ -0.125469 & \text { Durbin-Watson } & 2.249512\end{array}$

Equation 2: d_lnP_ID

d_lnP_JB_1

Coefficient

Std. Error

t-ratio

p-value

0.112848

0.0520537

2.168

0.0308

0.211365

0.0729209

2.899

0.0040

0.129943

0.0472726

2.749

0.0063

$$
\begin{aligned}
& * * \\
& * * * \\
& * * *
\end{aligned}
$$

Mean dependent var Sum squared resid

$-0.002030$

S.D. dependent var

0.027859

0.275015

S.E. of regression

0.027449

0.047374

Adjusted R-squared

0.034324

$-0.014566$

Durbin-Watson

2.027326

Cross-equation covariance matrix:

$$
\begin{aligned}
& \ln \mathrm{P} \text { JB } \ln \mathrm{P} \text { ID } \\
& \text { lnP_JB } 0.00044949 \quad 0.00027555 \\
& \text { lnP_ID } 0.00027555 \quad 0.00074128
\end{aligned}
$$

determinant $=2.5727 \mathrm{e}-007$ 
Appendix 2. 16 VECM Estimation between Jambi FFB and Indonesian CPO before the Breakpoint

VECM system, lag order 2

Maximum likelihood estimates, observations 2011-11-02-2014-01-01 $(\mathrm{T}=114)$

Cointegration rank $=1$

Case 2: Restricted constant

beta (cointegrating vectors, standard errors in parentheses)

$\begin{array}{ll}\text { lnP_JB } & 1.0000 \\ & (0.00000) \\ \text { lnP_ID } & -1.3186 \\ & (0.11053) \\ \text { const } & 1.5235 \\ & (0.051871) \\ \text { ET } & 1.2885 \\ & (0.31794)\end{array}$

alpha (adjustment vectors)

lnP_JB $\quad-0.21157$

$\ln P$ ID 0.15544

Log-likelihood $=535.81993$

Determinant of covariance matrix $=2.8348578 \mathrm{e}-007$

$\mathrm{AIC}=-9.2600$

$\mathrm{BIC}=-9.0680$

$\mathrm{HQC}=-9.1821$

Equation 1: d_lnP_JB

d_lnP_JB_1

d_lnP_ID_1

EC1

Mean dependent var

Sum squared resid

R-squared

rho

$\begin{array}{lc} & \text { Coefficient } \\ \text { d_lnP_JB_1 } & 0.214220 \\ \text { d_lnP_ID_1 } & 0.0813139 \\ \text { EC1 } & 0.155437\end{array}$

Mean dependent var

Sum squared resid

R-squared

rho

$\begin{array}{lccl}\text { Std. Error } & \text { t-ratio } & p \text {-value } & \\ 0.0789317 & 2.423 & 0.0170 & * * \\ 0.0962188 & 2.741 & 0.0072 & * * * \\ 0.0679147 & -3.115 & 0.0023 & * * *\end{array}$

$0.000367 \quad$ S.D. dependent var

0.027960

0.022440

0.355988

0.373086

S.E. of regression

2.133894

Equation 2: d_lnP_ID

$$
\begin{aligned}
& \text { Std. Error } \\
& 0.100875 \\
& 0.122968 \\
& 0.0867956
\end{aligned}
$$

t-ratio

p-value

2.124

0.0359

0.6613

0.5098

1.791

0.0761

$\begin{array}{rll}-0.001045 & \text { S.D. dependent var } & 0.029274 \\ 0.090469 & \text { S.E. of regression } & 0.028678 \\ 0.066935 & \text { Adjusted R-squared } & 0.041487 \\ -0.009036 & \text { Durbin-Watson } & 2.002806\end{array}$

Cross-equation covariance matrix:

$$
\text { lnP_JB lnP_ID }
$$

lnP_JB $0.00048588 \quad 0.00031953$

lnP_ID $0.00031953 \quad 0.00079359$

determinant $=2.83486 \mathrm{e}-007$ 
Appendix 2. 17 VECM Estimation between Jambi FFB and Indonesian CPO after the Breakpoint

VECM system, lag order 2

Maximum likelihood estimates, observations 2014-01-22-2018-12-05 ( $\mathrm{T}=255)$

Cointegration rank $=1$

Case 2: Restricted constant

beta (cointegrating vectors, standard errors in parentheses)

$\begin{array}{ll}\ln P_{-} \text {JB } & 1.0000 \\ & (0.00000) \\ \text { lnP_ID } & -1.3512 \\ & (0.037368) \\ \text { const } & 1.4216 \\ & (0.019997) \\ \text { ET } & 1.3963 \\ & (0.18839) \\ \text { TL } & 0.036912 \\ & (0.010764)\end{array}$

alpha (adjustment vectors)

$\ln P_{-}$JB $\quad-0.26788$

lnP_ID $\quad 0.038235$

Log-likelihood $=1220.6718$

Determinant of covariance matrix $=2.3832027 \mathrm{e}-007$

$\mathrm{AIC}=-9.5112$

$\mathrm{BIC}=-9.4001$

$\mathrm{HQC}=-9.4665$

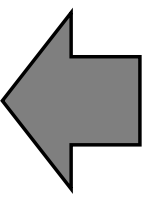

Equation 1: d_lnP_JB

d_lnP_JB_1

d_lnP_ID_1

EC1

Mean dependent var

Sum squared resid

R-squared

rho

d_lnP_JB_1

d_lnP_ID_1

EC1

Mean dependent var

Sum squared resid

R-squared

rho

$\begin{array}{ccccc}\text { Coefficient } & \text { Std. Error } & \text { t-ratio } & p \text {-value } & \\ 0.184076 & 0.0457755 & 4.021 & <0.0001 & * * * \\ 0.410339 & 0.0689450 & 5.952 & <0.0001 & * * * \\ -0.267875 & 0.0438832 & -6.104 & <0.0001 & * * *\end{array}$

$\begin{aligned}-0.002869 & \text { S.D. dependent var } \\ 0.103071 & \text { S.E. of regression } \\ 0.575223 & \text { Adjusted R-squared } \\ -0.138180 & \text { Durbin-Watson }\end{aligned}$

0.030774

0.020305

0.568426

2.275964

Equation 2: d_lnP_ID

$\begin{array}{cccc}\text { Coefficient } & \text { Std. Error } & \text { t-ratio } & p \text {-value } \\ 0.0622092 & 0.0612367 & 1.016 & 0.3107 \\ 0.191260 & 0.0922318 & 2.074 & 0.0391 \\ 0.0382349 & 0.0587052 & 0.6513 & 0.5154\end{array}$

$\begin{array}{rll}-0.002551 & \text { S.D. dependent var } & 0.027345 \\ 0.184455 & \text { S.E. of regression } & 0.027163 \\ 0.037259 & \text { Adjusted R-squared } & 0.021855 \\ -0.010216 & \text { Durbin-Watson } & 2.011778\end{array}$

Cross-equation covariance matrix:

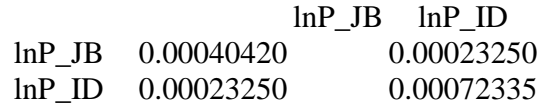

determinant $=2.3832 \mathrm{e}-007$ 
Appendix 3. 1 Name of Regencies, Districts and Villages of Survey Location

\begin{tabular}{|c|c|c|}
\hline Regencies & Districts & Villages \\
\hline \multirow[t]{4}{*}{ 1. SAROLANGUN } & 1. Pelawan & $\begin{array}{ll}\text { 1. } & \text { Pematang Kolim } \\
\text { 2. } & \text { Batu Putih }\end{array}$ \\
\hline & 2. Singkut & $\begin{array}{l}\text { 1. } \text { Bukit Murau } \\
\text { 2. } \text { Payo Lebar }\end{array}$ \\
\hline & 3. Pauh & $\begin{array}{ll}\text { 1. } & \text { Pauh } \\
\text { 2. } & \text { Semaran } \\
\text { 3. } & \text { Danau Serdang }\end{array}$ \\
\hline & 4. Air Hitam & $\begin{array}{l}\text { 1. Baru } \\
\text { 2. Pematang Kabau }\end{array}$ \\
\hline \multirow[t]{5}{*}{ 2. BATANGHARI } & 1. Bathin XXIV & $\begin{array}{l}\text { 1. Simpang Karmeo } \\
\text { 2. Jangga }\end{array}$ \\
\hline & 2. Muara Bulian & $\begin{array}{l}\text { 1. Sridadi } \\
\text { 2. } \quad \text { Simpang Terusan }\end{array}$ \\
\hline & 3. Bajubang & 1. Bungku \\
\hline & 4. Maro Sebo Ilir & $\begin{array}{l}\text { 1. Bulian Jaya } \\
\text { 2. } \text { Bukit Sari }\end{array}$ \\
\hline & 5. Pemayung & 1. Pulau Raman \\
\hline \multirow[t]{4}{*}{ 3. MUARO JAMBI } & 1. Sungai Bahar & 1. Mulya Jaya \\
\hline & 2. Kumpeh Ulu & 1. Tarikan \\
\hline & 3. Sungai Gelam & $\begin{array}{ll}\text { 1. } & \text { Ladang Panjang } \\
\text { 2. } & \text { Parit } \\
\end{array}$ \\
\hline & 4. Maro Sebo & 1. Tanjung Katung \\
\hline \multirow[t]{5}{*}{ 4. TEBO } & 1. Sumay & $\begin{array}{ll}\text { 1. } & \text { Teriti } \\
\text { 2. } & \text { Muara Sekalo }\end{array}$ \\
\hline & 2. Rimbo llir & $\begin{array}{ll}\text { 1. } & \text { Giriwinangun } \\
\text { 2. } & \text { Sepakat Bersatu }\end{array}$ \\
\hline & 3. Tebo Ulu & $\begin{array}{ll}\text { 1. } & \text { Pulau Panjang } \\
\text { 2. } & \text { Rantau Langkap }\end{array}$ \\
\hline & 4. VII Koto & 1. Aur Cino \\
\hline & 5. Rimbo Ulu & 1. $\quad$ Sumber Sari \\
\hline \multirow[t]{4}{*}{ 5. BUNGO } & 1. Pelepat Ilir & $\begin{array}{l}\text { 1. Muara Kuamang } \\
\text { 2. Maju Jaya }\end{array}$ \\
\hline & 2. Bathin III Ulu & $\begin{array}{ll}\text { 1. } & \text { Lubuk Beringin } \\
\text { 2. } & \text { Laman Panjang }\end{array}$ \\
\hline & 3. Muko Muko Bathin VII & $\begin{array}{ll}\text { 1. } & \text { Tebing Tinggi } \\
2 . & \text { Tanjung Agung } \\
\end{array}$ \\
\hline & 4. Tanah Sepenggal & $\begin{array}{l}\text { 1. Teluk Pandak } \\
\text { 2. Tenam }\end{array}$ \\
\hline
\end{tabular}


Appendix 3. 2 Stata Output of Variable Descriptive Statistics Year 2012

- sum tp edu exp func info stat num cred land vehic comp smph supp com trans trrev loc

\begin{tabular}{|c|c|c|c|c|c|}
\hline Variable & $\mathrm{Obs}$ & Mean & Std. Dev. & Min & Max \\
\hline$t p$ & 295 & .7186441 & .4504248 & 0 & 1 \\
\hline edu & 295 & .9457627 & .2268702 & 0 & 1 \\
\hline exp & 295 & 8.872881 & 8.054551 & 1 & 47 \\
\hline func & 295 & .2 & .4006797 & 0 & 1 \\
\hline info & 295 & .6169492 & .4869566 & 0 & 1 \\
\hline stat & 295 & .7762712 & .4174505 & 0 & 1 \\
\hline num & 295 & 6.027119 & 6.064221 & 0 & 35 \\
\hline cred & 295 & .7152542 & .4520601 & 0 & 1 \\
\hline land & 295 & 11.28534 & 15.00797 & 0 & 95 \\
\hline vehic & 295 & .8237288 & .3816982 & 0 & 1 \\
\hline comp & 295 & .2983051 & .4582915 & 0 & 1 \\
\hline smph & 295 & .1864407 & .3901237 & 0 & 1 \\
\hline supp & 295 & 34.09492 & 34.48846 & 2 & 250 \\
\hline $\mathrm{com}$ & 295 & 11.68814 & 5.289352 & 0 & 21 \\
\hline trans & 295 & .1728814 & .3787872 & 0 & 1 \\
\hline trrev & 295 & 12.38375 & 20.25782 & .3 & 150 \\
\hline loc & 295 & 64.67458 & 29.39114 & 4 & 155 \\
\hline
\end{tabular}

\section{Appendix 3. 3 Stata Output of Variable Descriptive Statistics Year 2015}

- sum tp edu exp func info stat num cred land vehic comp smph supp com trans trrev loc

\begin{tabular}{|c|c|c|c|c|c|}
\hline Variable & Obs & Mean & Std. Dev. & Min & $\operatorname{Max}$ \\
\hline$t p$ & 293 & .7167235 & .4513604 & 0 & 1 \\
\hline edu & 292 & .8561644 & .3515254 & 0 & 1 \\
\hline exp & 292 & 10.22432 & 7.139397 & 1 & 39 \\
\hline func & 292 & .1472603 & .3549735 & 0 & 1 \\
\hline info & 292 & .3287671 & .4705716 & 0 & 1 \\
\hline stat & 292 & .260274 & .4395373 & 0 & 1 \\
\hline num & 293 & 4.003413 & 4.068336 & 0 & 32 \\
\hline cred & 292 & .7842466 & .4120502 & 0 & 1 \\
\hline land & 293 & 10.33993 & 12.51335 & 0 & 100 \\
\hline vehic & 292 & .8458904 & .3616736 & 0 & 1 \\
\hline comp & 292 & .0787671 & .2698374 & 0 & 1 \\
\hline smph & 292 & .1575342 & .3649291 & 0 & 1 \\
\hline supp & 292 & 30.65753 & 31.15033 & 3 & 250 \\
\hline $\mathrm{com}$ & 292 & 10.57534 & 5.184348 & 0 & 21 \\
\hline trans & 292 & .1986301 & .3996539 & 0 & 1 \\
\hline trrev & 292 & 6.159683 & 9.220843 & .15 & 80 \\
\hline loc & 292 & 67.13014 & 27.65305 & 4 & 155 \\
\hline
\end{tabular}


Appendix 3. 4 Stata Output of Variable Descriptive Statistics Year 2018

- sum tp edu exp func info stat num cred land vehic comp smph supp com trans trrev loc

\begin{tabular}{|c|c|c|c|c|c|}
\hline Variable & Obs & Mean & Std. Dev. & Min & $\operatorname{Max}$ \\
\hline$t p$ & 325 & .6430769 & .4798306 & 0 & 1 \\
\hline edu & 325 & .9107692 & .2855161 & 0 & 1 \\
\hline exp & 325 & 10.52154 & 6.797977 & 1 & 38 \\
\hline func & 325 & .08 & .2717115 & 0 & 1 \\
\hline info & 325 & .6215385 & .4857514 & 0 & 1 \\
\hline stat & 325 & .3261538 & .4695273 & 0 & 1 \\
\hline num & 325 & 4.901538 & 4.8096 & 0 & 34 \\
\hline cred & 325 & .8369231 & .3700055 & 0 & 1 \\
\hline land & 325 & 9.771415 & 10.7516 & 0 & 70 \\
\hline vehic & 325 & .8738462 & .3325347 & 0 & 1 \\
\hline comp & 325 & .16 & .3671714 & 0 & 1 \\
\hline smph & 325 & .4523077 & .4984877 & 0 & 1 \\
\hline supp & 325 & 38.60308 & 45.32468 & 3 & 325 \\
\hline $\mathrm{com}$ & 325 & 11.72 & 5.606302 & 0 & 25 \\
\hline trans & 325 & .1384615 & .3459163 & 0 & 1 \\
\hline trrev & 325 & 12.0911 & 19.48656 & .2 & 160 \\
\hline $10 \mathrm{C}$ & 325 & 66.28923 & 25.67898 & 4 & 155 \\
\hline
\end{tabular}




\section{Appendix 3. 5 Stata Output of Logit Estimation Year 2012}

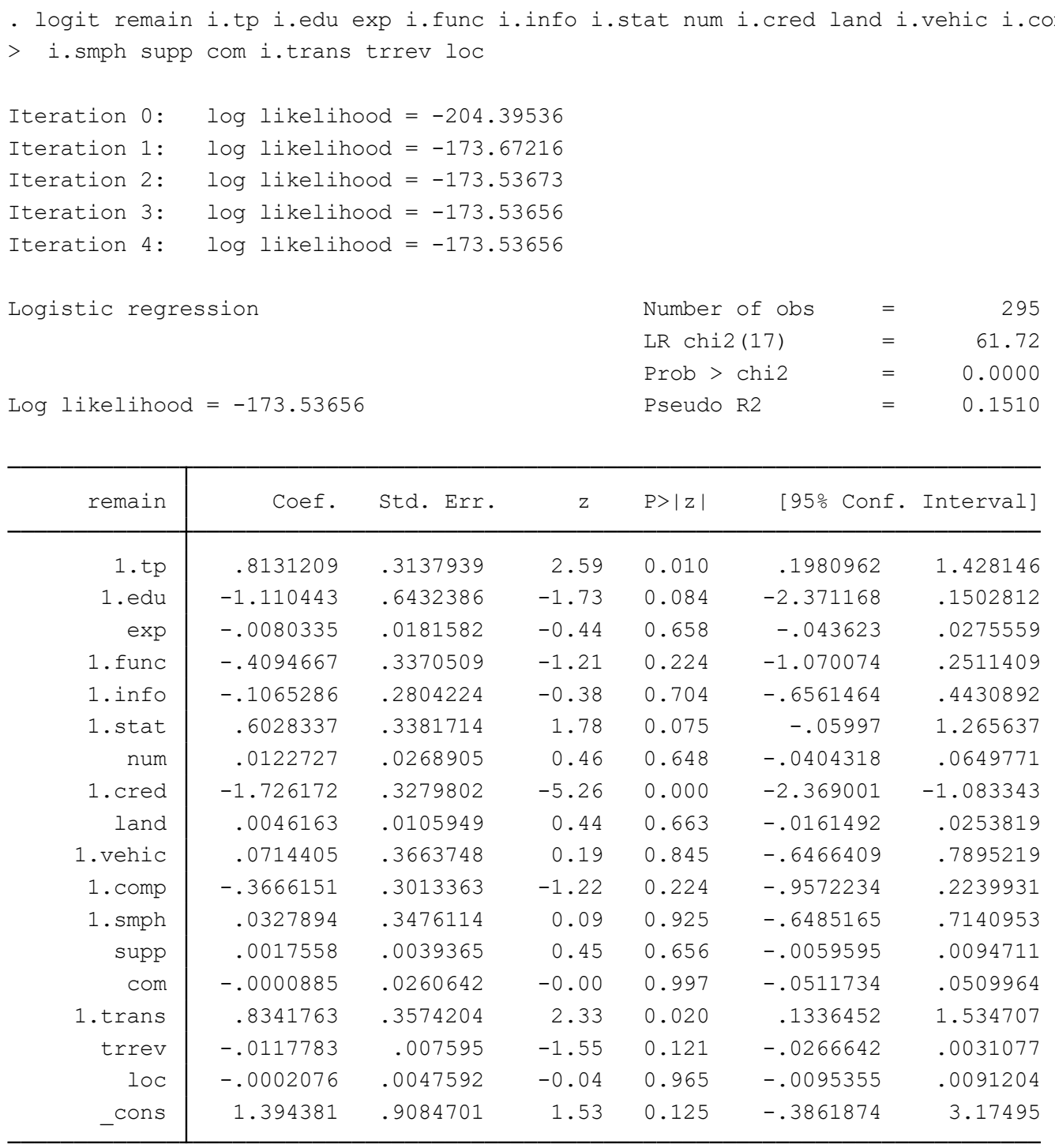


Appendix 3. 6 Stata Output of Marginal Effect Estimation Year 2012

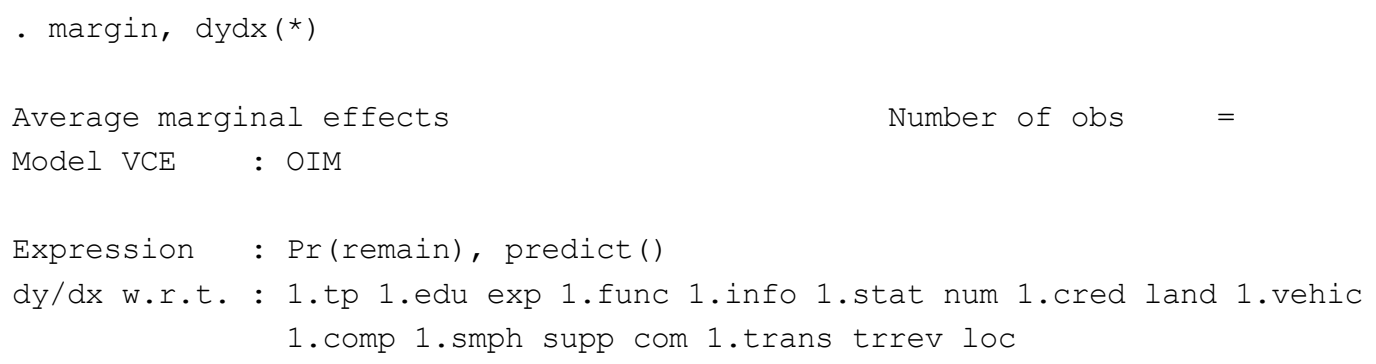

\begin{tabular}{|c|c|c|c|c|c|c|}
\hline & $d y / d x$ & $\begin{array}{l}\text { elta-metho } \\
\text { std. Err. }\end{array}$ & z & $\mathrm{P}>|\mathrm{z}|$ & [95\% Conf. & Interval] \\
\hline $1 . t p$ & .1667961 & .0629113 & 2.65 & 0.008 & .0434922 & .2900999 \\
\hline 1.edu & -.2150113 & .1119647 & -1.92 & 0.055 & -.434458 & .0044354 \\
\hline exp & -.0016187 & .0036545 & -0.44 & 0.658 & -.0087814 & .005544 \\
\hline 1. func & -.0826901 & .0675675 & -1.22 & 0.221 & -.2151199 & .0497398 \\
\hline 1.info & -.0215217 & .0567604 & -0.38 & 0.705 & -.13277 & .0897265 \\
\hline 1. stat & .1212588 & .0664524 & 1.82 & 0.068 & -.0089854 & .2515031 \\
\hline num & .0024728 & .0054124 & 0.46 & 0.648 & -.0081352 & .0130809 \\
\hline 1. cred & -.3564509 & .0573524 & -6.22 & 0.000 & -.4688595 & -.2440422 \\
\hline land & .0009302 & .0021323 & 0.44 & 0.663 & -.003249 & .0051093 \\
\hline 1.vehic & .0143873 & .0737221 & 0.20 & 0.845 & -.1301054 & .1588799 \\
\hline 1. comp & -.0744092 & .0610855 & -1.22 & 0.223 & -.1941346 & .0453163 \\
\hline 1. smph & .0066041 & .0699823 & 0.09 & 0.925 & -.1305586 & .1437668 \\
\hline supp & .0003538 & .0007923 & 0.45 & 0.655 & -.001199 & .0019066 \\
\hline $\mathrm{com}$ & -.0000178 & .0052517 & -0.00 & 0.997 & -.010311 & .0102754 \\
\hline 1.trans & .1676354 & .0688033 & 2.44 & 0.015 & .0327835 & .3024873 \\
\hline trrev & -.0023732 & .0015101 & -1.57 & 0.116 & -.0053329 & .0005864 \\
\hline $10 \mathrm{C}$ & -.0000418 & .0009589 & -0.04 & 0.965 & -.0019213 & .0018377 \\
\hline
\end{tabular}

Note: dy/dx for factor levels is the discrete change from the base level. 
Appendix 3. 7 Stata Output of Logit Estimation Year 2015

- logit remain i.tp i.edu exp i.func i.info i.stat num i.cred land i.vehic i.comp

$>$ i.smph supp com i.trans trrev loc

$\begin{array}{lll}\text { Iteration 0: } & \log \text { likelihood }=-178.70999 \\ \text { Iteration 1: } & \log \text { likelihood }=-158.60336 \\ \text { Iteration 2: } & \log \text { likelihood }=-157.6246 \\ \text { Iteration 3: } & \log \text { likelihood }=-157.61431 \\ \text { Iteration 4: } & \log \text { likelihood }=-157.6143\end{array}$

Logistic regression

Number of obs $=292$

LR $\operatorname{chi2}(17)=42.19$

Prob $>$ chi2 $=0.0006$

Log likelihood $=-157.6143$

Pseudo R2 = 0.1180

\begin{tabular}{r|rrrrrr}
\hline remain & Coef. & Std. Err. & $z$ & P $>|z|$ & [95\% Conf. Interval] \\
\hline 1.tp & .7210577 & .3368864 & 2.14 & 0.032 & .0607724 & 1.381343 \\
1. edu & -.7833169 & .45212 & -1.73 & 0.083 & -1.669456 & .1028221 \\
exp & .043068 & .0237277 & 1.82 & 0.070 & -.0034374 & .0895733 \\
1. func & .5399779 & .4343338 & 1.24 & 0.214 & -.3113007 & 1.391257 \\
1. info & .0920677 & .3064726 & 0.30 & 0.764 & -.5086077 & .692743 \\
1. stat & .4390833 & .3627313 & 1.21 & 0.226 & -.271857 & 1.150024 \\
num & .00742 & .0415288 & 0.18 & 0.858 & -.0739748 & .0888149 \\
1. cred & .7516832 & .3335158 & 2.25 & 0.024 & .0980043 & 1.405362 \\
land & -.0394647 & .0128783 & -3.06 & 0.002 & -.0647057 & -.0142237 \\
1. vehic & .7971226 & .3807064 & 2.09 & 0.036 & .0509518 & 1.543293 \\
1. comp & -.6330536 & .4886475 & -1.30 & 0.195 & -1.590785 & .3246779 \\
1. smph & -.1504273 & .3943546 & -0.38 & 0.703 & -.9233481 & .6224935 \\
supp & .0001396 & .005962 & 0.02 & 0.981 & -.0115456 & .0118249 \\
com & -.0482794 & .0281207 & -1.72 & 0.086 & -.103395 & .0068362 \\
$1 . t r a n s$ & .0440653 & .3595999 & 0.12 & 0.902 & -.6607377 & .7488682 \\
trrev & .053066 & .027339 & 1.94 & 0.052 & -.0005175 & .1066494 \\
loc & .0018053 & .0052247 & 0.35 & 0.730 & -.0084349 & .0120455 \\
cons & -.2708329 & .8076663 & -0.34 & 0.737 & -1.85383 & 1.312164 \\
\hline & & & & & &
\end{tabular}




\section{Appendix 3. 8 Stata Output of Marginal Effect Estimation Year 2015}

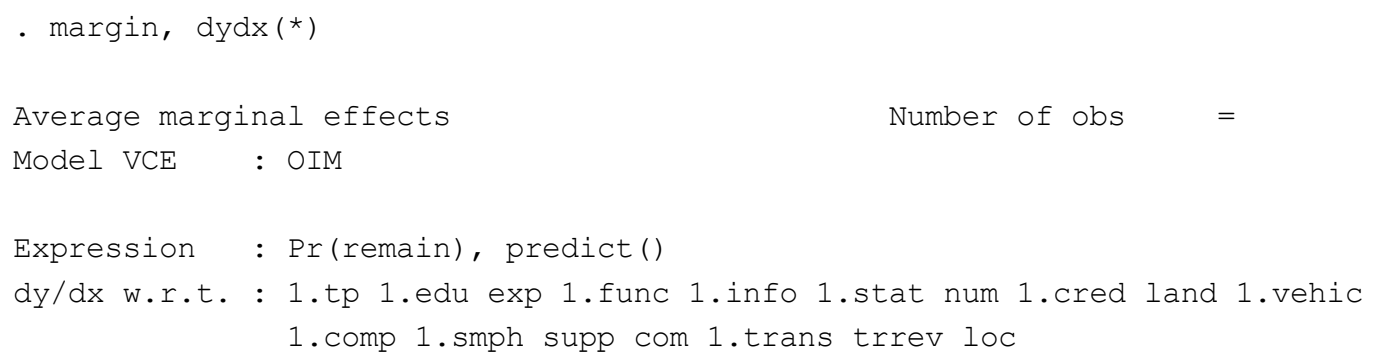

\begin{tabular}{|c|c|c|c|c|c|c|}
\hline & $d y / d x$ & $\begin{array}{l}\text { elta-metho } \\
\text { std. Err. }\end{array}$ & z & $\mathrm{P}>|\mathrm{z}|$ & [95\% Conf. & Interval] \\
\hline $1 . t p$ & .1351579 & .0635813 & 2.13 & 0.034 & .0105408 & .2597749 \\
\hline 1.edu & -.1282899 & .0648282 & -1.98 & 0.048 & -.2553508 & -.001229 \\
\hline exp & .0077974 & .0042191 & 1.85 & 0.065 & -.0004718 & .0160666 \\
\hline 1. func & .0918167 & .0682762 & 1.34 & 0.179 & -.0420021 & .2256355 \\
\hline 1.info & .0165978 & .0549871 & 0.30 & 0.763 & -.0911748 & .1243705 \\
\hline 1.stat & .077089 & .0610766 & 1.26 & 0.207 & -.0426189 & .196797 \\
\hline num & .0013434 & .0075172 & 0.18 & 0.858 & -.0133901 & .0160769 \\
\hline 1.cred & .1468276 & .0678224 & 2.16 & 0.030 & .0138981 & .2797572 \\
\hline land & -.007145 & .0021976 & -3.25 & 0.001 & -.0114522 & -.0028379 \\
\hline 1.vehic & .1572627 & .0787475 & 2.00 & 0.046 & .0029205 & .3116049 \\
\hline 1. comp & -.1228838 & .0993739 & -1.24 & 0.216 & -.317653 & .0718853 \\
\hline 1.smph & -.0276224 & .0733514 & -0.38 & 0.706 & -.1713885 & .1161437 \\
\hline supp & .0000253 & .0010794 & 0.02 & 0.981 & -.0020903 & .0021409 \\
\hline $\mathrm{com}$ & -.0087409 & .0050068 & -1.75 & 0.081 & -.0185541 & .0010722 \\
\hline 1.trans & .0079459 & .0645757 & 0.12 & 0.902 & -.1186202 & .134512 \\
\hline trrev & .0096075 & .0048551 & 1.98 & 0.048 & .0000917 & .0191233 \\
\hline $10 \mathrm{C}$ & .0003268 & .0009453 & 0.35 & 0.730 & -.0015259 & .0021796 \\
\hline
\end{tabular}

Note: dy/dx for factor levels is the discrete change from the base level. 


\section{Appendix 3. 9 Stata Output of Specification Error Year 2012}

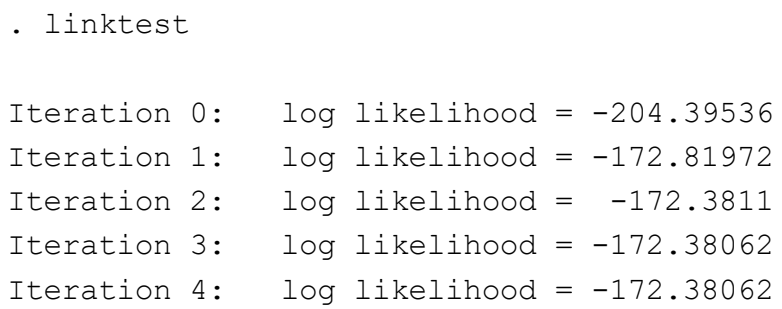

\begin{tabular}{r|rrrrrr}
\hline remain & Coef. & Std. Err. & $z$ & P $>|z|$ & [95\% Conf. Interval] \\
\hline _hat & .9852397 & .1461047 & 6.74 & 0.000 & .6988797 & 1.2716 \\
- ${ }^{\text {hatsq }}$ & .1870438 & .1225771 & 1.53 & 0.127 & -.053203 & .4272906 \\
_cons & -.1491667 & .1627824 & -0.92 & 0.359 & -.4682144 & .169881 \\
\hline
\end{tabular}

\section{Appendix 3. 10 Stata Output of Specification Error Year 2015}

- linktest

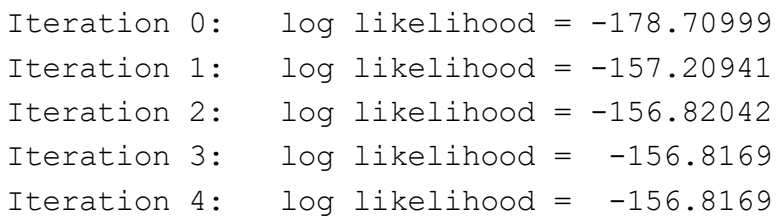

\begin{tabular}{r|rrrrrr}
\hline remain & Coef. & Std. Err. & $z$ & P $>|z|$ & [95\% Conf. Interval] \\
\hline _hat & 1.24622 & .265599 & 4.69 & 0.000 & .7256556 & 1.766785 \\
- hatsq & -.1493225 & .1069492 & -1.40 & 0.163 & -.3589391 & .0602941 \\
_cons & -.0035206 & .1915014 & -0.02 & 0.985 & -.3788564 & .3718152 \\
\hline
\end{tabular}


Appendix 3. 11 Stata Output of Collinearity Diagnostics Year 2012

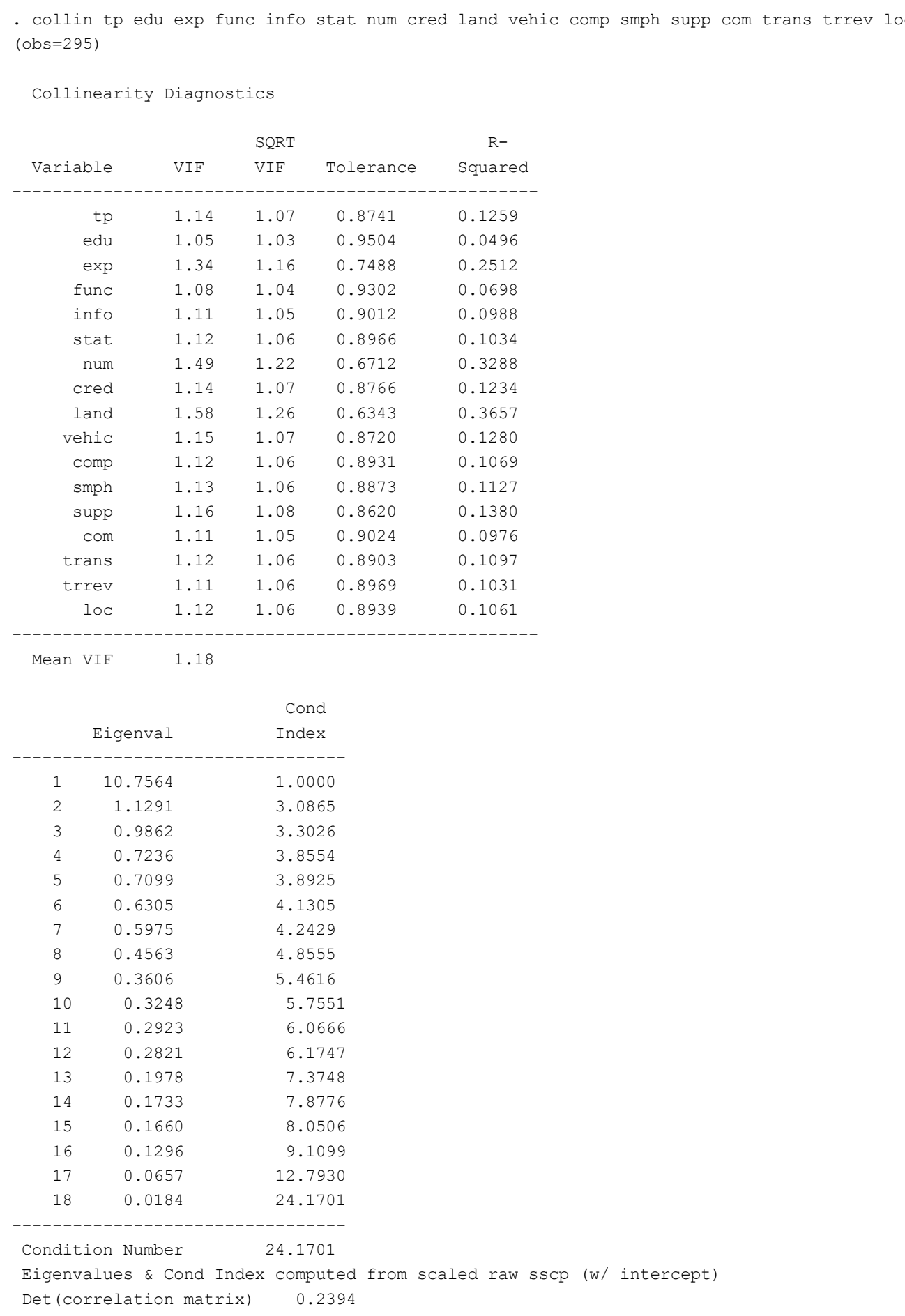




\section{Appendix 3. 12 Stata Output of Collinearity Diagnostics Year 2015}

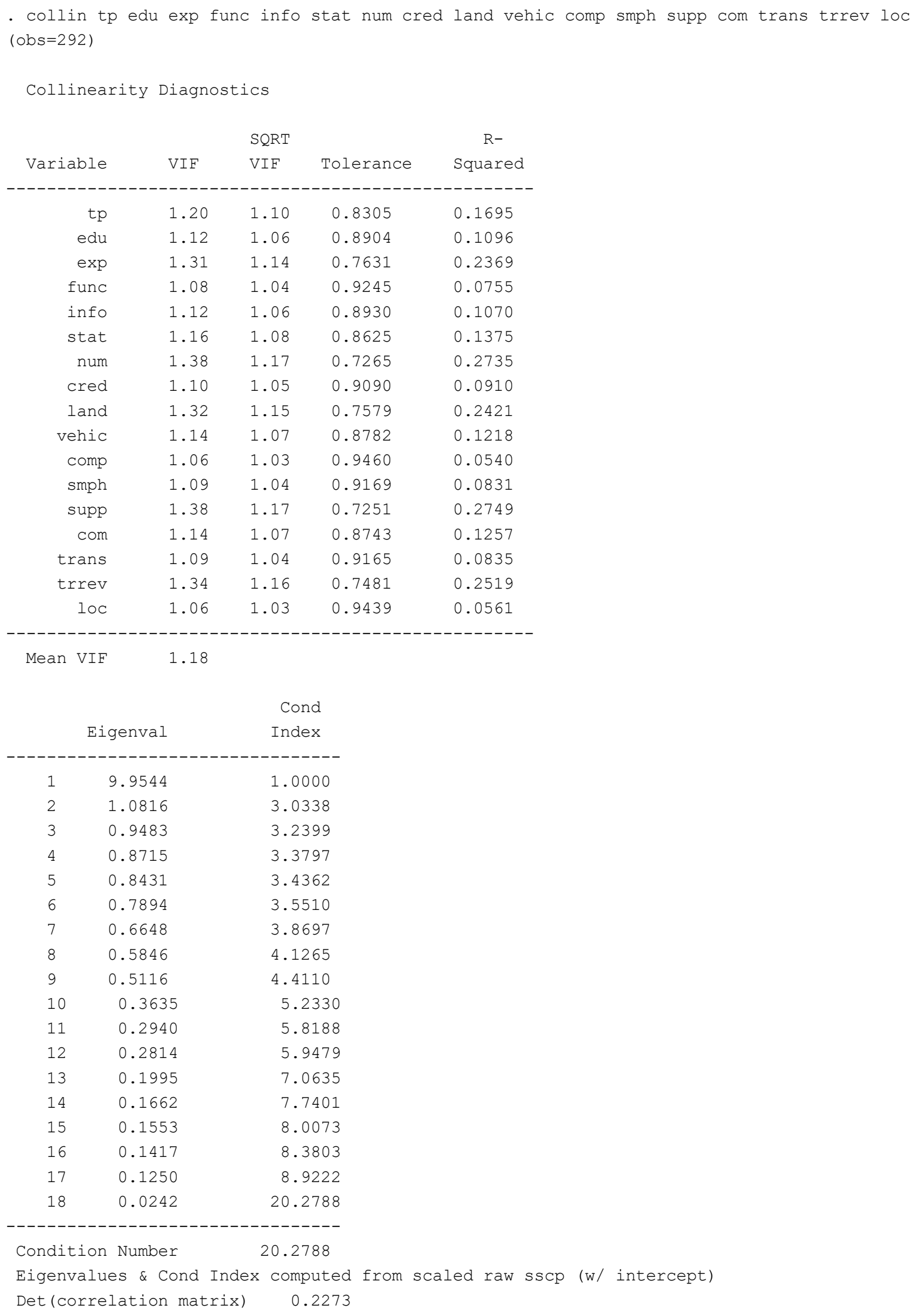


Appendix 3. 13 Stata Output of Wilcoxon Rank-sum (Mann-Whitney Test of Farming Revenue by Traders' Status

- ranksum frrev, by (stat)

Two-sample Wilcoxon rank-sum (Mann-Whitney) test

\begin{tabular}{r|rrr} 
stat & obs & rank sum & expected \\
\hline 0 & 66 & 8302.5 & 9768 \\
1 & 229 & 35357.5 & 33892 \\
\hline combined & 295 & 43660 & 43660
\end{tabular}

\begin{tabular}{lr} 
unadjusted variance & 372812.00 \\
adjustment for ties & -1396.82 \\
\cline { 2 - 2 } & 371415.18 \\
adjusted variance & frrev (stat==1) \\
Ho: frrev(stat==0) & $\begin{aligned} & \text { f } \\
& \mathrm{z}=-2.405 \\
& \text { Prob }>|\mathrm{z}|= 0.0162\end{aligned}$
\end{tabular}


Appendix 3.14 Stata Output of Trading Revenue Summary Statistics by Remain Year 2015

- sum trrev if remain==1

\begin{tabular}{r|cccc} 
Variable & Obs & Mean & Std. Dev. & Min \\
\hline trrev & 204 & 6.826593 & 10.42516 & .15
\end{tabular}

- sum trrev if remain $==0$

\begin{tabular}{r|rrrrr} 
Variable & Obs & Mean & Std. Dev & Min & Max \\
\hline trrev & 88 & 4.613665 & 5.228212 & .28
\end{tabular}

Appendix 3. 15 Stata Output of Trading Revenue Summary Statistics Year 2012 and 2015

- $* 2012$

- sum trrev

\begin{tabular}{r|rrrrr} 
Variable & Obs & Mean & Std. Dev. & Min & Max \\
\hline trrev & 295 & 12.38375 & 20.25782 & .3 & 150
\end{tabular}

. $* 2015$

- sum trrev

\begin{tabular}{r|ccccc} 
Variable & Obs & Mean & Std. Dev. & Min & Max \\
\hline trrev & 292 & 6.159683 & 9.220843 & .15
\end{tabular}




\section{Appendix 3.16 Wilcoxon rank-sum (Mann-Whitney) non-parametric test}

. ranksum num, by (nt)

Two-sample Wilcoxon rank-sum (Mann-Whitney) test

\begin{tabular}{r|rrr} 
nt & obs & rank sum & expected \\
\hline 0 & 258 & 44231 & 42054 \\
1 & 67 & 8744 & 10921 \\
\hline combined & 325 & 52975 & 52975
\end{tabular}

unadjusted variance 469603.00

adjustment for ties $\quad-5098.88$

adjusted variance $\quad 464504.12$

Ho: $\operatorname{num}(\mathrm{nt}==0)=\operatorname{num}(\mathrm{nt}==1)$

$\begin{aligned} z & =3.194 \\ \text { Prob }>|z| & =0.0014\end{aligned}$

- ranksum land, by (nt)

Two-sample Wilcoxon rank-sum (Mann-Whitney) test

\begin{tabular}{r|rrr} 
nt & obs & rank sum & expected \\
\hline 0 & 258 & 44718.5 & 42054 \\
1 & 67 & 8256.5 & 10921 \\
\hline combined & 325 & 52975 & 52975
\end{tabular}

unadjusted variance 469603.00

adjustment for ties

adjusted variance $\overline{468343.08}$

Ho: $l$ and $(\mathrm{nt}==0)=\operatorname{land}(\mathrm{nt}==1)$

$$
\text { Prob }>|z|=0.0001
$$

. ranksum supp, by (nt)

Two-sample Wilcoxon rank-sum (Mann-Whitney) test

\begin{tabular}{r|rrr} 
nt & obs & rank sum & expected \\
\hline 0 & 258 & 42455 & 42054 \\
1 & 67 & 10520 & 10921 \\
\hline combined & 325 & 52975 & 52975
\end{tabular}

unadjusted variance 469603.00

adjustment for ties $\quad-2169.70$

adjusted variance $\quad \overline{467433.30}$

Ho: $\operatorname{supp}(n t==0)=\operatorname{supp}(n t==1)$

$z=0.587$

Prob $>|z|=0.5575$
- ranksum com, by (nt)

Two-sample Wilcoxon rank-sum (Mann-Whitney) test

\begin{tabular}{r|rrr} 
nt & obs & rank sum & expected \\
\hline 0 & 258 & 41840 & 42054 \\
1 & 67 & 11135 & 10921 \\
\hline combined & 325 & 52975 & 52975
\end{tabular}

\begin{tabular}{lr} 
unadjusted variance & 469603.00 \\
adjustment for ties & -5390.59 \\
\cline { 2 - 2 } adjusted variance & 464212.41
\end{tabular}

adjusted variance

Ho: $\operatorname{com}(n t==0)=\operatorname{com}(n t==1)$

$\begin{aligned} z & =-0.314 \\ \text { Prob }>|z| & =0.7535\end{aligned}$

- ranksum trrev, by (nt)

Two-sample Wilcoxon rank-sum (Mann-Whitney) test

\begin{tabular}{r|rrr} 
nt & obs & rank sum & expected \\
\hline 0 & 258 & 43588 & 42054 \\
1 & 67 & 9387 & 10921 \\
\hline combined & 325 & 52975 & 52975
\end{tabular}

unadjusted variance $\quad 469603.00$

adjustment for ties $\quad-701.70$

adjusted variance $\quad 4668901.30$

Ho: $\operatorname{trrev}(n t==0)=\operatorname{trrev}(n t==1)$

$\begin{aligned} z & =2.240 \\ \text { Prob }>|z| & =0.0251\end{aligned}$

. ranksum loc, by (nt)

Two-sample Wilcoxon rank-sum (Mann-Whitney) test

\begin{tabular}{r|rrr} 
nt & obs & rank sum & expected \\
\hline 0 & 258 & 42112 & 42054 \\
1 & 67 & 10863 & 10921 \\
\hline combined & 325 & 52975 & 52975
\end{tabular}

unadjusted variance 469603.00

adjustment for ties $\quad-1155.11$

adjusted variance $\quad 468447.89$

Ho: $\operatorname{loc}(n t==0)=10 \mathrm{C}(\mathrm{nt}==1)$

$z=0.085$

Prob $>|z|=0.9325$ 
Appendix 3.17 Pearson Chi2 test

- tab tp nt, chi2

\begin{tabular}{|c|c|c|c|}
\hline tp & $0^{n+}$ & 1 & Total \\
\hline 0 & 77 & 39 & 116 \\
\hline 1 & 181 & 28 & 209 \\
\hline Total & 258 & 67 & 325 \\
\hline
\end{tabular}

- tab edu nt, chi2

\begin{tabular}{r|rr|r} 
edu & $0^{\text {nt }}$ & 1 & Total \\
\hline 0 & 24 & 5 & 29 \\
1 & 234 & 62 & 296 \\
\hline Total & 258 & 67 & 325 \\
\multicolumn{2}{|c|}{ Pearson $\operatorname{chi2}(1)=$} & 0.2215 & Pr $=0.638$
\end{tabular}

- tab func nt, chi2

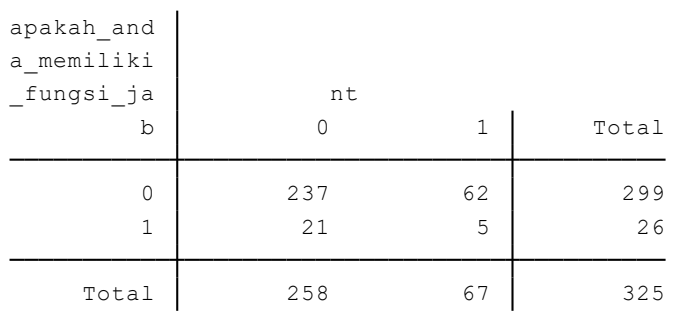

Pearson chi2 $(1)=0.0331 \quad \operatorname{Pr}=0.856$

- tab info nt, chi2

\begin{tabular}{r|rr|r} 
info & $0^{\text {nt }}$ & 1 & Total \\
\hline 0 & 96 & 27 & 123 \\
1 & 162 & 40 & 202 \\
\hline Total & 258 & 67 & 325 \\
& & & \\
\hline & Pearson chi2 $(1)=$ & 0.2158 & $\operatorname{Pr}=0.642$
\end{tabular}

- tab stat nt, chi2

\begin{tabular}{r|cc|c}
\multirow{2}{*}{ stat } & $0^{\text {nt }}$ & 1 & Total \\
\hline 0 & 172 & 47 & 219 \\
1 & 86 & 20 & 106 \\
\hline Total & 258 & 67 & 325 \\
& & & \\
& Pearson $\operatorname{chi2}(1)=$ & 0.2935 & Pr $=0.588$
\end{tabular}

. tab cred nt, chi2

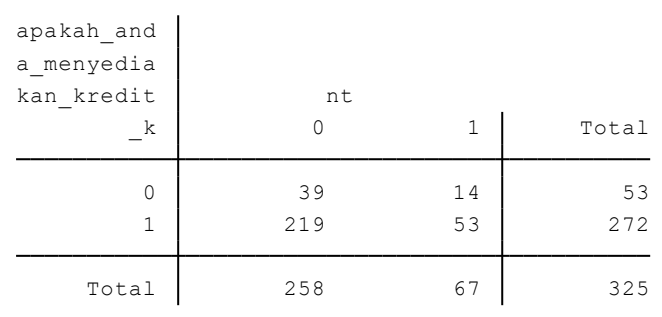

Pearson $\operatorname{chi2}(1)=1.3016 \quad \operatorname{Pr}=0.254$

- tab vehic nt, chi2

\begin{tabular}{r|rr|r} 
vehic & $0^{\text {nt }}$ & 1 & Total \\
\hline 0 & 31 & 10 & 41 \\
1 & 227 & 57 & 284 \\
\hline Total & 258 & 67 & 325
\end{tabular}

Pearson $\operatorname{chi2}(1)=0.4085 \quad \operatorname{Pr}=0.523$

- tab comp nt, chi2

\begin{tabular}{r|rr|r} 
comp & $0^{\text {nt }}$ & 1 & Total \\
\hline 0 & 215 & 58 & 273 \\
1 & 43 & 9 & 52 \\
\hline Total & 258 & 67 & 325 \\
\multicolumn{2}{|c|}{ Pearson $\operatorname{chi2}(1)=0.4139$} & Pr $=0.520$
\end{tabular}

. tab smph nt, chi2

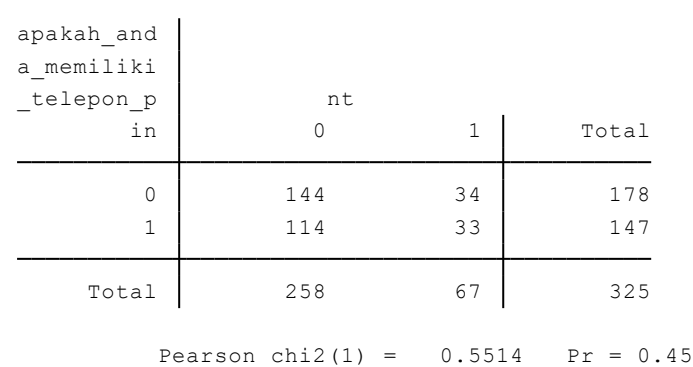

- tab trans nt, chi2

\begin{tabular}{|c|c|c|c|}
\hline $\begin{array}{r}\text { apakah_and } \\
\text { a_transmig } \\
\text { rasi }\end{array}$ & $0^{n}$ & 1 & Total \\
\hline 0 & 219 & 61 & 280 \\
\hline 1 & 39 & 6 & 45 \\
\hline Total & 258 & 67 & 325 \\
\hline
\end{tabular}

Pearson chi2 $(1)=1.6925 \quad \operatorname{Pr}=0.193$ 
Appendix 4. 1 A Choice Set
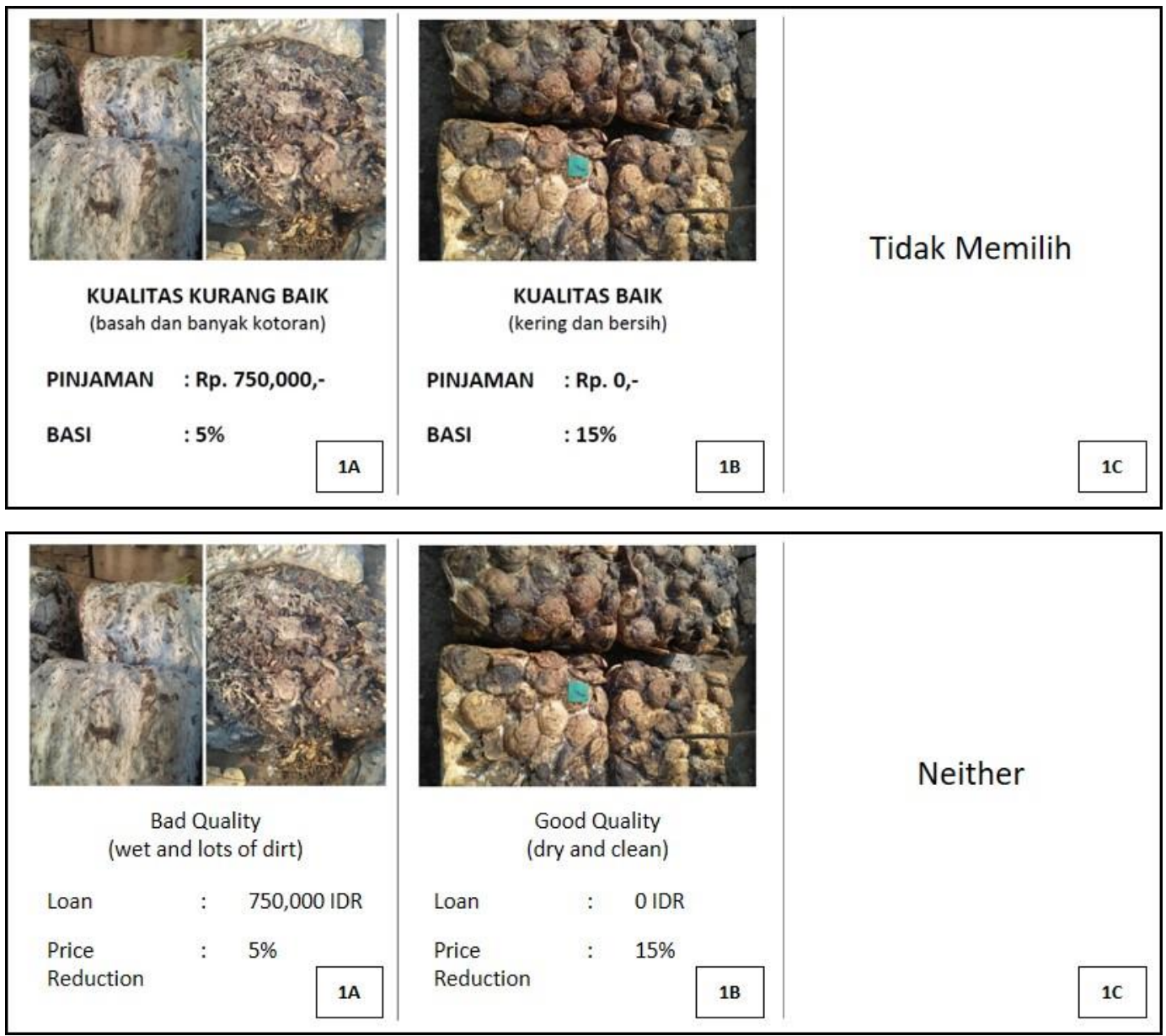
Appendix 4. 2 Descriptive Statistics of Respondents ( $n=210)$

\begin{tabular}{|c|c|c|c|c|c|c|c|}
\hline No & Variable & Mean & SD & Min & Max & Type & Unit \\
\hline 1 & traded_products & 1.1238 & 0.3302 & 1 & 2 & Categoric & $\begin{array}{r}1=\text { rubber } \\
2=\text { rubber } \& \text { palm oil }\end{array}$ \\
\hline 2 & age & 45.1762 & 10.5632 & 23 & 75 & Cont. & years \\
\hline 3 & education & 1.9857 & 0.3971 & 1 & 3 & Categoric & $\begin{array}{l}1=\text { no education } \\
2=\text { prim/secondary } \\
3=\text { under/post-grad }\end{array}$ \\
\hline 4 & experience & 12.2119 & 7.0327 & 1 & 38 & Cont. & years \\
\hline 5 & transmigrant & 0.1442 & 0.3521 & 0 & 1 & Categoric & yes/no \\
\hline 6 & family_number & 4.1190 & 1.1197 & 1 & 9 & Cont. & person \\
\hline 7 & village_function & 0.0714 & 0.2582 & 0 & 1 & Categoric & yes/no \\
\hline 8 & trader_status & 0.3429 & 0.4758 & 0 & 1 & Categoric & yes/no \\
\hline 9 & ownership & 1.0238 & 0.1528 & 1 & 2 & Cont. & person \\
\hline 10 & worker_number & 4.9190 & 5.0564 & 0 & 34 & Cont. & person \\
\hline 11 & credit_availability & 0.8238 & 0.3819 & 0 & 1 & Categoric & yes/no \\
\hline 12 & obligation_to_sell & 0.6571 & 0.4758 & 0 & 1 & Categoric & yes/no \\
\hline 13 & price_information & 0.6286 & 0.4843 & 0 & 1 & Categoric & yes/no \\
\hline 14 & suppliers_number & 39.8381 & 51.6029 & 3 & 500 & Cont. & person \\
\hline 15 & competitors_number & 11.2905 & 4.6839 & 0 & 25 & Cont. & person \\
\hline 16 & product_source & 0.8761 & 0.3302 & 0 & 1 & Categoric & yes/no \\
\hline 17 & land_ownership & 10.4690 & 11.0861 & 0 & 70.0000 & Cont. & ha \\
\hline 18 & operational_vehicle & 0.8333 & 0.3736 & 0 & 1 & Categoric & yes/no \\
\hline 19 & computer_ownership & 0.1667 & 0.3736 & 0 & 1 & Categoric & yes/no \\
\hline 20 & smartphone_ownership & 0.4333 & 0.4967 & 0 & 1 & Categoric & yes/no \\
\hline 21 & total_revenue & 24.7000 & 63.0000 & 1.00 & 782.00 & Cont. & million IDR \\
\hline 22 & total_trade_revenue & 12.3000 & 32.1000 & 1.00 & 400.00 & Cont. & million IDR \\
\hline 23 & quantity_purchased & 15.3857 & 33.7164 & 0.20 & 300.00 & Cont. & ton \\
\hline
\end{tabular}




\section{Appendix 4. 3 Stata Output of Shapiro-Wilk Normality Test}

- swilk trrev

Shapiro-Wilk W test for normal data

\begin{tabular}{r|ccccc} 
Variable & Obs & W & V & Z & Prob>z \\
\hline trrev & 210 & 0.30198 & 108.659 & 10.813 & 0.00000
\end{tabular}

- swilk quan

Shapiro-Wilk W test for normal data

\begin{tabular}{|c|c|c|c|c|c|}
\hline Variable & Obs & $\mathrm{W}$ & $\mathrm{V}$ & $\mathrm{z}$ & Prob $>z$ \\
\hline quan & 210 & 0.42277 & 89.856 & 10.375 & 0.00000 \\
\hline
\end{tabular}

- swilk num

Shapiro-Wilk W test for normal data

\begin{tabular}{r|ccrrr} 
Variable & Obs & W & V & z & Prob>z \\
\hline num & 210 & 0.84788 & 23.680 & 7.299 & 0.00000
\end{tabular}

- swilk supp

Shapiro-Wilk W test for normal data

\begin{tabular}{r|ccccc} 
Variable & Obs & W & V & Z & Prob>z \\
\hline supp & 210 & 0.55182 & 69.767 & 9.792 & 0.00000
\end{tabular}

- swilk com

Shapiro-Wilk W test for normal data

\begin{tabular}{|c|c|c|c|c|c|}
\hline Variable & Obs & W & V & z & Prob>z \\
\hline com & 210 & 0.96838 & 4.922 & 3.676 & 0.00012 \\
\hline
\end{tabular}


Appendix 4. 4 Stata Output of Wilcoxon Rank-sum (Mann-Whitney) Test by Traders' Status (left) and Credit Provision Status (right)

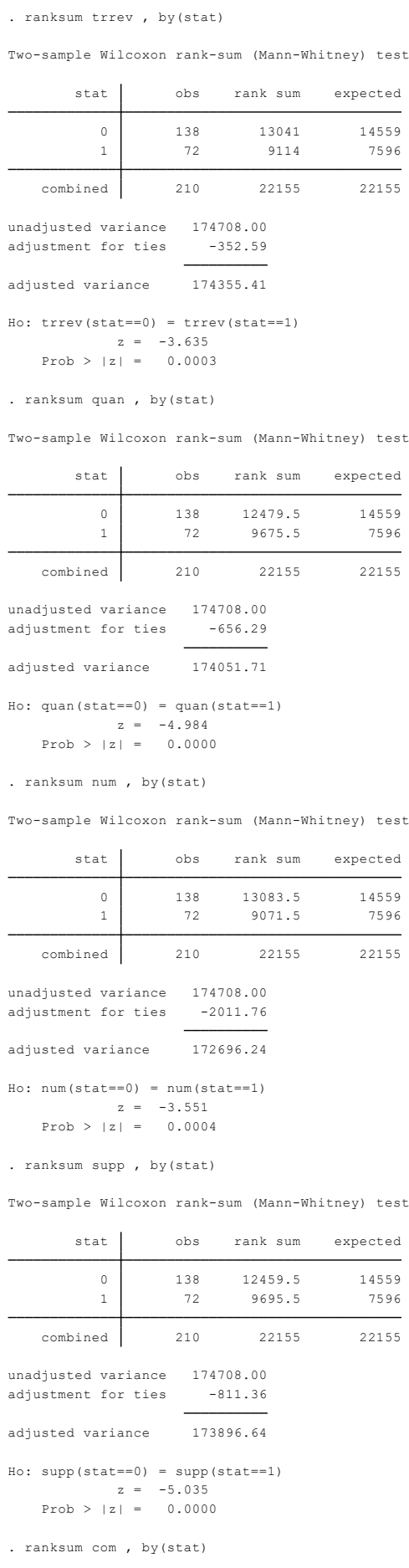

Two-sample Wilcoxon rank-sum (Mann-Whitney) test

\begin{tabular}{r|rrr} 
stat & obs & rank sum & expected \\
\hline 0 & 138 & 15792.5 & 14559 \\
1 & 72 & 6362.5 & 7596 \\
\hline combined & 210 & 22155 & 22155
\end{tabular}

unadjusted variance 174708.00

\begin{tabular}{lr} 
unadjusted variance & 174708.00 \\
adjustment for ties & -3982.44 \\
\hline
\end{tabular}

adjusted variance $\overline{170725.56}$

Ho: $\operatorname{com}($ stat $==0)=\operatorname{com}($ stat $==1$

$\begin{aligned} z & =2.985 \\ \text { Prob }>|z| & =0.0028\end{aligned}$
- ranksum trrev, by (cred)

Two-sample wilcoxon rank-sum (Mann-whitney) test

\begin{tabular}{r|rrr} 
cred & obs & rank sum & expected \\
\hline 0 & 37 & 3612.5 & 3903.5 \\
1 & 173 & 18542.5 & 18251.5 \\
\hline combined & 210 & 22155 & 22155
\end{tabular}

unadjusted variance 112550.92

adjustment for ties

adjusted variance $\overline{112323.77}$

Ho: $\operatorname{trrev}($ cred $==0)=\operatorname{trrev}($ cred $==1$

$\begin{aligned} z & =-0.868 \\ \text { Prob }>|z| & =0.3852\end{aligned}$

. ranksum quan, by (cred)

Two-sample Wilcoxon rank-sum (Mann-Whitney) tes

\begin{tabular}{r|rrr} 
cred & obs & rank sum & expected \\
\hline 0 & 37 & 3501 & 3903.5 \\
1 & 173 & 18654 & 18251.5 \\
\hline combined & 210 & 22155 & 22155
\end{tabular}

unadjusted variance 112550.92

adjustment for ties $\quad-422.80$

adjusted variance $\overline{112128.12}$

Ho: quan $($ cred $==0)=$ quan $($ cred $==1)$

$\begin{aligned} z & =-1.202 \\ \text { Prob }>|z| & =0.2294\end{aligned}$

. ranksum num, by (cred)

Two-sample Wilcoxon rank-sum (Mann-Whitney) tes

\begin{tabular}{r|rrr} 
cred & obs & rank sum & expected \\
\hline 0 & 37 & 3391 & 3903.5 \\
1 & 173 & 18764 & 18251.5 \\
\hline combined & 210 & 22155 & 22155
\end{tabular}

unadjusted variance 112550.92

adjustment for ties $\quad-1296.02$

adjusted variance $\overline{111254.89}$

Hо: $\operatorname{num}($ cred $=0)=\operatorname{num}($ cred $==1)$

$\begin{aligned} z & =-1.537 \\ \text { Prob }>|z| & =0.1244\end{aligned}$

. ranksum supp, by (cred

Two-sample Wilcoxon rank-sum (Mann-Whitney) tes

\begin{tabular}{r|rrr} 
cred & obs & rank sum & expected \\
\hline 0 & 37 & 2845 & 3903.5 \\
1 & 173 & 19310 & 18251.5 \\
\hline combined & 210 & 22155 & 22155
\end{tabular}

unadjusted variance 112550.92

adjustment for ties $\quad-522.70$

adjusted variance $\overline{112028.22}$

Hо: $\operatorname{supp}($ cred $==0)=\operatorname{supp}($ cred $==1)$

$\begin{aligned} z & =-3.162 \\ \text { Prob }>|z| & =0.0016\end{aligned}$

ranksum com, by (cred)

Two-sample wilcoxon rank-sum (Mann-Whitney) test

\begin{tabular}{r|rrr} 
cred & obs & rank sum & expected \\
\hline 0 & 37 & 4164.5 & 3903.5 \\
1 & 173 & 17990.5 & 18251.5 \\
\hline combined & 210 & 22155 & 22155
\end{tabular}

unadjusted variance 112550.92

adjustment for ties $\quad-2565.58$

adjusted variance $\overline{109985.34}$

Ho: $\operatorname{com}(\operatorname{cred}==0)=\operatorname{com}(\operatorname{cred}==1)$

$\begin{aligned} z & =0.787 \\ \text { Prob }>|z| & =0.431\end{aligned}$ 


\section{Appendix 4. 5 Stata Output of Spearman's Rank Correlation Coefficients}

- spearman p_red qual debt
rans_X $x$ qual trans_X_debt

(obs $=6300$ )

\begin{tabular}{|c|c|c|c|c|c|c|c|c|c|c|c|c|c|c|c|c|c|c|c|c|c|c|}
\hline & p_red & qual & debt & no & $-\mathrm{t}$ & $t_{-} c^{2}$ & $=z^{s}$ & t_con & $1 t_{-} s^{\sim}$ & $1 t_{-} \mathrm{t} \sim \mathrm{s}$ & $e_{-} \sim 1$ & $r^{r e v} \sim t$ & ed_x- & red_x $x+t$ & upp_x $x$ & upp_x & com_x_ $\sim 1$ & $o m_{-} x_{-} \sim t$ & tat_ $x \sim 1$ & stat_x $x \sim t$ & rans_ $\sim 1$ & trans_ $\sim t$ \\
\hline p_red & 1.0000 & & & & & & & & & & & & & & & & & & & & & \\
\hline qual & 0.4060 & 1.0000 & & & & & & & & & & & & & & & & & & & & \\
\hline debt & 0.5027 & 0.2345 & 1.0000 & & & & & & & & & & & & & & & & & & & \\
\hline none & -0.8470 & -0.4727 & -0.5890 & 1.0000 & & & & & & & & & & & & & & & & & & \\
\hline dalt_trrev & 0.7075 & 0.3892 & 0.4816 & -0.8323 & 1.0000 & & & & & & & & & & & & & & & & & \\
\hline dalt_cred & 0.6629 & 0.3627 & 0.4484 & -0.7805 & 0.6704 & 1.0000 & & & & & & & & & & & & & & & & \\
\hline dalt_supp & 0.7089 & 0.3897 & 0.4813 & -0.8326 & 0.8128 & 0.7256 & 1.0000 & & & & & & & & & & & & & & & \\
\hline dalt_com & 0.6980 & 0.3959 & 0.4994 & -0.8315 & 0.6492 & 0.6296 & 0.6629 & 1.0000 & & & & & & & & & & & & & & \\
\hline dalt_stat & 0.3254 & 0.1810 & 0.2257 & -0.3849 & 0.4490 & 0.3108 & 0.4985 & 0.2166 & 1.0000 & & & & & & & & & & & & & \\
\hline dalt_trans & 0.1948 & 0.1113 & 0.1415 & -0.2336 & 0.1738 & 0.2136 & 0.2757 & 0.2661 & 0.0993 & 1.0000 & & & & & & & & & & & & \\
\hline trrev_o $\bar{x}_{\text {qual }}$ & 0.3987 & 0.9778 & 0.2270 & -0.4622 & 0.4596 & 0.3600 & 0.4116 & 0.3757 & 0.2102 & 0.1044 & 1.0000 & & & & & & & & & & & \\
\hline trrev_x_debt & 0.4964 & 0.2422 & 0.9381 & -0.5814 & 0.6095 & 0.4542 & 0.5280 & 0.4731 & 0.2769 & 0.1323 & 0.2689 & 1.0000 & & & & & & & & & & \\
\hline cred_x_qual & 0.3588 & 0.8705 & 0.2012 & -0.4115 & 0.3501 & 0.5273 & 0.3780 & 0.3349 & 0.1614 & 0.1142 & 0.8574 & 0.2133 & 1.0000 & & & & & & & & & \\
\hline cred_x_debt & 0.4336 & 0.2043 & 0.8464 & -0.5084 & 0.4298 & 0.6514 & 0.4618 & 0.4193 & 0.1939 & 0.1445 & 0.2009 & 0.8128 & 0.3096 & 1.0000 & & & & & & & & \\
\hline supp_x_qual & 0.3986 & 0.9779 & 0.2258 & -0.4623 & 0.4112 & 0.3735 & 0.4598 & 0.3791 & 0.2218 & 0.1309 & 0.9731 & 0.2473 & 0.8728 & 0.2066 & 1.0000 & & & & & & & \\
\hline supp_X_debt & 0.4974 & 0.2392 & 0.9460 & -0.5814 & 0.5277 & 0.4749 & 0.6036 & 0.4798 & 0.2953 & 0.1731 & 0.2455 & 0.9466 & 0.2202 & 0.8388 & 0.2631 & 1.0000 & & & & & & \\
\hline com_x_qual & 0.3948 & 0.9749 & 0.2351 & -0.4609 & 0.3677 & 0.3482 & 0.3699 & 0.4686 & 0.1512 & 0.1278 & 0.9467 & 0.2374 & 0.8425 & 0.2022 & 0.9478 & 0.2357 & 1.0000 & & & & & \\
\hline com_x_debt & 0.4928 & 0.2412 & 0.9662 & -0.5794 & 0.4597 & 0.4365 & 0.4627 & 0.5966 & 0.1872 & 0.1676 & 0.2303 & 0.9076 & 0.2053 & 0.8160 & 0.2302 & 0.9162 & 0.2685 & 1.0000 & & & & \\
\hline stat_x_qual & 0.2098 & 0.5143 & 0.1223 & -0.2431 & 0.2819 & 0.1911 & 0.3105 & 0.1376 & 0.6316 & 0.0632 & 0.5483 & 0.1617 & 0.4530 & 0.0933 & 0.5641 & 0.1680 & 0.4669 & 0.1038 & 1.0000 & & & \\
\hline stat_X_debt & 0.2487 & 0.1241 & 0.4716 & -0.2923 & 0.3400 & 0.2238 & 0.3710 & 0.1673 & 0.7593 & 0.0753 & 0.1470 & 0.5213 & 0.0958 & 0.4025 & 0.1514 & 0.5436 & 0.1046 & 0.4195 & 0.4596 & 1.0000 & & \\
\hline trans_x_qual & 0.1321 & 0.3274 & 0.0847 & -0.1548 & 0.1160 & 0.1403 & 0.1839 & 0.1771 & 0.0655 & 0.6625 & 0.3138 & 0.0833 & 0.3096 & 0.0900 & 0.3516 & 0.1077 & 0.3467 & 0.1025 & 0.1769 & 0.0433 & 1.0000 & \\
\hline trans_x_debt & 0.1548 & 0.0838 & 0.2945 & -0.1843 & 0.1388 & 0.1680 & 0.2178 & 0.2100 & 0.0763 & 0.7887 & 0.0794 & 0.2796 & 0.0882 & 0.2809 & 0.0980 & 0.3297 & 0.0959 & 0.3238 & 0.0430 & 0.1512 & 0.5137 & 1.0000 \\
\hline
\end{tabular}


Appendix 4. 6 Results across Different Model Estimations

\begin{tabular}{|c|c|c|c|c|c|c|c|c|c|c|c|c|c|c|c|}
\hline \multirow{2}{*}{ Attributes } & \multicolumn{3}{|c|}{ CL_1 } & \multicolumn{3}{|c|}{ CL_2 } & \multicolumn{3}{|c|}{ ML_1 } & \multicolumn{3}{|c|}{ ML_2 } & \multicolumn{3}{|c|}{ ML_3 } \\
\hline & Coeff. & & SE & Coeff. & & $\mathrm{SE}$ & Coeff. & & SE & Coeff. & & $\mathrm{SE}$ & Coeff. & & SE \\
\hline \multicolumn{16}{|l|}{ Mean } \\
\hline p_red & 0.0003 & $* * *$ & $(0.0001)$ & 0.0003 & $* * *$ & $(0.0001)$ & 0.0007 & $* * *$ & $(0.0001)$ & 0.0007 & $* * *$ & $(0.0001)$ & 0.0007 & $* * *$ & $(0.0001)$ \\
\hline qual & 1.7486 & $* * *$ & $(0.0675)$ & 0.8894 & $* * *$ & $(0.2573)$ & 3.5872 & $* * *$ & $(0.3143)$ & 1.6480 & $*$ & $(0.9059)$ & 1.6750 & $*$ & $(0.9003)$ \\
\hline debt & -0.2605 & $* *$ & (0.1134) & -0.7371 & * & (0.4259) & -0.9105 & $* * *$ & $(0.2609)$ & -1.9086 & $* *$ & $(0.9488)$ & -1.9484 & $* *$ & $(0.9621)$ \\
\hline dalt (opt-out) & 0.6771 & $* * *$ & $(0.1290)$ & -0.1508 & & $(0.3598)$ & 0.5837 & $* * *$ & (0.1549) & -0.1110 & & $(0.4054)$ & -0.1559 & & $(0.4059)$ \\
\hline dalt_trrev & & & & 0.0075 & $*$ & $(0.0040)$ & & & & 0.0094 & * & $(0.0050)$ & 0.0094 & * & $(0.0050)$ \\
\hline dalt cred & & & & 0.9987 & $* * *$ & $(0.2484)$ & & & & 0.8596 & $* * *$ & $(0.2840)$ & 0.8623 & $* * *$ & $(0.2828)$ \\
\hline dalt_supp & & & & -0.0070 & $* *$ & $(0.0027)$ & & & & -0.0085 & $* * *$ & $(0.0032)$ & -0.0085 & $* * *$ & $(0.0032)$ \\
\hline dalt_com & & & & 0.0213 & & $(0.0230)$ & & & & 0.0215 & & $(0.0253)$ & 0.0228 & & $(0.0253)$ \\
\hline dalt_stat & & & & -0.3030 & & $(0.2371)$ & & & & -0.3790 & & $(0.2636)$ & -0.3650 & & $(0.2631)$ \\
\hline dalt_trans & & & & 0.5529 & $*$ & $(0.3037)$ & & & & 0.6552 & * & $(0.3402)$ & 0.6495 & $*$ & $(0.3381)$ \\
\hline trrev_X_qual & & & & -0.0064 & $* *$ & $(0.0029)$ & & & & -0.0124 & & $(0.0109)$ & -0.0118 & & $(0.0110)$ \\
\hline trrev_X_debt & & & & -0.0015 & & (0.0051) & & & & 0.0052 & & $(0.0105)$ & 0.0054 & & (0.0107) \\
\hline cred $X$ qual & & & & -0.1140 & & $(0.1857)$ & & & & -0.0272 & & $(0.6658)$ & -0.0438 & & $(0.6723)$ \\
\hline cred_X_debt & & & & 0.2847 & & (0.3070) & & & & 1.0145 & & (0.6876) & 1.0095 & & $(0.7012)$ \\
\hline supp_X_qual & & & & 0.0058 & $* * *$ & (0.0021) & & & & 0.0126 & & $(0.0077)$ & 0.0134 & * & $(0.0080)$ \\
\hline supp_X_debt & & & & -0.0003 & & $(0.0036)$ & & & & -0.0036 & & $(0.0071)$ & -0.0037 & & $(0.0072)$ \\
\hline com $X$ qual & & & & 0.0543 & $* * *$ & $(0.0156)$ & & & & 0.1018 & * & $(0.0550)$ & 0.0989 & * & $(0.0540)$ \\
\hline com_X_debt & & & & 0.0324 & & $(0.0255)$ & & & & 0.0294 & & $(0.0555)$ & 0.0269 & & $(0.0561)$ \\
\hline stat_X_qual & & & & 1.0452 & $* * *$ & $(0.1766)$ & & & & 1.9702 & $* * *$ & $(0.6022)$ & 1.9841 & $* * *$ & $(0.6056)$ \\
\hline stat_X_debt & & & & -0.1418 & & $(0.2832)$ & & & & -0.0283 & & $(0.5876)$ & -0.0391 & & (0.5915) \\
\hline $\operatorname{trans} \bar{x}_{\bar{X}} \bar{x}_{\text {qqual }}$ & & & & -0.3663 & $*$ & (0.1908) & & & & -1.0488 & & $(0.7122)$ & -1.0172 & & (0.7219) \\
\hline \multirow{2}{*}{\multicolumn{16}{|c|}{ Standard Deviation of Random Parameters Distribution }} \\
\hline & & & & & & & & & & & & & & & \\
\hline qual & & & & & & & 3.0088 & $* * *$ & $(0.3101)$ & 2.8441 & $* * *$ & $(0.2936)$ & 2.8724 & $* * *$ & $(0.2976)$ \\
\hline debt & & & & & & & 2.6674 & $* * *$ & $(0.2717)$ & 2.6058 & $* * *$ & $(0.2755)$ & 2.6344 & $* * *$ & $(0.2786)$ \\
\hline \multicolumn{16}{|l|}{ Cholesky Matrix } \\
\hline$/ 111$ & & & & & & & & & & & & & 2.8728 & $* * *$ & $(0.2967)$ \\
\hline$/ 121$ & & & & & & & & & & & & & -0.3835 & & $(0.3014)$ \\
\hline$/ 122$ & & & & & & & & & & & & & 2.6063 & $* * *$ & $(0.2746)$ \\
\hline \multicolumn{16}{|c|}{ Goodness of fit Measures } \\
\hline Log-likelihood & \multicolumn{3}{|c|}{-1450.4206} & \multirow{2}{*}{\multicolumn{3}{|c|}{-1396.0336}} & \multirow{2}{*}{\multicolumn{3}{|c|}{-1179.9023}} & \multicolumn{3}{|c|}{-1154.4063} & \multicolumn{3}{|c|}{-1153.5881} \\
\hline Pseudo- $R^{2}$ & \multicolumn{3}{|c|}{0.3713} & & & & & & 0.4886 & \multicolumn{3}{|c|}{0.4996} & \multicolumn{3}{|c|}{0.5000} \\
\hline AIC & \multirow{2}{*}{\multicolumn{3}{|c|}{$\begin{array}{l}2908.8410 \\
2935.8340\end{array}$}} & \multicolumn{3}{|c|}{2836.0670} & & 71.8050 & & & 56.8130 & & & 7.1760 & \\
\hline $\mathrm{BIC}$ & & & & & 84.5300 & & & 12.2940 & & & 18.7720 & & & 5.8840 & \\
\hline Number of obs. & & 6300 & & & 6300 & & & 6300 & & & 6300 & & & 5300 & \\
\hline Number of resp: & & 210 & & & 210 & & & 210 & & & 210 & & & 210 & \\
\hline
\end{tabular}

Note: Based on model estimations result on Appendix 8-12;*** $\mathrm{p}<0.01, * * \mathrm{p}<0.05, * \mathrm{p}<0.1$ 
Appendix 4. 7 Stata Output of CL_1 Model Estimation

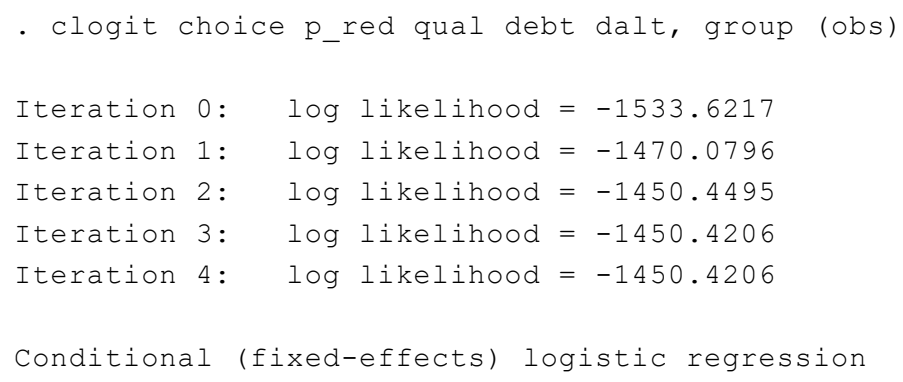

\begin{tabular}{|c|c|c|c|}
\hline \multicolumn{2}{|c|}{ Number of obs } & $=$ & 6,300 \\
\hline \multicolumn{2}{|c|}{ LR chi2(4) } & $=$ & 1713.33 \\
\hline \multicolumn{2}{|c|}{ Prob > chi2 } & $=$ & 0.0000 \\
\hline \multicolumn{2}{|c|}{ Pseudo R2 } & $=$ & 0.371 \\
\hline$P>|z|$ & {$[95 \%$} & Conf. & Interval] \\
\hline 0.003 & .0001 & 1014 & .0005037 \\
\hline 0.000 & 1.616 & 6359 & 1.880794 \\
\hline 0.022 & -.4827 & 7031 & -.0382787 \\
\hline 0.000 & .4242 & 2571 & .9300232 \\
\hline
\end{tabular}

\begin{tabular}{|c|c|c|c|c|c|c|}
\hline choice & Coef. & Std. Err. & z & $\mathrm{P}>|\mathrm{z}|$ & [95\% Conf. & Interval] \\
\hline p_red & .0003025 & .0001026 & 2.95 & 0.003 & .0001014 & .0005037 \\
\hline qual & 1.748577 & .0674592 & 25.92 & 0.000 & 1.616359 & 1.880794 \\
\hline debt & -.2604909 & .1133757 & -2.30 & 0.022 & -.4827031 & -.0382787 \\
\hline dalt & .6771401 & .1290243 & 5.25 & 0.000 & .4242571 & .9300232 \\
\hline
\end{tabular}

- estimate stats

Akaike's information criterion and Bayesian information criterion

\begin{tabular}{r|ccrrr}
\hline Model & Obs ll(null) 11 (model) & df & AIC \\
\hline$\cdot$ & $6,300-2307.086$ & -1450.421 & 4 & 2908.841 & 2935.834 \\
\hline
\end{tabular}

Note: N=Obs used in calculating BIC; see [R] BIC note. 


\section{Appendix 4. 8 Stata Output of CL_2 Model Estimation}

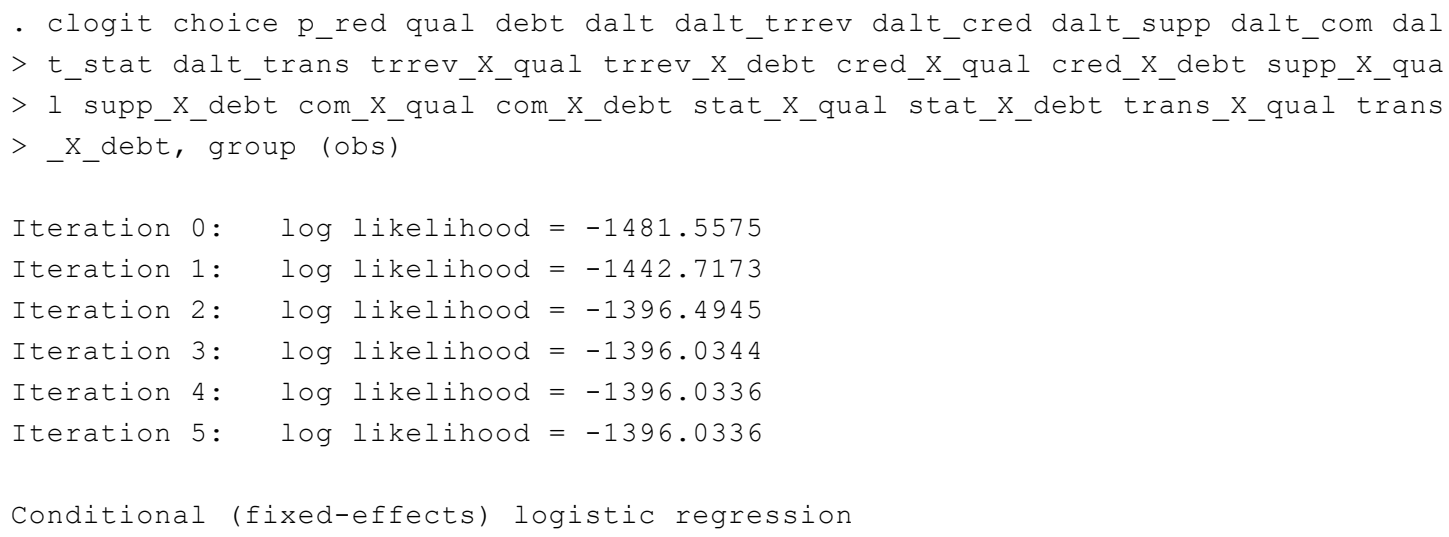

\begin{tabular}{|c|c|c|c|c|c|c|}
\hline choice & Coef. & Std. Err. & z & $\mathrm{P}>|\mathrm{z}|$ & [95\% Conf. & Interval] \\
\hline P_red & .0003099 & .0001041 & 2.98 & 0.003 & .0001059 & .0005139 \\
\hline qual & .8894306 & .2573292 & 3.46 & 0.001 & .3850748 & 1.393787 \\
\hline debt & -.7371133 & .4259414 & -1.73 & 0.084 & -1.571943 & .0977164 \\
\hline dalt & -.1508277 & .359752 & -0.42 & 0.675 & -.8559286 & .5542732 \\
\hline dalt_trrev & .0075275 & .0040298 & 1.87 & 0.062 & -.0003708 & .0154258 \\
\hline dalt_cred & .998677 & .2483933 & 4.02 & 0.000 & .5118351 & 1.485519 \\
\hline dalt_supp & -.0069533 & .0027 & -2.58 & 0.010 & -.0122452 & -.0016614 \\
\hline dalt_com & .0212922 & .0230138 & 0.93 & 0.355 & -.023814 & .0663983 \\
\hline dalt_stat & -.3029766 & .2370865 & $-1 \cdot 28$ & 0.201 & -.7676577 & .1617045 \\
\hline dalt_trans & .5528894 & .3036693 & 1.82 & 0.069 & -.0422915 & 1.14807 \\
\hline trrev_X_qual & -.0064198 & .0029041 & -2.21 & 0.027 & -.0121117 & -.0007279 \\
\hline trrev_x_debt & -.0015306 & .0050574 & -0.30 & 0.762 & -.011443 & .0083818 \\
\hline cred_X_qual & -.1139548 & .1856843 & -0.61 & 0.539 & -.4778894 & .2499798 \\
\hline cred_x_debt & .284663 & .307034 & 0.93 & 0.354 & -.3171127 & .8864387 \\
\hline supp_X_qual & .0058436 & .0021168 & 2.76 & 0.006 & .0016947 & .0099924 \\
\hline supp_X_debt & -.0002788 & .0035751 & -0.08 & 0.938 & -.0072859 & .0067282 \\
\hline com_X_qual & .0543091 & .0155613 & 3.49 & 0.000 & .0238094 & .0848088 \\
\hline com_X_debt & .0323736 & .025548 & 1.27 & 0.205 & -.0176996 & .0824469 \\
\hline stat_X_qual & 1.045158 & .1766074 & 5.92 & 0.000 & .699014 & 1.391302 \\
\hline stat_X_debt & -.1417844 & .2832108 & -0.50 & 0.617 & -.6968673 & .4132984 \\
\hline trans_X_qual & -.3662978 & .1908374 & -1.92 & 0.055 & -.7403323 & .0077367 \\
\hline trans_x_debt & -.4365248 & .3231352 & -1.35 & 0.177 & -1.069858 & .1968086 \\
\hline
\end{tabular}

- estimate stats

Akaike's information criterion and Bayesian information criterion

\begin{tabular}{|c|c|c|c|c|c|c|}
\hline Model & Obs & 11 (null) & 11 (model) & $d f$ & $\mathrm{AIC}$ & BIC \\
\hline . & 6,300 & -2307.086 & -1396.034 & 22 & 2836.067 & 2984.53 \\
\hline
\end{tabular}




\section{Appendix 4.9 Stata Output of ML_1 Model Estimation}

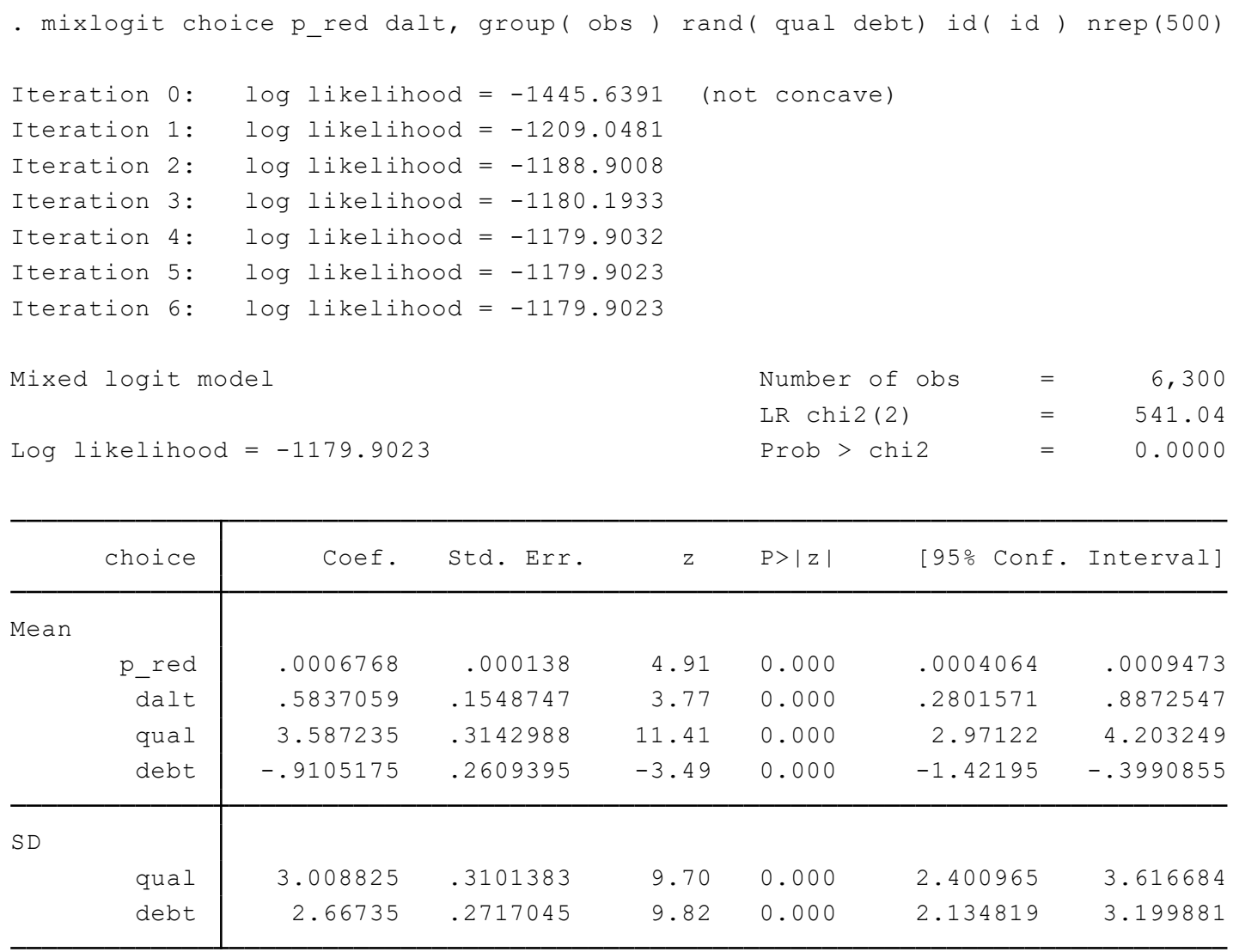

The sign of the estimated standard deviations is irrelevant: interpret them as being positive

- estimate stats

Akaike's information criterion and Bayesian information criterion

\begin{tabular}{r|rrrrr}
\hline Model & Obs ll(null) & ll(model) & df & AIC & BIC \\
\hline$\cdot$ & $6,300-1450.421$ & -1179.902 & 6 & 2371.805 & 2412.294 \\
\hline
\end{tabular}

Note: N=Obs used in calculating BIC; see [R] BIC note. 


\title{
Appendix 4. 10 Stata Output of ML_2 Model Estimation
}

\begin{abstract}
- mixlogit choice p_red dalt dalt_trrev dalt_cred dalt_supp dalt_com dalt_stat d $>$ alt_trans trrev_X_qual trrev_X_debt cred_X_qual cred_X_debt supp_X_qual supp_X $>$ _debt com_X_qual com_X_debt stat_X_qual stat_X_debt trans_X_qual trans_X_debt $>$, group ( obs ) rand( qual debt) id( id) nrep(500)
\end{abstract}

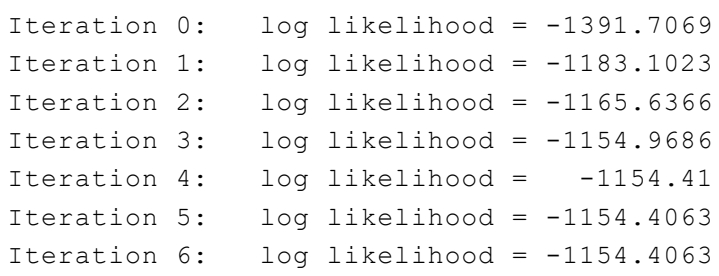

(not concave)

Mixed logit model

$\begin{array}{llr}\text { Number of obs } & = & 6,300 \\ \text { LR chi2(2) } & = & 483.25 \\ \text { Prob > chi2 } & = & 0.0000\end{array}$

Log likelihood $=-1154.4063$

Prob > chi2

0.0000

\begin{tabular}{|c|c|c|c|c|c|c|}
\hline choice & Coef. & Std. Err. & z & $P>|z|$ & [95\% Conf. & Interval] \\
\hline \multicolumn{7}{|l|}{ Mean } \\
\hline p_red & .0006874 & .0001381 & 4.98 & 0.000 & .0004167 & .0009581 \\
\hline dalt & -.1110411 & .4053591 & -0.27 & 0.784 & -.9055303 & .683448 \\
\hline dalt_trrev & .0093766 & .0050174 & 1.87 & 0.062 & -.0004573 & .0192105 \\
\hline dalt_cred & .8595852 & .2839714 & 3.03 & 0.002 & .3030114 & 1.416159 \\
\hline dalt_supp & -.0085387 & .00317 & -2.69 & 0.007 & -.0147518 & -.0023256 \\
\hline dalt_com & .0214721 & .0252976 & 0.85 & 0.396 & -.0281103 & .0710546 \\
\hline dalt_stat & -.3790035 & .2635615 & -1.44 & 0.150 & -.8955745 & .1375676 \\
\hline dalt_trans & .6551674 & .3402414 & 1.93 & 0.054 & -.0116935 & 1.322028 \\
\hline trrev_X_p_qual & -.0123972 & .0109305 & -1.13 & 0.257 & -.0338207 & .0090263 \\
\hline trrev_x_debt & .0052378 & .0104514 & 0.50 & 0.616 & -.0152467 & .0257223 \\
\hline cred_X_qual & -.0271561 & .6658068 & -0.04 & 0.967 & -1.332113 & 1.277801 \\
\hline cred_X_debt & 1.0145 & .687557 & 1.48 & 0.140 & -.3330873 & 2.362087 \\
\hline supp_x_qual & .0126331 & .0077494 & 1.63 & 0.103 & -.0025555 & .0278217 \\
\hline supp_x_debt & -.0035955 & .0071231 & -0.50 & 0.614 & -.0175566 & .0103656 \\
\hline com_x_qual & .1017665 & .0549536 & 1.85 & 0.064 & -.0059407 & .2094736 \\
\hline com_x_debt & .0294384 & .0554837 & 0.53 & 0.596 & -.0793077 & .1381845 \\
\hline stat $x$ qual & 1.970207 & .6021886 & 3.27 & 0.001 & .789939 & 3.150475 \\
\hline stat $X$ debt & -.0283131 & .5876455 & -0.05 & 0.962 & -1.180077 & 1.123451 \\
\hline trans_x_qual & -1.048777 & .7121806 & -1.47 & 0.141 & -2.444625 & .3470715 \\
\hline trans_x_debt & -.3422247 & .7189553 & -0.48 & 0.634 & -1.751351 & 1.066902 \\
\hline qual & 1.648026 & .9058799 & 1.82 & 0.069 & -.1274661 & 3.423518 \\
\hline debt & -1.908593 & .9488355 & -2.01 & 0.044 & -3.768277 & -.0489099 \\
\hline \multicolumn{7}{|l|}{$\mathrm{SD}$} \\
\hline qual & 2.844126 & .2936468 & 9.69 & 0.000 & 2.268589 & 3.419663 \\
\hline debt & 2.605781 & .2754901 & 9.46 & 0.000 & 2.065831 & 3.145732 \\
\hline
\end{tabular}

The sign of the estimated standard deviations is irrelevant: interpret them as being positive

- estimate stats

Akaike's information criterion and Bayesian information criterion

\begin{tabular}{r|rrrrr}
\hline Model & Obs ll(null) & ll(model) & df & AIC & BIC \\
\hline$\cdot$ & $6,300-1396.034$ & -1154.406 & 24 & 2356.813 & 2518.772
\end{tabular}

Note: $\mathrm{N}=\mathrm{Obs}$ used in calculating BIC; see [R] BIC note. 


\section{Appendix 4.11 Stata Output of ML_3 Model Estimation}

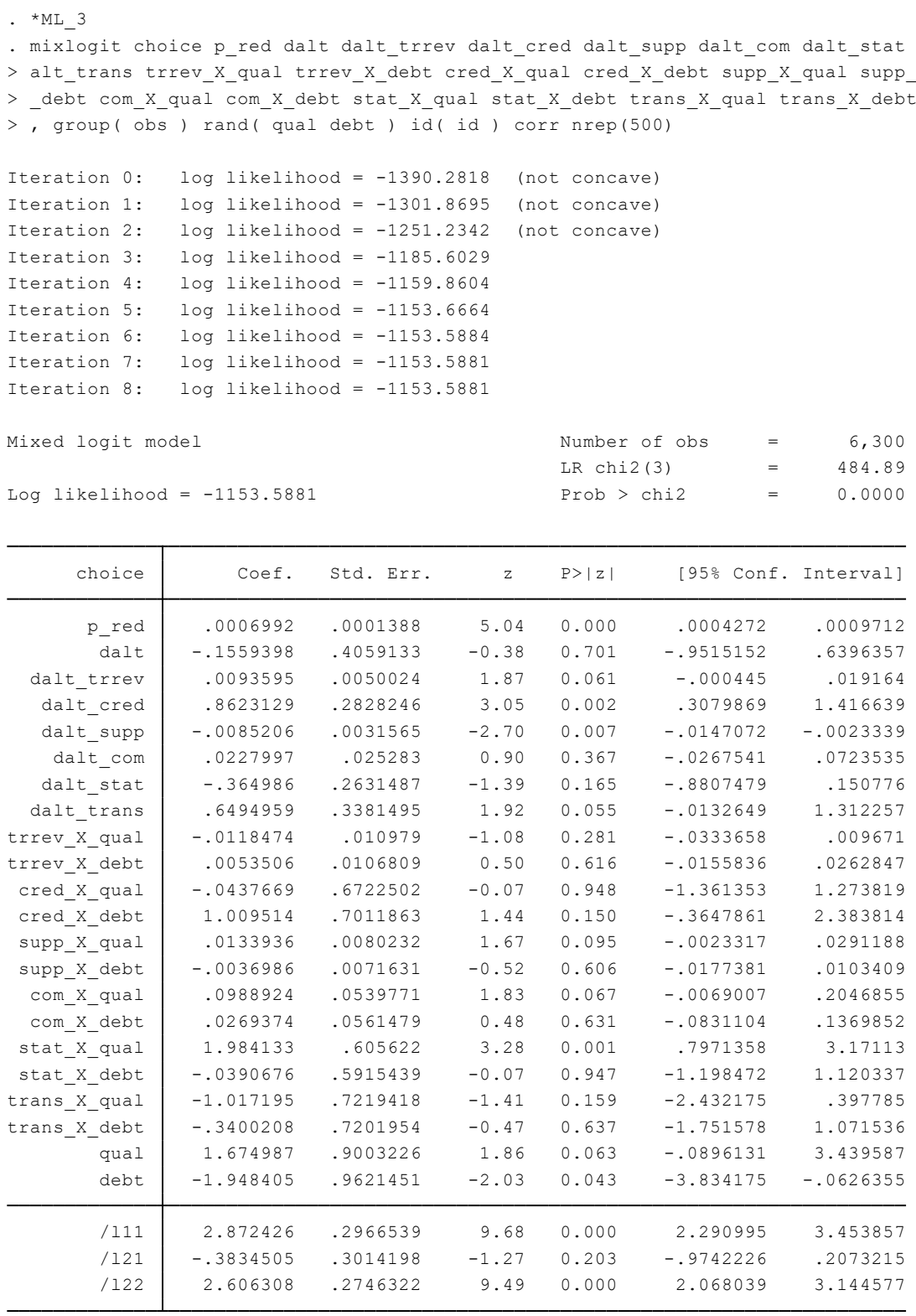

. mixlcov, sd

qual: sqrt([111]_b[_cons]*[111]_b[_cons])

debt: sqrt([121]_b[_cons]*[121]_b[_cons] + [122]_b[_cons]*[122]_b[_cons

$>$ ])

\begin{tabular}{r|rrrrrr}
\hline choice & Coef. & Std. Err. & $z$ & P > |z| & [95\% Conf. Interval] \\
\hline qual & 2.872426 & .2966539 & 9.68 & 0.000 & 2.290995 & 3.453857 \\
debt & 2.634364 & .278576 & 9.46 & 0.000 & 2.088365 & 3.180363 \\
\hline
\end{tabular}

- estimate stats

Akaike's information criterion and Bayesian information criterion

\begin{tabular}{r|rrrrrr}
\hline Model & Obs 11 (null) & ll(model) & df & AIC & BIC \\
\hline$\cdot$ & 6,300 & -1396.034 & -1153.588 & 25 & 2357.176 & 2525.884 \\
\hline
\end{tabular}

Note: N=Obs used in calculating BIC; see [R] BIC note. 
Appendix 4. 12 The Cholesky Factorization of the Covariance Matrix

\begin{tabular}{lrr}
\hline & qual & debt \\
\hline qual & 2.8724 & \\
debt & -0.3835 & 2.6063 \\
\hline
\end{tabular}

Appendix 4. 13 Stata Output of the ML_3 Random Coefficients Covariance Matrix

. mixlcov

v11: [111]_b[_cons]*[111]_b[_cons]

v21: [121]_b[_cons]*[111]_b[_cons]

v22: [121]_b[_cons]*[121]_b[_cons] + [122]_b[_cons]*[122]_b[_cons]

\begin{tabular}{r|rrrrrr}
\hline choice & Coef. & Std. Err. & $z$ & P>|z| & [95\% Conf. Interval] \\
\hline v11 & 8.250829 & 1.704232 & 4.84 & 0.000 & 4.910595 & 11.59106 \\
v21 & -1.101433 & .8887921 & -1.24 & 0.215 & -2.843434 & .6405674 \\
v22 & 6.939874 & 1.467741 & 4.73 & 0.000 & 4.063154 & 9.816595 \\
\hline
\end{tabular}


Appendix 4. 14 Summary of Rubber Traders' WTC Price Reduction for All Attributes across Different Model Estimations

\begin{tabular}{|c|c|c|c|c|c|c|c|c|c|c|c|c|c|c|c|c|}
\hline \multirow{2}{*}{ Attributes } & \multicolumn{3}{|c|}{ CL_1 } & \multicolumn{3}{|c|}{ CL_2 } & \multicolumn{4}{|c|}{ ML_1 } & \multicolumn{3}{|c|}{ ML_2 } & \multicolumn{3}{|c|}{ ML_3 } \\
\hline & WTC & Min. & Max. & WTC & Min. & Max. & WTC & & Min. & Max. & WTC & Min. & Max. & WTC & Min. & Max. \\
\hline qual & $-5,779.57^{* * *}$ & $-16,427.93$ & $-3,428.13$ & $-2,869.82 * * *$ & $-8,510.64$ & $-1,115.09$ & $-5,300.05$ & $* * *$ & $-8,813.71$ & $-3,660.01$ & $-2,397.48 *$ & $-5,763.19$ & -149.19 & $-2,395.48^{*}$ & $-5,680.84$ & 92.77 \\
\hline debt & $861.00^{* * *}$ & 116.26 & $2,768.26$ & $2,378.36^{*}$ & -360.18 & $8,300.65$ & $1,345.27$ & ${ }^{* * *}$ & 583.77 & $2,546.99$ & $2,776.54 * *$ & -84.55 & $6,285.63$ & $2,786.50$ ** & 86.98 & $6,278.60$ \\
\hline dalt_trrev & & & & $-24.29 *$ & -82.86 & 1.71 & & & & & $-13.64^{*}$ & -32.62 & 0.73 & $-13.39 *$ & -31.79 & 0.71 \\
\hline dalt_cred & & & & $-3,222.32 * * *$ & $-9,667.04$ & $-1,376.92$ & & & & & $-1,250.49^{* * *}$ & $-2,538.36$ & -410.00 & $-1,233.23^{* * *}$ & $-2,485.45$ & -410.02 \\
\hline dalt_supp & & & & $22.44^{* *}$ & 4.91 & 71.06 & & & & & $12.42^{* * *}$ & 3.33 & 25.88 & $12.19^{* * *}$ & 3.29 & 25.22 \\
\hline dalt_com & & & & -68.70 & -317.72 & 86.40 & & & & & -31.24 & -115.25 & 40.39 & -32.61 & -115.26 & 37.52 \\
\hline dalt_stat & & & & 977.58 & -548.43 & $3,913.49$ & & & & & 551.36 & -200.98 & $1,514.28$ & 521.98 & -217.66 & $1,450.35$ \\
\hline dalt_trans & & & & $-1,783.94 *$ & $-6,059.25$ & 176.80 & & & & & $-953.11 *$ & $-2,222.23$ & 25.99 & $-928.87 *$ & $-2,159.26$ & 26.57 \\
\hline trrev_x_qual & & & & $20.71^{* *}$ & 1.54 & 68.23 & & & & & 18.03 & -13.82 & 55.70 & 16.94 & -14.45 & 53.86 \\
\hline trrev_x_debt & & & & 4.94 & -35.51 & 51.64 & & & & & -7.62 & -41.76 & 23.84 & -7.65 & -42.03 & 24.00 \\
\hline cred_x_qual & & & & 367,68 & $-1,000.33$ & $2,181.72$ & & & & & 39.51 & $-2,007.59$ & $2,146.49$ & 62.59 & $-1,961.10$ & $2,150.77$ \\
\hline cred_x_debt & & & & -918.49 & $-4,319.78$ & $1,223.27$ & & & & & $-1,475.85$ & $3,992.40$ & 510.05 & $-1,443.75$ & $-3,930.93$ & 532.89 \\
\hline supp_x_qual & & & & $-18.85 * * *$ & -58.02 & -4.68 & & & & & -18.38 & -46.99 & 4.15 & $-19.15 *$ & -48.13 & 3.56 \\
\hline supp_x_debt & & & & 0.90 & -26.93 & 31.70 & & & & & 5.23 & -16.11 & 28.13 & 5.29 & -15.99 & 27.48 \\
\hline com_x_qual & & & & $-175.23^{* * *}$ & -514.08 & -66.40 & & & & & $-148.05^{*}$ & -356.51 & 7.32 & $-141.43^{*}$ & -340.45 & 9.05 \\
\hline com_x_debt & & & & -104.46 & -401.73 & 69.98 & & & & & -42.83 & -221.74 & 126.85 & -38.52 & -218.01 & 129.49 \\
\hline stat_x_qual & & & & $-3,372.29^{* * *}$ & $-9,538.08$ & $-1,748.31$ & & & & & $-2,866.18^{* * *}$ & $-5,620.40$ & $-1,106.14$ & $-2,837.60^{* * *}$ & $-5,555.25$ & $-1,088.06$ \\
\hline stat_x_debt & & & & 457,48 & $-1,707.48$ & $3,124.85$ & & & & & 41.19 & $-1,757.88$ & $1,860.62$ & 55.87 & $-1,734.02$ & $1,853.19$ \\
\hline trans_x_qual & & & & $1,181.89$ * & -21.80 & $3,944.20$ & & & & & $1,525.72$ & -473.64 & $4,118.37$ & $1,454.74$ & -544.34 & $4,005.18$ \\
\hline trans_x_debt & & & & $1,408.48$ & -692.10 & $5,383.38$ & & & & & 497.85 & $-1,622.50$ & $2,812.17$ & 486.28 & $-1,586.82$ & $2,737.23$ \\
\hline
\end{tabular}

Note: Based on WTC result on Appendix 16-20;*** $\mathrm{p}<0.01, * * \mathrm{p}<0.05, * \mathrm{p}<0.1$ 


\section{Appendix 4. 15 WTC Stata Output of CL_1 Model Estimation}

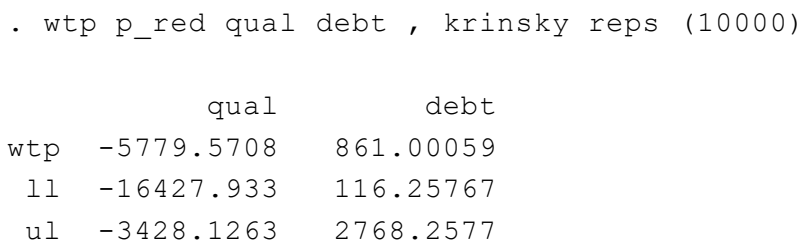

\section{Appendix 4. 16 WTC Stata Output of CL_2 Model Estimation}

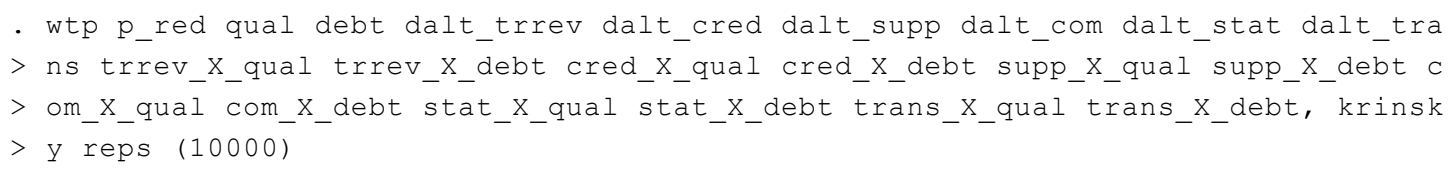

\section{Appendix 4. 17 WTC Stata Output of ML_1 Model Estimation}

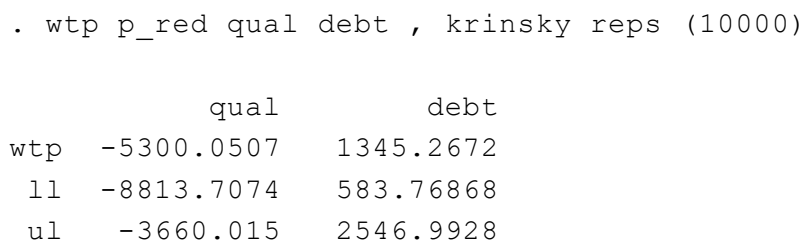




\section{Appendix 4.18 WTC Stata Output of ML_2 Model Estimation}

- wtp p_red qual debt dalt_trrev dalt_cred dalt_supp dalt_com dalt_stat dalt_tra

$>$ ns trrev_X_qual trrev_X_debt cred_X_qual cred_X_debt supp_X_qual supp_x_debt c

$>$ om_X_qual com_X_debt stat_X_qual stat_X_debt trans_X_qual trans_X_debt, krinsk

$>y$ reps $(10000)$

\begin{tabular}{|c|c|c|c|c|c|}
\hline & qual & debt & dalt_trrev & dalt_cred & dalt_supp \\
\hline wtp & -2397.4807 & 2776.5436 & -13.640672 & -1250.4893 & 12.421798 \\
\hline 11 & -5763.19 & 84.548628 & -32.61855 & -2538.3588 & 3.3340584 \\
\hline \multirow[t]{2}{*}{ ul } & 149.19242 & 6285.6279 & .73449223 & -409.99973 & 25.884108 \\
\hline & dalt_com & dalt_stat & dalt_trans & trrev_x_qual & trrev_x_debt \\
\hline wtp & -31.2368 & 551.35877 & -953.11081 & 18.034944 & -7.6197354 \\
\hline 11 & -115.24758 & -200.98047 & -2222.2301 & -13.823633 & -41.757385 \\
\hline \multirow[t]{2}{*}{ ul } & 40.387888 & 1514.2768 & 25.987509 & 55.703638 & 23.839381 \\
\hline & cred_X_qual & cred_X_debt & supp_X_qual & supp_x_debt & com_X_qual \\
\hline wtp & 39.505521 & -1475.8527 & -18.378116 & 5.2305822 & -148.04567 \\
\hline 11 & -2007.5935 & -3992.3978 & -46.98688 & -16.108645 & -356.50866 \\
\hline \multirow[t]{2}{*}{ ul } & 2146.4934 & 510.0531 & 4.1493358 & 28.132794 & 7.3163255 \\
\hline & com_x_debt & stat_x_qual & stat_x_debt & trans_x_qual & trans_x_debt \\
\hline wtp & -42.825819 & -2866.1764 & 41.188672 & 1525.7175 & 497.85445 \\
\hline 11 & -221.74057 & -5620.3983 & -1757.8764 & -473.63704 & -1622.4994 \\
\hline ul & 126.8477 & -1106.1434 & 1860.6154 & 4118.3659 & 2812.1698 \\
\hline
\end{tabular}

\section{Appendix 4.19 WTC Stata Output of ML_3 Model Estimation}

- wtp p_red qual debt dalt_trrev dalt_cred dalt_supp dalt_com dalt_stat dalt_tra $>$ ns trrev_X_qual trrev_X_debt cred_X_qual cred_X_debt supp_X_qual supp_X_debt c $>$ om_X_qual com_X_debt stat_X_qual stat_X_debt trans_X_qual trans_X_debt, krinsk $>$ y reps $(10000)$

\begin{tabular}{|c|c|c|c|c|c|}
\hline & qual & debt & dalt_trrev & dalt_cred & dalt_supp \\
\hline wtp & -2395.4765 & 2786.5049 & -13.385411 & -1233.2338 & 12.185643 \\
\hline 11 & -5680.8444 & 86.976805 & -31.794771 & -2485.4526 & 3.287972 \\
\hline \multirow[t]{2}{*}{ ul } & 92.774808 & 6278.5978 & .70640345 & -410.01716 & 25.216756 \\
\hline & dalt_com & dalt_stat & dalt_trans & trrev_x_qual & trrev_x_debt \\
\hline wtp & -32.606901 & 521.98338 & -928.87434 & 16.943526 & -7.6521076 \\
\hline 11 & -115.26274 & -217.66204 & -2159.2577 & -14.445075 & -42.026748 \\
\hline \multirow[t]{2}{*}{ ul } & 37.520813 & 1450.353 & 26.572476 & 53.863794 & 24.000661 \\
\hline & cred_X_qual & cred_x_debt & supp_X_qual & supp_X_debt & com_X_qual \\
\hline $\mathrm{tp}$ & 62.593025 & -1443.7526 & -19.154765 & 5.2895524 & -141.43059 \\
\hline 11 & -1961.1018 & -3930.9332 & -48.130365 & -15.986124 & -340.44811 \\
\hline \multirow[t]{2}{*}{ ul } & 2150.7686 & 532.89306 & 3.5649008 & 27.477563 & 9.0451465 \\
\hline & com_x_debt & stat_X_qual & stat_X_debt & trans_x_qual & trans_x_debt \\
\hline & -38.524436 & -2837.601 & 55.872366 & 1454.7377 & 486.27953 \\
\hline 11 & -218.00867 & -5555.2467 & -1734.018 & -544.33697 & -1586.8164 \\
\hline & 129.49391 & -1088.0583 & 1853.1851 & 4005.1761 & 2737.2305 \\
\hline
\end{tabular}


Curriculum Vitae

_ not available _ 


\section{Declaration}

1. I, hereby, declare that this Ph.D. dissertation has not been presented to any other examining body either in its present or a similar form.

Göttingen,

(Signature)

(Name in block capitals)

2. I hereby, solemnly declare that this dissertation was undertaken independently and without any unauthorized aid.

Göttingen,

(Signature)

(Name in block capitals) 